\title{
Economic preferences and attitudes : origins, behavioral impact, stability and measurement
}

Citation for published version (APA):

Zumbuehl, M. A. (2015). Economic preferences and attitudes : origins, behavioral impact, stability and measurement. [Doctoral Thesis, Maastricht University]. Maastricht University. https://doi.org/10.26481/dis.20150910mz

Document status and date:

Published: 01/01/2015

DOI:

10.26481/dis.20150910mz

Document Version:

Publisher's PDF, also known as Version of record

\section{Please check the document version of this publication:}

- A submitted manuscript is the version of the article upon submission and before peer-review. There can be important differences between the submitted version and the official published version of record.

People interested in the research are advised to contact the author for the final version of the publication, or visit the DOI to the publisher's website.

- The final author version and the galley proof are versions of the publication after peer review.

- The final published version features the final layout of the paper including the volume, issue and page numbers.

Link to publication

\footnotetext{
General rights rights.

- You may freely distribute the URL identifying the publication in the public portal. please follow below link for the End User Agreement:

www.umlib.nl/taverne-license

Take down policy

If you believe that this document breaches copyright please contact us at:

repository@maastrichtuniversity.nl

providing details and we will investigate your claim.
}

Copyright and moral rights for the publications made accessible in the public portal are retained by the authors and/or other copyright owners and it is a condition of accessing publications that users recognise and abide by the legal requirements associated with these

- Users may download and print one copy of any publication from the public portal for the purpose of private study or research.

- You may not further distribute the material or use it for any profit-making activity or commercial gain

If the publication is distributed under the terms of Article $25 \mathrm{fa}$ of the Dutch Copyright Act, indicated by the "Taverne" license above, 
ECONOMIC PREFERENCES AND ATTITUDES 
CMaria Zumbuehl, Maastricht 2015

All rights reserved. No part of this publication may be reproduced, stored in a retrieval system, or transmitted in any form, or by any means, electronic, mechanical, photocopying, recording, or otherwise, without the prior permission in writing, from the author.

Published by ROA

Postbus 616

6200 MD Maastricht

ISBN: 978-90-5321-541-8

Printed in the Netherlands by Canon 


\title{
Economic preferences and attitudes
}

\section{Origins, behavioral impact, stability and measurement}

\author{
DISSERTATION
}

TO OBTAIN THE DEGREE OF DOCTOR AT MAASTRICHT UNIVERSITY, ON THE AUTHORITY OF THE RECTOR MAGNIFICUS,

PROF. DR. L. L. G. SOETE

IN ACCORDANCE WITH THE DECISION OF THE BOARD OF DEANS,

TO BE DEFENDED IN PUBLIC

ON THURSDAY 10 SEPTEMBER 2015, AT 16:00 HOURS

BY

Maria Andrea Zumbuehl 


\section{Supervisors}

Prof. dr. T. Dohmen, University of Bonn

Prof. dr. G. A. Pfann

\section{Assessment Committee}

Prof. dr. A. de Grip, (chairman)

Prof. dr. L. Goette, University of Bonn

Prof. dr. K. G. Salvanes, Norwegian School of Economics, Bergen

Prof. dr. B. ter Weel 


\section{Acknowledgements}

I could not have written this thesis without the support of so many great people. Thanks to everybody who inspired me through a nice chat, helped me with good advice or supported me in one of countless other ways.

I thank my supervisors Thomas Dohmen and Gerard Pfann who have given me the opportunity and the environment to write the thesis and guided me through the process of it. I also thank Franziska Tausch and my 3 roommates Jan Feld, Ahmed Mohamed and Nicolas Salamanca, you have made the time of my $\mathrm{PhD}$ such a great time and were always there to discuss a new idea or an upcoming problem. I further want to thank to all my friends and colleagues at ROA, Maastricht University and the University of Bonn for many interesting discussions and good suggestions.

A special thanks also to my boyfriend Anton Akhmerov whose curiosity and mathematical support helped me improve on my research on several occasions. And last but not least I thank my family for always being there for me; and to my parents in particular, for instilling your children with the preferences and attitudes it takes to pursue our own way, and for supporting us in what we do. 



\section{Contents}

1 Introduction to the thesis 1

1.1 Motivation . . . . . . . . . . . . . . . . . 1

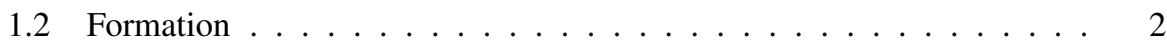

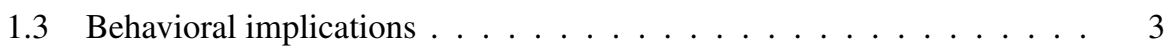

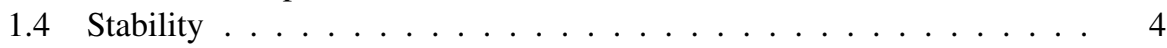

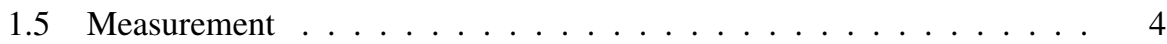

$1.6 \operatorname{Road} \operatorname{map} \ldots \ldots \ldots \ldots \ldots$

2 Parental Investment and the Intergenerational Transmission of Economic $\begin{array}{ll}\text { Preferences and Attitudes } & 7\end{array}$

2.1 Introduction . . . . . . . . . . . . . . . . . 7

2.2 Data . . . . . . . . . . . . . . . . . . . 9

2.2.1 Similarity in preferences ....................... 10

2.2.2 Parental investment . . . . . . . . . . . . . . . 13

2.3 Results . . . . . . . . . . . . . . . . . . . . . 15

2.3.1 Measurement error . . . . . . . . . . . . . . . . . 18

2.3.2 Robustness checks ................ 20

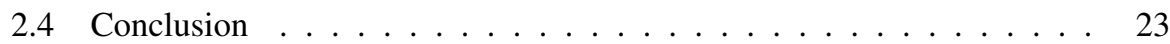

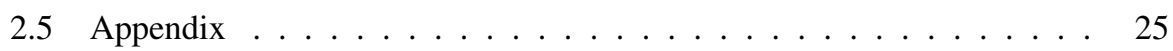

3 A model of negative reciprocity on relationship formation 29

3.1 Introduction . . . . . . . . . . . . . . . . . . . . . . . 29



3.3 Empirical Analysis . . . . . . . . . . . . . . . . . 35

3.3.1 Positive assortative marriage . . . . . . . . . . . . . 36

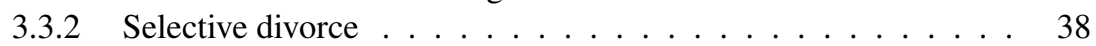

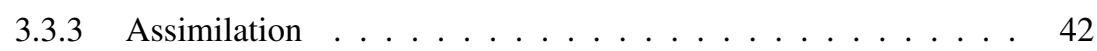

3.4 Discussion and Conclusion . . . . . . . . . . . . . . . . . . 44

3.5 Appendix ........................... 46

4 Stability of self-stated risk preferences and media coverage of economic news 
4.1 Introduction . . . . . . . . . . . . . . . . . . 51

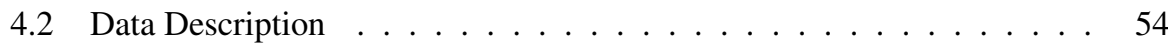

4.2.1 Risk Attitudes and Risk Perception . . . . . . . . . . . . . . . 54

4.2.2 News Coverage . . . . . . . . . . . . . . . . . 55

4.2 .3 Combined data set . . . . . . . . . . . . . . 57

4.3 Results . . . . . . . . . . . . . . . . . . . 60

4.3.1 News Coverage and Risk Attitudes . . . . . . . . . . . . . . . . . 60

4.3.2 Explanatory Value of News . . . . . . . . . . . . . 63

4.3 .3 Risk perception . . . . . . . . . . . . . . . 65

4.3.4 Affective reaction . . . . . . . . . . . . . . 67

4.3.5 Heterogeneity based on demographics and personality traits . . 68

4.3.6 The good news share . . . . . . . . . . . . . . . 70

4.4 Conclusion . . . . . . . . . . . . . . . . 73

4.5 Data Appendix . . . . . . . . . . . . . . . 75

4.5.1 SOEP Data . . . . . . . . . . . . . . . . . . . . 75

4.5.2 Media Tenor Data . . . . . . . . . . . . . . . . . 75

4.5 .3 GDP ..................... 77

5 Introspection, focal points and measurement errors in survey questions $\quad 79$

5.1 Introduction . . . . . . . . . . . . . . . . . . . . . 79

5.2 Model of survey response and introspection . . . . . . . . . . . 81

5.2.1 How individuals form beliefs from introspection . . . . . . . 82

5.2.2 The process of introspection . . . . . . . . . . . . 82

5.2 .3 Reporting the answers . . . . . . . . . . . . . 83

5.3 Econometric model . . . . . . . . . . . . . . . . . . . 84

5.4 Simulations . . . . . . . . . . . . . . . . 86

5.4.1 The DGP and estimation strategy . . . . . . . . . . 87

5.4 .2 Strength of focality . . . . . . . . . . . . . . . . . . . . 88

5.4 .3 Number of focal points . . . . . . . . . . . . . . . . . 88

5.4 .4 Explained Variance . . . . . . . . . . . . . . . . . . . . . . . 91

5.4.5 Explained Heteroscedasticity . . . . . . . . . . . . . . . . 92

$5.4 .6 \gamma$ and $p$ combinations . . . . . . . . . . . . . . 92

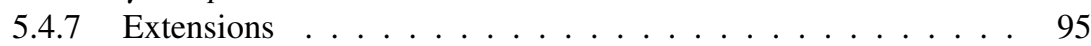

5.4.8 Robustness to model misspecification . . . . . . . . . . . . 97

5.5 Discussion . . . . . . . . . . . . . . . . . 98

5.6 Appendix .............................. 100

6 Conclusion 101 


\section{List of Tables}

2.1 Descriptive statistics: Investment variables by risk and trust sample . . 14

2.2 Descriptive statistics on high and low investing parents . . . . . . . 16

2.3 PCA: The impact of parental investments on differences in risk attitudes 17

2.4 PCA: The impact of parental investments on differences in trust attitudes 19

2.5 Measurement error correction: Lubotsky-Wittenberg. The impact of parental investments on differences in risk and trust attitudes . . . . . 21

2.6 Impact of an increase in investment on the difference in attitude . . . . 22

A2.1 Robustness check: controlling for the relation between mother and child 25

A2.2 Robustness check: controlling for the relation between father and child 26

A2.3 Robustness check: using age adjusted preference differences mother and child . . . . . . . . . . . . . . . . . . . 27

A2.4 Robustness check: using age adjusted preference differences father and

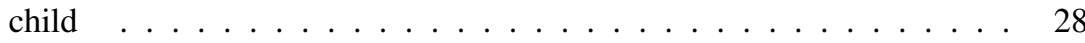

$3.1 \quad$ Joint marriage benefit threshold $B_{i j}^{M^{*}} \ldots \ldots \ldots \ldots \ldots \ldots \ldots$

3.2 Joint marriage and divorce benefit thresholds, $\left[B_{i j}^{M^{*}}, B_{i j}^{D^{*}}\right] \ldots \ldots \ldots . . \ldots 35$

3.3 Assortative marriage on negative reciprocity . . . . . . . . . 38

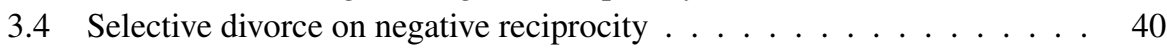

A3.1 Descriptive statistics for all 3 samples . . . . . . . . . . . . 48

A3.2 Selective divorce on negative reciprocity - all drop-outs are considered to be divorced . . . . . . . . . . . . . . . . . . . . 49

4.1 Descriptives - risk and control variables . . . . . . . . . . . 56

4.2 Descriptives - demographics and personality traits . . . . . . . 57

4.3 Descriptives - news by year $\ldots \ldots \ldots \ldots \ldots \ldots$

4.4 Risk preference - News on willingness to take risks (FE) . . . . . . 61

4.5 Risk preference - News and GDP on willingness to take risks (FE) . . . 64

4.6 Risk perception - News on worries (FE) . . . . . . . . . . . 66

4.7 Affect - Impact of different time-spans in news on risk . . . . . . . . 68

4.8 Heterogeneity on reaction to news - Interactions with demographics and personality . . . . . . . . . . . . . . . . . . . 69 
$4.9 \mathrm{Good} / \mathrm{Bad}$ news ratio - News on willingness to take risks and good news share ....................... . . 71

A4.1 Subtopics ........................... 76 


\section{List of Figures}

2.1 Risk attitudes . . . . . . . . . . . . . . . . . . . . 10

2.2 Trust in strangers . . . . . . . . . . . . . . . . . 11

2.3 Difference in attitudes between parent and child . . . . . . . . 12

3.1 Assortative marriage on negative reciprocity . . . . . . . . . . . . 37

3.2 Kaplan-Meier survival estimates for marriages by difference in negative reciprocity . . . . . . . . . . . . . . . . . . . . . 39

3.3 Cox proportional hazard by $|\Delta|$ negative reciprocity $\ldots \ldots \ldots \ldots . . .41$

3.4 Stability in negative reciprocity correlation within couples $\ldots \ldots . .43$

4.1 News - year measure, month measure and deviation measure . . . . . 59

4.2 News and share of positive news $\ldots \ldots \ldots \ldots \ldots$

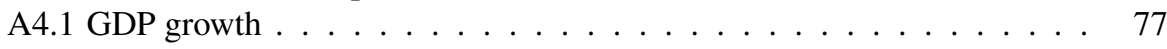

5.1 Response behavior . . . . . . . . . . . . . . . . . 85

5.2 Relative performance of estimators for different strengths of focality . . 89

5.3 Relative performance of estimators for different number of focal points in the distribution . . . . . . . . . . . . . . . . . 90

5.4 Relative performance of estimators for different $R^{2}$ of $\bar{Y}$ on $x \ldots \ldots 1$

5.5 Relative performance of estimators for different $R^{2}$ of $\operatorname{Var}[\bar{Y}]$ on $z \quad \ldots \quad 92$

5.6 Relative precision of estimators for different $R^{2}$ of $\operatorname{Var}[\bar{Y}]$ on $z \quad \ldots .93$

5.7 Relative performance of estimators for different strength of focality $(1-\gamma)$ and explained variance of $\bar{Y}$ by $x \ldots \ldots \ldots \ldots$

5.8 Correspondence between the unobserved $R^{2}$ of $\bar{Y}$ on $X_{i}$ and the observed

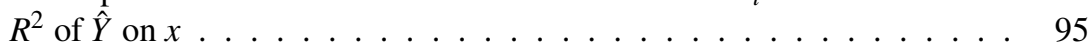

5.9 Correspondence between the unobserved $R^{2}$ of $\ln \sigma^{2}$ on $z$ and the observed $R^{2}$ of $\ln \left(\hat{r}^{2}\right)$ on $z \ldots \ldots \ldots \ldots \ldots \ldots$

5.10 Correspondence between the unobserved $\gamma$ (absence of focal points) and the observed share of focal points in the distribution of $\hat{Y} \ldots \ldots \ldots$. . . 



\section{Chapter 1}

\section{Introduction to the thesis}

\subsection{Motivation}

One of the main goals in micro economics is to understand how individuals make decisions. They constantly face situations in which they have to make trade-offs between several options. The preferences that are thereby revealed may be as simple as the preference for one particular good over another. There are however also more general preferences, like risk preferences, time preferences, preferences over work and leisure, and social preferences, that are relevant for different decision situations with a similar underlying structure. These more general preferences are referred to as economic preferences. They guide decision making for example if individuals have to decide between a safe option and a more valuable but more risky option, an amount today versus a larger amount tomorrow, or the distribution of goods between several individuals (including themselves or not). While preferences are latent factors in the identity of an individual, we often can only measure the individual's attitude on the particular topic we are eliciting. ${ }^{2}$ Another approach to understanding heterogeneity in decision making from the psychology literature bases on personality traits. Measures of personality, like the Big 5 (Goldberg, 1993), are increasingly also used by economists (for a discussion of personality traits in economics see Borghans et al., 2008). While they also measure latent individual traits they are rather complementary to economic preferences in explaining individual decision making and economic outcomes (Becker et al., 2012). Together with preferences and attitudes they are guiding individual decision making. This set of influencing factors can therefore be understood as the motivation of human behavior.

The idea of a broad spectrum of preferences and attitudes is not new to the economic discipline; Adam Smith extensively discusses different behavioral decision motives in his

\footnotetext{
${ }^{1}$ Attitude is a concept borrowed from social psychology and represents an individual's affective valuation of a mental representation of a state of the world (Kahneman et al., 1999). Therefore, unlike preferences, attitudes are subject to framing and other biases that can lead to preference reversal.

${ }^{2}$ In accordance with these definitions I will use the term preference for the underlying, often theoretical, concept, and attitude when I discuss empirically assessed measures of preferences.
} 
book "The theory of moral sentiments", first published in 1759 . However, for a long time they have been largely disregarded in favor of a simpler and more convenient working model. The construct of the homo economicus, who is assumed to be selfish, rational and risk neutral, has long dominated the representation of human nature in economic theory and thus pushed a more detailed discussion of preferences to the background. With the rise of behavioral economics preferences and attitudes have increasingly received more attention. Instead of merely being input to economic models, they have emerged as a focus of research on decision making. Many studies document the existence of diverse preferences and their heterogeneity among individuals (e.g. Camerer and Thaler, 1995 or Barsky et al., 1997 and many others). Correlates of preferences, demographics and background characteristics, as well as the relation between preferences and economic outcomes have been investigated (see Almlund et al., 2011 for an overview). However, the big picture that research draws on preferences is still very incomplete and much is to be added on how preferences are formed and how they influence the economic outcomes of individuals.

My thesis integrates into this exciting and fast growing field of economic preferences by investigating the following four research questions that contribute to a better understanding of what preferences are and what they do:

1. Where do economic preferences come from, how are they shaped?

2. What do economic preferences explain, how predictive are they for economic outcomes of individuals?

3. Are preferences stable over the life cycle, are there any systematic changes across situational contexts and over time?

4. What is the best way to measure economic preferences?

In the following I briefly introduce the four different topics and elaborate on the particular aspects that are treated in this thesis.

\subsection{Formation}

For a long time preferences have simply been taken as given in economics. During the last decade considerable attention has been drawn to how preferences come about. Theoretical models of both, the formation of individual preferences (see for example Bisin and Verdier, 2001; Doepke and Zilibotti, 2014 or Heckman and Cunha, 2007) and the formation of preferences in our society (Bowles and Gintis, 2011) have been proposed. The models on formation of preferences mainly focus on the importance and possibilities of socialization. Empirical evidence supports the hypothesis that preferences and attitudes are transmitted from parents to their children, and that socialization plays a crucial role in this transmission process (Dohmen et al., 2012). This literature is closely related to the research on the development of cognitive and non-cognitive skills. ${ }^{3}$ In

\footnotetext{
${ }^{3}$ The term "non-cognitive skills" captures important character traits and abilities of individuals that are not directly defined as a type of intelligence. This category traditionally includes traits such as self-control
} 
preschool experiments Heckman (2006) and Heckman et al. (2013) provide evidence that the early childhood environment has a significant impact on the development of not only cognitive skills, but also on personality and preferences, that are crucial for success later in life.

While there is evidence on the intergenerational transmission of preferences, less is known about how this transmission from parents to their children actually works. Theoretical models on (cultural) transmission of preferences assume that parents can choose to invest to shape their children's preferences. In this thesis I present empirical results that support such a possibility for parental investments. In chapter 2 I study empirically whether there is scope for parents to shape the economic preferences and attitudes of their children through purposeful investments. I exploit information on the risk and trust attitudes of parents and their children, as well as rich information about parental efforts in the upbringing of their children from the German Socio-Economic Panel Study (SOEP). The results show that parents who invest more in the upbringing of their children are more similar to them with respect to risk and trust attitudes and thus transmit their own attitudes more strongly. The results are robust to including variables on the relationship between children and parents, family size, and the parents' socio-economic background.

\subsection{Behavioral implications}

In numerous fields of economics like labor economics, economics of education, health economics, economics of crime or finance there has been a growing amount of investigations on how economic preferences, attitudes and personality traits influence economic outcomes. It has for example been investigated how they affect the selection into occupation and the prospects for earning and employment (Dohmen, 2014); or how they are related to education (Koch et al., 2014) and individual health (Almlund et al., 2011).

In this thesis I investigate the impact of a particular social preference, negative reciprocity, on the formation of cooperative partnerships. This is on one hand important for individual and also the societal economic success. On the other hand it is also related to chapter 2. If the match in preferences influences the selection of mates, in particular if there is positive assortative mating, the intergenerational transmission of economic preferences stands to be stronger.

In chapter 3 I study theoretically and empirically how negative reciprocity, the inclination to punish unkind actions of others, influences the formation and stability of partnerships. I develop a marriage model in which individuals decide on entering a partnership in presence of uncertainty about the other's negative reciprocity. My model predicts positive assortative mating with respect to negatively reciprocal inclinations and that partnerships between like-minded individuals are not only more likely but also more stable. Evidence from the SOEP supports these predictions. In a sample of individuals in newly formed marriages I find a strong positive correlation between the negative

or perseverance, but also economic preferences, such as risk or time preferences, can be accounted for as non-cognitive skills. 
reciprocity of spouses. Moreover divorce rates are higher among couples who are more heterogeneous with respect to negative reciprocity.

\subsection{Stability}

In standard micro economic theory preferences are not only assumed to be given, but also considered constant over time. However, this might not necessarily be the case and preferences could change over the life course. A lack of stability in measured preferences can result from different scenarios. On one end of the spectrum it could be that preferences are in fact stable, but they are measured with error, which leads to instability over time (and measurements). On the other end of the spectrum preferences are not stable over time, but rather depend on the situation and recent experiences of the individual. Recent evidence on economic preferences indicates that the truth lies somewhere in between, with stable, underlying preferences, that are however to a certain extent malleable (see a discussion on possible specifications of stability of preferences in e.g Borghans et al., 2008). ${ }^{4}$

If preferences are to a certain degree malleable, this begs the question whether the factors that lead to changes are systematic and can be predicted. In this thesis I examine a potential factor which could be related to changes in preferences and find evidence for a systematic relationship. In chapter 4 I investigate the impact of exogenous changes the economic environment that individuals are exposed to on their self-stated risk preferences. I exploit changes in media coverage of economic news as proxy for changes in the economy. I use information on risk preferences from the SOEP and combine it with data on the average daily frequency of economic news reports during the year and the month preceding the date of the risk elicitation. Using fixed effects regressions I find that a persistent increase in economic news, irrespective of their valuation, is negatively related to individuals' willingness to take risk. In the short term however, an increase in news relates to a decrease in risk aversion if the news are predominantly good. The strength of the relations depends on individuals' personal characteristics and personality traits. A positive correlation between bad news coverage and individuals' worries suggests that changes in risk perception may mediate the relation between news coverage and risk attitudes.

\subsection{Measurement}

One of the key challenges in empiric work on economic preferences is the measurement of the preferences, since they are latent factors and difficult to pinpoint. While already the conceptualization of a preference or attitude is a complex task, measuring them is even more difficult. There are two direct approaches to this task. One is by experimentally

\footnotetext{
${ }^{4}$ The psychologist Mischel split the field of personality psychology in 1968 by stating that there was no stability in traits, but only in situations. He has since come to integrate the concepts of stability in traits and situations and suggests an interactive relation between the two (Mischel, 2004).
} 
eliciting certain preferences (in the lab). The advantage of this method is that individuals are incentivized to reveal their true preferences in very controlled situations. It is however rather costly to elicit preference in this manner, and sometimes cognitively demanding for the subjects. This leads to small and often selective subject pools. The other way to elicit preferences is to simply ask individuals about their own preferences. This is less time and cost intensive and allows to administer the questions to a large amount of people, for example in household surveys. The disadvantage of this method is that the situations in which individuals answer the questions are not as well controlled as in the laboratory, and that individuals are not incentivized to give a truthful account of their preferences. However, even despite these problems, self reported preferences have become quite popular measures for preferences in economics, since big samples and/or a panel structure of the data are of importance for many research questions concerning preferences, due to the low explanatory power of single factors in this area.

Aside from intentional misreporting (for example due to social desirability) individuals also make mistakes in simply stating their preference or attitude. In the last chapter of my thesis I thus discuss how to deal with these measurement errors, and how we can learn more about an individual by acknowledging the precision of their answer. In chapter $5 \mathrm{I}$ address the problem that self-reported data are often subject to non-classical measurement error; that respondents round values and make use of focal answers. Starting from a behavioral survey response model that incorporates costly introspection, I postulate a theory of how focal answers arise in survey data. The model links the presence of focal answers in the dependent variable to a specific form of heteroscedasticity. By incorporating this heteroscedasticity into the estimation procedure, we obtain better population parameter estimates and are also able to identify the drivers of focal response behavior. The estimator is undemanding in terms of additional data and can be easily implemented through subroutines already available in most statistical packages.

\subsection{Road map}

To summarize, the thesis is structured as follows: in chapter 2 I discuss an aspect of preference formation. In chapter $3 \mathrm{I}$ investigate the impact of a preference on the formation and stability of partnerships. Chapter 4 addresses the issue of stability of preferences and chapter 5 focuses on measurement issues in self-stated answers, that are often used for assessing the preferences of individuals. Finally in chapter $6 \mathrm{I}$ bring the four topics back together and discuss how they help us develop a more coherent picture on the topic of economic preferences. 



\section{Chapter 2}

\section{Parental Investment and the Intergenerational Transmission of Economic Preferences and Attitudes ${ }^{\dagger}$}

\subsection{Introduction}

Mounting evidence in the economics, psychology and sociology literature indicates that preferences, attitudes and personality traits are transmitted from parents to children. ${ }^{12}$ The transmission of preferences, attitudes and other non-cognitive skills is expected to contribute to the intergenerational correlation in economic outcomes such as income and schooling that has been well documented in the literature (for recent reviews see Björklund and Salvanes, 2011; Black and Devereux, 2011; and Holmlund et al., 2011). ${ }^{3}$ As social mobility is of prime interest for society, social scientists need to better understand the channels through which non-cognitive skills are transmitted from parents to children. Of particular concern for policy makers is the role of nurture in the formation of preferences. ${ }^{4}$ But very little is known about the channels through which socialization affects preference

\footnotetext{
$\dagger$ Joint work with Thomas Dohmen (University of Bonn) and Gerard Pfann (Maastricht University)

${ }^{1}$ Psychologists and sociologists have been studying the transmission of personality traits from parents to children since the 1930s (Loehlin, 2008).

${ }^{2}$ In the economics literature e.g. Cesarini et al. (2009) and Dohmen et al. (2012) document an intergenerational correlation in risk and trust attitudes.

${ }^{3}$ Bowles and Gintis (2002), for example, investigate how the transmission of personality traits, as well as IQ and race, influences intergenerational mobility in socio-economic status.

${ }^{4}$ There is evidence that both nature and nurture play a role in preference transmission. Cesarini et al. (2009) show that there is a genetic effect on preferences, while Dohmen et al. (2012) point out the importance of socialization in the intergenerational transmission of preferences.
} 
formation. An unanswered question is whether there is a technology for parents to shape children's preferences by purposeful investments.

This paper assesses empirically whether parents can make investments that strengthen preference transmission. We show that parents can engage in activities that make children more like them in terms of economic preferences, and thus demonstrate that there is scope to shape children's preferences by purposeful investments. Our focus is on providing evidence for the existence of a technology that parents can utilize to make investments to intentionally shape their children's preferences. We do not claim that parents in our data set exploit this technology by intentionally making certain investments. Instead we want to document that parents could purposefully shape the preferences of their child if they wanted to. ${ }^{5}$

Our key insight, that such investment strategies exist, is also important for theoretical models of cultural transmission (e.g., Bisin and Verdier, 2001; or Doepke and Zilibotti, 2008), since it empirically supports a central assumption in these models, namely, that parental investments can affect the transmission of culture and preferences. ${ }^{6}$

The type of investment we consider relates to parental involvement, which we assess by combining proxies that measure how frequently parents have engaged in certain activities in direct interaction with their children, as in talking about the child's life and worries, and proxies that measure how much the parents were involved with their children's educational development. Our construct of activities thus captures a very general investment strategy. However, our measure of parental involvement as an investment variable is far from comprehensive, and many facets of investment are not captured. Thus our results should be considered a lower bound and an estimate of the importance of investments in the transmission mechanism.

Our empirical analysis focuses on risk and trust attitudes, which have been shown to play an important role in economic decision making. ${ }^{7}$ Using data from the German Socio-Economic Panel Study (SOEP) we find that parents who invested more effort in the upbringing of their children are more similar to their adult children with respect to risk and trust attitudes.

The remainder of this paper is structured as follows. Section 2 introduces our data and explains the choice of the main variables. Section 3 introduces the model, discusses the results, and applies robustness checks. Section 4 concludes the paper.

\footnotetext{
${ }^{5}$ There are two main reasons why abstain from answering the question whether parents deliberately follow an optimal investment strategy: First we lack data on parental intentions and their utility functions. Second, we do not observe investment costs and returns, i.e. we lack information that is essential for making judgments about optimal investment strategies according to theoretical predictions.

${ }^{6}$ One example of a study that provides evidence on cultural transmission is by Fernandez and Fogli (2009), who trace the current labor force participation of female migrants in the United States to such preferences in their countries of origin. However, neither this study nor any other on cultural transmission (to our knowledge) empirically tests the assumption that it is possible for parents to invest in their children to increase their impact on their children's cultural traits and preferences.

${ }^{7}$ Risk attitudes have an impact not only on financial decision making but also on other realms of a person's life, such as choice of education or occupation or smoking (Dohmen et al., 2011). Guiso et al. (2008) show the importance of trust toward strangers for the development of impersonal markets and the well-functioning of political systems, while Butler et al. (2009) investigate the importance of trust attitudes for the individual, showing that trust and trustworthiness influence personal income.
} 


\subsection{Data}

Our analysis uses data from the SOEP, ${ }^{8}$ which not only provides information about economic attitudes and parental investment, but also allows us to link grown up children to their parents. We hereafter refer to these young adults who are our main observations as children, according to their position in the family. The SOEP is a large representative household survey that has been conducted yearly since $1984 .{ }^{9}$ Once sampled in the SOEP, each individual is followed, even after leaving the initially sampled household. This feature is especially important for our study, since it allows us to observe also young adults and their parents who no longer live in the same household.

An important source of information for our paper is the youth biography questionnaire that is requested of every newly entering young individual since 2000. This questionnaire is administered to young people who live in a SOEP household and have just become old enough (turning 18 in the following year) to enter the regular personal survey in the next year. Aside from background questions, such as personal education history, the respondents to the youth survey are asked detailed questions about their upbringing and their interaction and relationship with their parents. Since the information from this youth questionnaire is crucial for our research, we restrict our sample to individuals who answered this questionnaire. Therefore our sample contains only children between the ages of 17 and $26 .^{10}$

Further, measures for economic attitudes are not elicited in each wave of the SOEP. In particular, the two attitudes we focus on, risk and trust attitudes, were not always asked simultaneously. Therefore we construct two samples: one for trust and one for risk. These two samples largely contain the same observations, but since some individuals answered in one wave but not in another, not all individuals are part of both samples. If the individual answered the question to a certain attitude in several waves, we consider the first of those waves. ${ }^{11}$ The information on the attitudes of the parents is taken from the same wave as the child's attitudes. Every observation thus consists of a child-motherfather triplet. For risk attitudes we have a sample of 2,187 observations. Since the trust questions were asked only twice (compared to six waves with the risk questions), the trust sample has somewhat fewer observations, with 1,466 parent-child triplets.

\footnotetext{
${ }^{8}$ Socio-economic Panel (SOEP), Data for years 1984-2011, Version 28, SOEP, 2012, doi:10.5684/soep.v28.

${ }^{9}$ Schupp and Wagner (2002), Wagner et al. (2007) and Wagner et al. (2008) give detailed information on the construction and maintenance of the SOEP.

${ }^{10}$ With the exclusion of one 16-year-old who answered the regular survey and the youth questionnaire in the same year, which is not common practice.

${ }^{11}$ Since 2006 the risk question is also asked in the youth questionnaire. If a child answered the risk question in a subsequent regular SOEP survey we take the risk attitudes from this first regular answer. If the child answered the risk question only in the youth questionnaire, which is in particular the case for the SOEP participants who turned 17 in 2011, we take the risk attitude from the youth questionnaire. This increases our sample by 225 observations. However, our results change only marginally if we exclude those 225 observations.
} 


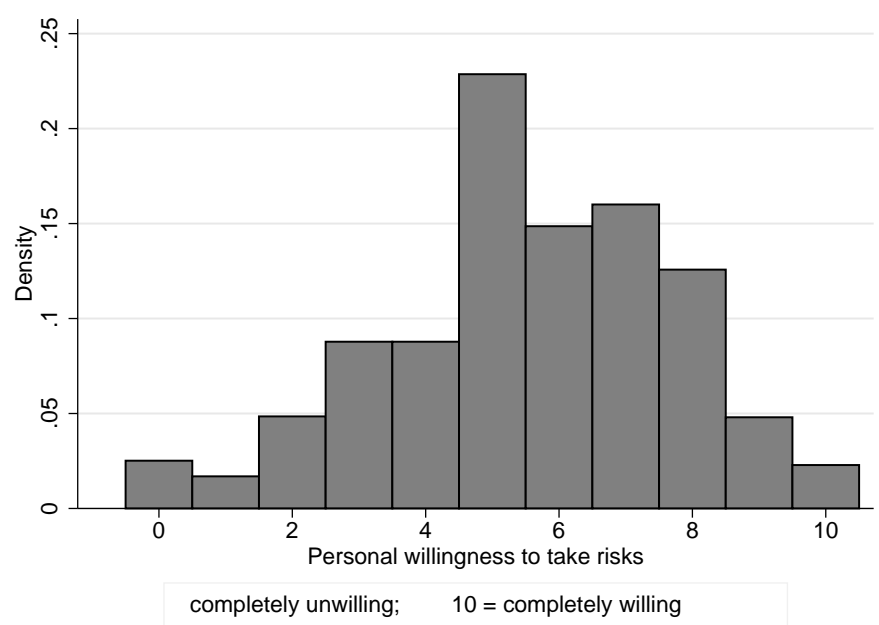

Figure 2.1: Risk attitudes

\footnotetext{
The histogram displays the distribution of answers to the general risk question of all children in our sample (at the time of their first encounter with the risk question). The wording of the risk question is: "How willing are you in general to take risks?"

Data source: SOEP, v28.
}

\subsubsection{Similarity in preferences}

This section describes how we construct our dependent variable and measure the underlying attitudes.

\section{Risk}

Individuals' risk attitudes are assessed based on a survey question asking the parents and children in our sample how willing they are to take risks in general. The answer categories range from zero, which denotes not willing to take risks at all, to ten, which stands for very willing to take risks. Figure 2.1 shows the distribution of answers in our sample of young adults. The survey question is experimentally validated in the study by Dohmen et al. (2011), which also documents that the answer to the general risk question is a good predictor for a number of risky decisions. The general risk question was asked in six waves: in 2004, 2006, 2008, 2009, 2010, and 2011.

\section{Trust}

The measure of trust attitudes is slightly more complex as it combines three survey questions into an aggregated trust index. In 2003 and 2008 the respondents of the main SOEP survey were asked how strongly they agreed with the following three statements on 


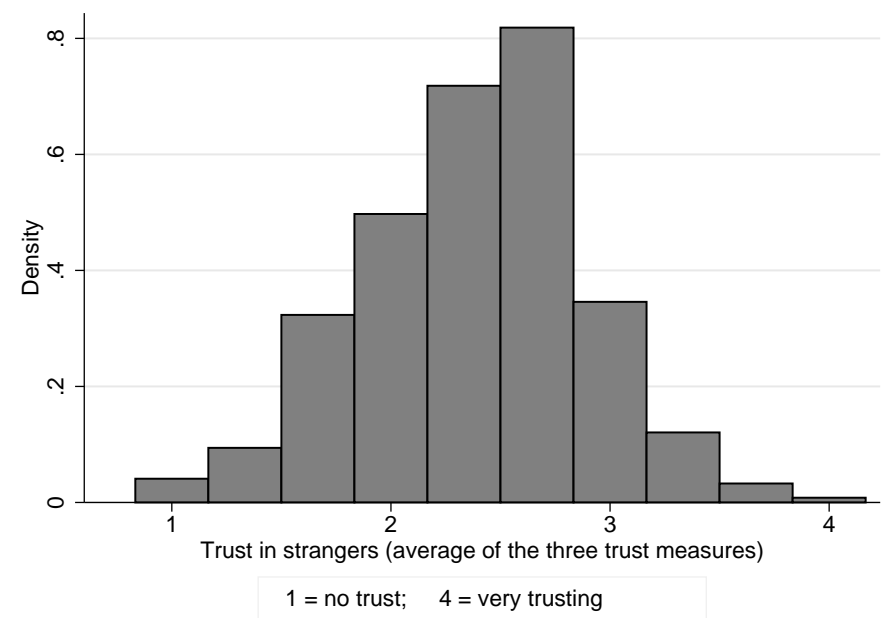

Figure 2.2: Trust in strangers

\begin{abstract}
The histogram displays the distribution of trust attitudes among the children in our trust sample (when they first answer the trust questions). The trust attitudes are measured in an index, which is the simple average over the answers to the three trust questions: "On the whole one can trust people" (scale reversed), "Nowadays one can't rely on anyone" and "If one is dealing with strangers, it is better to be careful before one can trust them".

Data source: SOEP, v28.
\end{abstract}

a scale from one to four, where one means "Agree completely" and four means "Disagree completely": "On the whole one can trust people," "Nowadays one can't rely on anyone," and "If one is dealing with strangers, it is better to be careful before one can trust them." We use a simple average over the three trust measures as our trust index. ${ }^{12}$ Figure 2.2 shows the distribution of the trust index for our sample of young adults. Fehr et al. (2003) validates this trust measure by showing that trust in strangers, measured by the three above-mentioned questions, indeed predicts first mover behavior in a trust game.

\title{
Similarity
}

We want to measure how strongly parents transmit their risk and trust attitudes. As such we are not interested in the absolute level of risk or trust attitudes of the child but, rather, in the relation between the child's and parents' attitudes. We therefore measure the impact of parents on the intergenerational transmission of preferences by the similarity of children to their parents in these preferences, and construct four different dependent variables: the difference in risk attitudes between mother and child $\left(\Delta_{R}^{M C}\right)$ and between

\footnotetext{
${ }^{12}$ We reversed the answers of the first question so that a higher number on the trust index indicates a higher level of trust.
} 

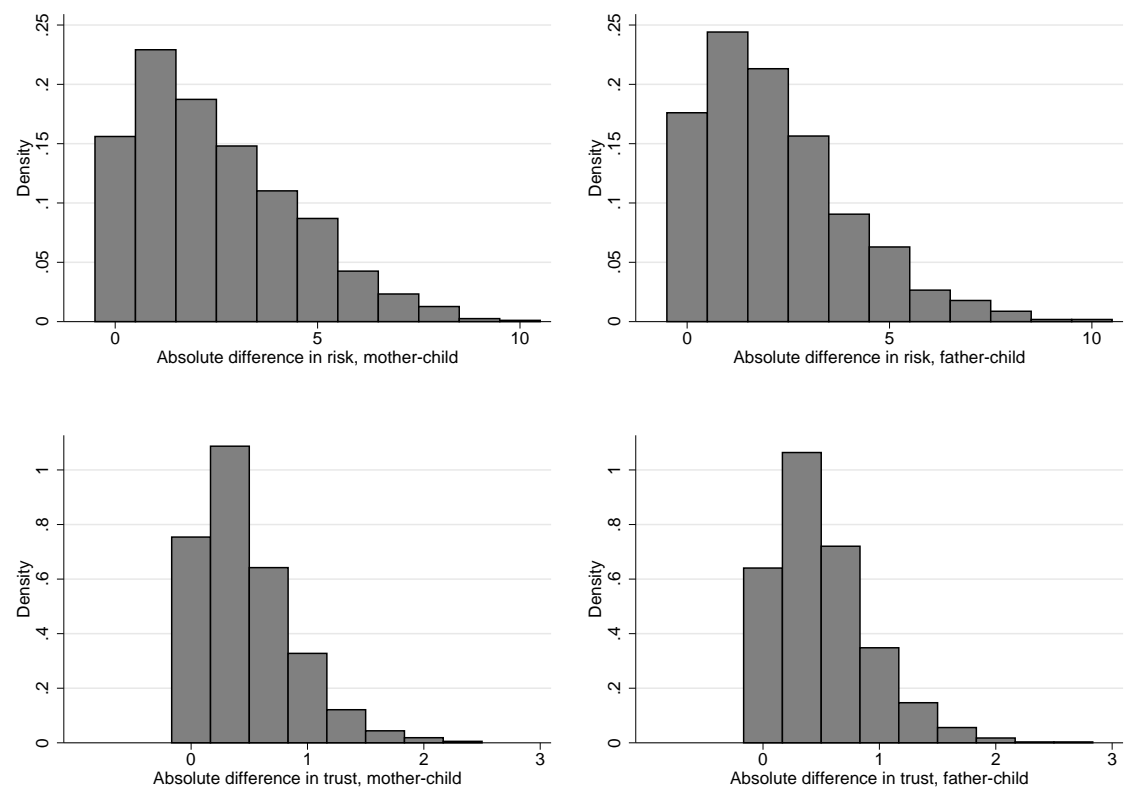

Figure 2.3: Difference in attitudes between parent and child

Distribution of the dependent variable, the absolute difference in attitude between parent and child $\left(\Delta_{P r e f}^{P C}\right)$. Own calibration; data source: SOEP, v28.

father and child $\left(\Delta_{R}^{F C}\right)$ and the difference in trust attitudes between mother and child $\left(\Delta_{T}^{M C}\right)$ and between father and child $\left(\Delta_{T}^{F C}\right)$.

We calculate the difference measure as the absolute difference between the child's and parent's attitude. We then standardize the difference measure. In our main model we use current measures of attitudes without controlling for the effect of age on attitudes. We do this for two reasons. First, we assume that the parents want to transmit their current attitudes, rather than the attitudes they had when they were of the same age as their children are now. Second, if children use their parents as role models, they can only observe the parents' current attitudes. However, we show in the robustness checks that this age-induced difference in attitudes is not driving our results.

Figure 2.3 illustrates the distribution of the four dependent variables. The average difference in risk attitudes between mothers and their children is 2.44 , with a standard deviation of 1.95 , while that between fathers and their children is 2.16 , with a standard deviation of 1.83. In trust attitudes, mothers and their children differ, on average, by 0.45 points on the trust index, with a standard deviation of 0.40 , while fathers differ by 0.50 points from their children, with a standard deviation of 0.42 . 


\subsubsection{Parental investment}

We are interested in whether parental investments, broadly defined, influence the transmission of economic preferences and attitudes. We focus on parental effort in the upbringing of children as parental investments. ${ }^{13}$ This includes, on the one hand, how much parents are involved in their children's school situation, which is an important part of a child's daily life, and, on the other hand, how strongly the parent participates in the child's life and how much the parent involves the child in family matters. ${ }^{14}$

We consider general parental investments for two reasons. First, we want to not only consider directed investments, but also investigate if general investments made by parents have an impact on the intergenerational transmission of preferences. Second, there is no very specific and easily observable parental investment we can link directly to the outcome, like it is possible for the research on the transmission of particular cultural traits or religion. ${ }^{15}$

\section{Investment proxies}

The youth questionnaire of the SOEP provides proxies for the investment that we are interested in. We can measure how involved parents are in their children's school situation, how much parents participate in the life of their children, and how strongly they integrate their children in decision processes. Table 2.1 lists the proxies we use in our study, with means and standard deviations for both (risk and trust) samples. All the proxies are measured either as binary variables or on a four- or five-point scale, as described in Table 2.1 in the last two columns. Most of the school-related proxies are measured on an aggregate level for both parents together, while for other proxies we can distinguish between the efforts of mothers and fathers. Together, these 13 proxies provide insight into the general investments of parents in their children's upbringing. However, there are many more possible investments that we cannot address in this study, such as the choice of residential neighborhood or joint leisure activities. We assume that all the proxy variables measure parental investment, but none of them measures it perfectly. We combine the proxies in an index to measure the underlying true parental investment. Using principal component analysis on the respective 13 proxies allows us to construct such an investment index for mothers and fathers (we take the first factor to be the investment index).

\footnotetext{
${ }^{13}$ The importance of parental effort or involvement in intergenerational transmission has been demonstrated in the transmission of economic outcomes. In an investigation of the driving forces of sibling correlations in long-run income, Björklund et al. (2010) find that parental involvement and parenting practices have strong predictive power in explaining sibling correlations.

${ }^{14}$ The measures for parental participation in a child's life and how much the parent involves the child in decision making are taken from a 9 item scale for supportive parenting (see Weinhardt and Schupp (2011) for more information on the supportive parenting scale and its application in the GSOEP). We use 7 out of the 9 items, excluding two items which might be reversely related with our dependent variable. The two omitted items are: "The parent shows that she/he loves you", and "The parent gives you the impression that she/he really trusts you".

${ }^{15}$ For example Patacchini and Zenou (2011) investigate the transmission of religiousness by using the frequency of taking children to religious services as a measure of investment.
} 


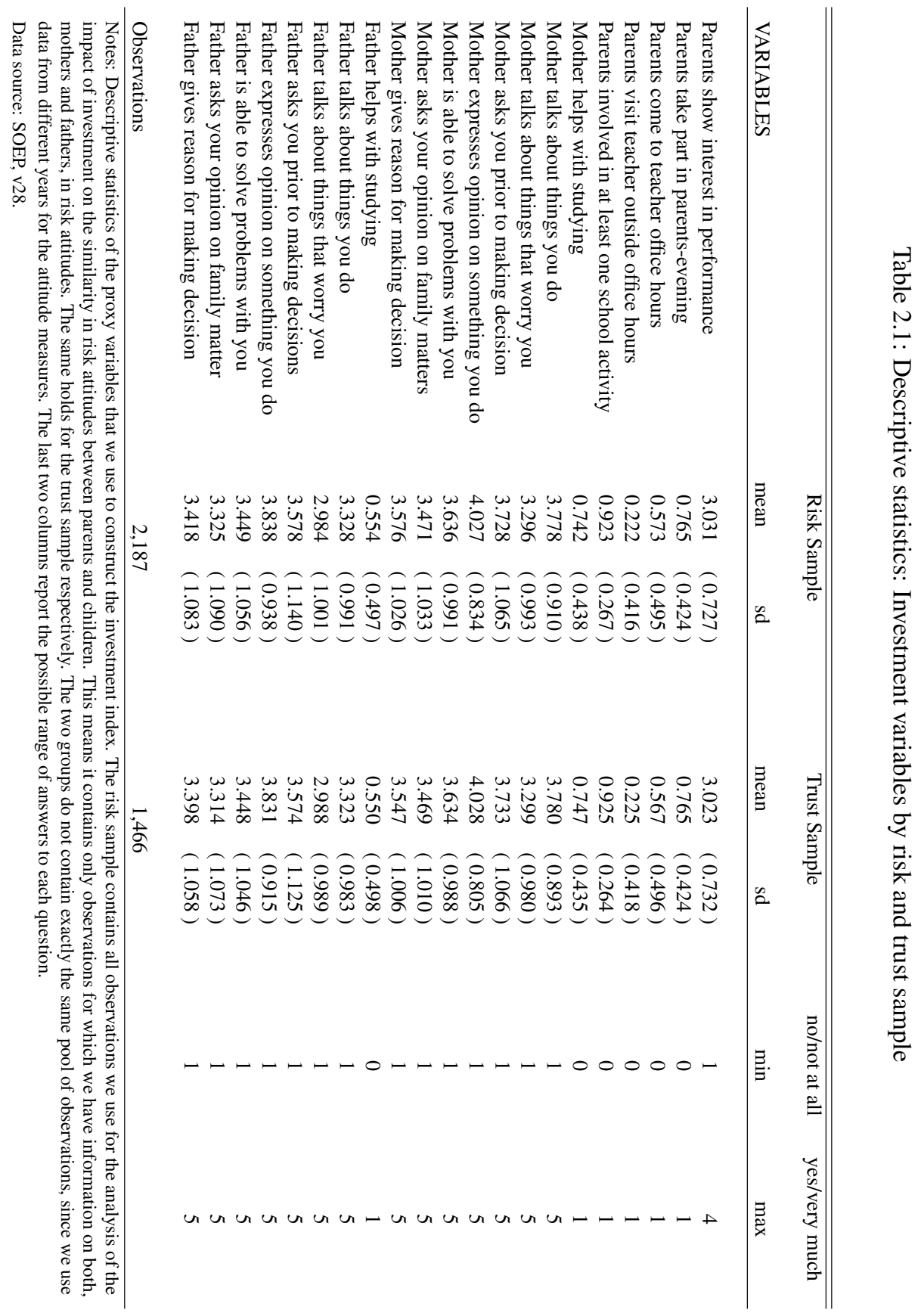


Parents who invest much in their children, as measured by our investment proxy, differ from parents who invest little in the upbringing of their children. Table 2.2 displays the means and standard deviations of background characteristics for the groups of high and low investing mothers and fathers. We find that parents who invest more in the upbringing of their children are on average more educated, earn more and are older than parents who invest less.

\subsection{Results}

We now turn to the analysis of the effect of parental investment on the similarity in risk and trust attitudes between parents and their children. We investigate the relationship for every attitude (risk, trust) and parent group (mothers, fathers) separately.

We start by regressing the standardized difference in risk attitudes between mothers and their children on the investments made by mothers. The results of this regression are displayed in Column (1) in Table 2.3. We find a negative relation between parental investment and the difference in risk attitudes, or in other words, that mothers who invest more in their children are more similar to them with respect to risk. One standard deviation increase in investment by the mother is related to a decrease in the absolute difference in risk attitudes between mother and child of 0.065 standard deviations.

Column (3) reports the relation between fathers' investments and the difference in risk attitudes between fathers and their children. We again find that higher levels of parental investment are associated with more similarity in attitudes.

Parents who invest much in their children also differ in many other aspects, as we show in Table 2.2. For our main analysis we thus have to control for an array of potentially important variables.

We control for the socio-economic background of the family by controlling for the level of education of both parents as well as for the level of household income per capita in the year when the child filled out the youth questionnaire (to make the income measure comparable across years we compute the vignitiles of per capita household income using the complete SOEP sample). Family size is another important variable in our analysis, since it can influence the formation of preferences and attitudes not only through available financial resources per child and potential environment effect of siblings, but also through the amount of time available to the parents for every single child in the family (Table 2.2 provides some evidence that parents with more children do on average invest less in every single child). We further control for age difference between the child and both parents. The literature on the intergenerational transmission of culture (e.g. Bisin and Verdier, 2001) shows that under certain assumptions minorities have larger incentives to invest in their children. We thus include a variable that captures whether the child has a migration background (both direct migration and migration of parents) to control for possible effects of being a member of an ethnic minority. We also include a measure of how heterogeneous the parents are with respect to the attitude in question. Finally we also control for the age of the child at the time of the attitude elicitation, the gender of the child and the year in which the attitude was elicited. 


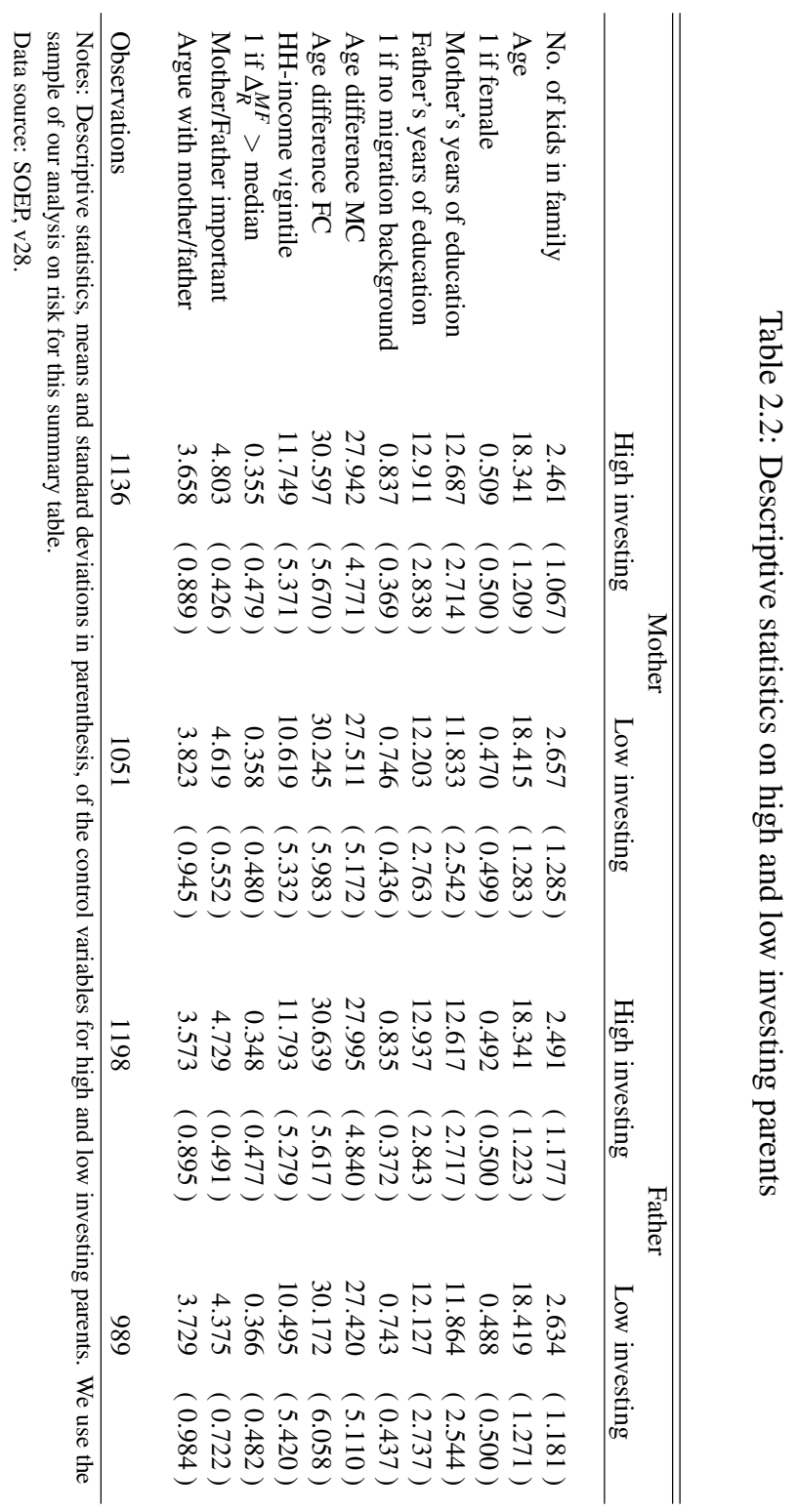


Table 2.3: PCA: The impact of parental investments on differences in risk attitudes

\begin{tabular}{|c|c|c|c|c|}
\hline \multirow[t]{2}{*}{ VARIABLES } & \multicolumn{2}{|c|}{$\Delta_{R}^{M C}$} & \multicolumn{2}{|c|}{$\Delta_{R}^{F C}$} \\
\hline & $(1)$ & $(2)$ & $(3)$ & (4) \\
\hline Investment mother (PCA) & $\begin{array}{c}-0.065 * * * \\
(0.023)\end{array}$ & $\begin{array}{c}-0.050 * * \\
(0.023)\end{array}$ & & \\
\hline Investment father (PCA) & & & $\begin{array}{r}-0.045 * \\
(0.024)\end{array}$ & $\begin{array}{r}-0.042 * \\
(0.025)\end{array}$ \\
\hline 1 if $\Delta_{R}^{M F}>$ median & & $\begin{array}{l}0.476 * * * \\
(0.048)\end{array}$ & & $\begin{array}{r}0.222 * \\
(0.048)\end{array}$ \\
\hline No. of kids in family & & $\begin{array}{c}0.003 \\
(0.020)\end{array}$ & & $\begin{array}{c}-0.015 \\
(0.019)\end{array}$ \\
\hline Age & & $\begin{array}{c}0.001 \\
(0.018)\end{array}$ & & $\begin{array}{c}0.006 \\
(0.020)\end{array}$ \\
\hline 1 if female & & $\begin{array}{c}-0.201 * * * \\
(0.041)\end{array}$ & & $\begin{array}{r}-0.077 * \\
(0.043)\end{array}$ \\
\hline Mother's years of education & & $\begin{array}{c}-0.008 \\
(0.011)\end{array}$ & & $\begin{array}{c}-0.002 \\
(0.011)\end{array}$ \\
\hline Father's years of education & & $\begin{array}{c}0.001 \\
(0.011)\end{array}$ & & $\begin{array}{c}-0.003 \\
(0.011)\end{array}$ \\
\hline 1 if no migration background & & $\begin{array}{c}-0.186 * * * \\
(0.057)\end{array}$ & & $\begin{array}{r}-0.080 \\
(0.064)\end{array}$ \\
\hline Age difference MC & & $\begin{array}{c}-0.001 \\
(0.007)\end{array}$ & & $\begin{array}{c}-0.003 \\
(0.007)\end{array}$ \\
\hline Age difference FC & & $\begin{array}{c}0.003 \\
(0.006)\end{array}$ & & $\begin{array}{c}0.007 \\
(0.006)\end{array}$ \\
\hline $\mathrm{HH}$-income vigintile & & $\begin{array}{c}0.002 \\
(0.005)\end{array}$ & & $\begin{array}{c}-0.002 \\
(0.005)\end{array}$ \\
\hline Constant & $\begin{array}{r}-0.016 \\
(0.023)\end{array}$ & $\begin{array}{c}0.051 \\
(0.376)\end{array}$ & $\begin{array}{r}-0.018 \\
(0.023)\end{array}$ & $\begin{array}{r}-0.049 \\
(0.399)\end{array}$ \\
\hline Observations & 2,187 & 2,187 & 2,187 & 2,187 \\
\hline R-squared & 0.004 & 0.078 & 0.002 & 0.022 \\
\hline
\end{tabular}

Notes: The dependent variables are the standardized difference in risk attitudes between mother and child in Columns(1)/(2) and father and child in Columns(3)/(4). Risk attitudes are measured in survey questions, explained in Section 2.2.1. The variables of interest, "Investment mother (PCA)" and "Investment father (PCA)", are indices, each constructed through factor analysis on 13 investment proxies. We use the first factor as final investment index. The variable " 1 if $\Delta_{R}^{M F}>$ median" is a binary variable that indicates parents that are heterogeneous in their risk attitudes. In addition to the listed variables we also control for the year of risk elicitation. Robust standard errors in parentheses allow for clustering at the parent level; ${ }^{*}$ significant at $10 \% ;{ }^{* *}$ significant at $5 \% ;{ }^{* * *}$ significant at $1 \%$. 
Including the control variables in our analysis does not change the point estimates we obtain for parental investments however. Columns (2) and (4) of Table 2.3 report the regression results for the impact of maternal/paternal investment on the difference in risk attitudes between mother and child, or father and child respectively, when controlling for the above mentioned variables.

We now turn to investigate the relation between parental investment and the similarity between parent and child with respect to trust attitudes. Since trust attitudes were only measured in two waves of the SOEP our sample size is much smaller here than in the analysis regarding risk attitudes. The results, displayed in Table 2.4, however are qualitatively similar. We find a negative relation between the parent's investments and the difference in trust attitudes between the parent and the child, albeit statistically not significant at conventional levels for the mother-child difference. While the effects of parental investment are rather small in size, they are very stable across specifications, which supports our hypothesis that there exists a possible investment technology to shape children's attitudes.

We now challenge our research strategy by conducting a placebo analysis. We investigate the impact of parental investments on the similarity in a trait that should not be influenced by parental investment behavior. We use the difference in height between parent and child for this purpose. Using the same regression set up with the same control variables as we do for our main results we do not find any significant impact of parental investment on the difference in height between child and parent. The point estimates for the parent's investments are $-0.014(0.018)$ for mothers and $0.02(0.025)$ for fathers.

\subsubsection{Measurement error}

We have so far shown that there is a relationship between parental investments and similarity in attitudes. However, our point estimates might strongly under-estimate the true effect, due to measurement error in the proxies. Aside from being rather noisy measures themselves, the proxy variables are all taken from the youth questionnaire, which means that they were measured at one point in time. The measurement error is thus very likely to be correlated across the proxy variables. The first principal component, which we used above as the investment index includes in this case also part of the measurement error, which leads to an attenuation bias in our analysis. We address this problem by constructing an alternative investment index, which combines the available proxy variables in an efficient way, so that the measurement error captured in the resulting index is minimized. The procedure we use has been introduced by Lubotsky and Wittenberg (2006).

To construct this new investment index we first regress the difference in attitudes between parents and children on all 13 proxy variables $x_{j}$ and all $K$ control variables $z_{k}$. In particular, for parent-child pair $i$,

$$
\Delta_{\text {Pref }_{i}}^{P C}=\sum_{j=1}^{13} x_{j i} b_{j}+\sum_{k}^{K} z_{k i} \gamma_{k}+\varepsilon_{i} .
$$

We then estimate 
Table 2.4: PCA: The impact of parental investments on differences in trust attitudes

\begin{tabular}{|c|c|c|c|c|}
\hline \multirow[t]{2}{*}{ VARIABLES } & \multicolumn{2}{|c|}{$\Delta_{T}^{M C}$} & \multicolumn{2}{|c|}{$\Delta_{T}^{F C}$} \\
\hline & $(1)$ & $(2)$ & (3) & $(4)$ \\
\hline Investment mother (PCA) & $\begin{array}{r}-0.030 \\
(0.025)\end{array}$ & $\begin{array}{r}-0.040 \\
(0.026)\end{array}$ & & \\
\hline Investment father (PCA) & & & $\begin{array}{c}-0.064 * * \\
(0.032)\end{array}$ & $\begin{array}{c}-0.062 * * \\
(0.031)\end{array}$ \\
\hline 1 if $\Delta_{T}^{M F}>$ median & & $\begin{array}{l}0.267 * * * \\
(0.057)\end{array}$ & & $\begin{array}{l}0.564 * * \\
(0.058)\end{array}$ \\
\hline No. of kids in family & & $\begin{array}{c}-0.015 \\
(0.025)\end{array}$ & & $\begin{array}{r}-0.037 * \\
(0.020)\end{array}$ \\
\hline Age & & $\begin{array}{c}0.000 \\
(0.019)\end{array}$ & & $\begin{array}{c}0.002 \\
(0.019)\end{array}$ \\
\hline 1 if female & & $\begin{array}{l}0.024 \\
(0.052)\end{array}$ & & $\begin{array}{c}0.071 \\
(0.051)\end{array}$ \\
\hline Mother's years of education & & $\begin{array}{l}0.013 \\
(0.013)\end{array}$ & & $\begin{array}{c}0.019 \\
(0.013)\end{array}$ \\
\hline Father's years of education & & $\begin{array}{r}-0.014 \\
(0.012)\end{array}$ & & $\begin{array}{c}-0.013 \\
(0.013)\end{array}$ \\
\hline 1 if no migration background & & $\begin{array}{c}0.073 \\
(0.065)\end{array}$ & & $\begin{array}{r}-0.043 \\
(0.075)\end{array}$ \\
\hline Age difference MC & & $\begin{array}{r}-0.002 \\
(0.007)\end{array}$ & & $\begin{array}{c}0.010 \\
(0.008)\end{array}$ \\
\hline Age difference FC & & $\begin{array}{c}0.003 \\
(0.007)\end{array}$ & & $\begin{array}{c}-0.007 \\
(0.007)\end{array}$ \\
\hline $\mathrm{HH}$-income vigintile & & $\begin{array}{c}-0.002 \\
(0.006)\end{array}$ & & $\begin{array}{r}-0.000 \\
(0.005)\end{array}$ \\
\hline Constant & $\begin{array}{r}-0.040 \\
(0.026)\end{array}$ & $\begin{array}{r}-0.150 \\
(0.420)\end{array}$ & $\begin{array}{c}0.002 \\
(0.027)\end{array}$ & $\begin{array}{r}-0.253 \\
(0.444)\end{array}$ \\
\hline Observations & 1,466 & 1,466 & 1,466 & 1,466 \\
\hline R-squared & 0.001 & 0.022 & 0.003 & 0.083 \\
\hline
\end{tabular}

Notes: The dependent variables are the standardized difference in trust attitudes between mother and child in Columns(1)/(2) and father and child in Columns(3)/(4). Trust attitudes are measured as the average of 3 survey questions on trust in strangers, explained in Section 2.2.1. The variables of interest, "Investment mother (PCA)" and "Investment father (PCA)", are indices, each constructed through factor analysis on 13 investment proxies. We use the first factor as final investment index. The variable " 1 if $\Delta_{R}^{M F}>$ median" is a binary variable that indicates parents that are heterogeneous in their risk attitudes. In addition to the listed variables we also control for the year of risk elicitation. Robust standard errors in parentheses allow for clustering at the parent level; * significant at $10 \% ;{ }^{* *}$ significant at $5 \% ;{ }^{* * *}$ significant at $1 \%$. 


$$
I_{i}=1 /\left(\sum_{j=1}^{13} \frac{\operatorname{cov}\left(\Delta_{\text {Pref }_{i}}^{P C}, x_{j}\right)}{\operatorname{cov}\left(\Delta_{\text {Pref }_{i}}^{\text {PC }}, x_{1}\right)} b_{j}\right) \sum_{j=1}^{13} x_{j i} b_{j} .
$$

Finally, we standardize $I$ and obtain our LW parental investment index. The assumptions made to generate the index are that the proxies and their measurement errors are not correlated with the error term and that all the proxies share this underlying trait. The weights that minimize the attenuation bias are endogenous to the system. The absolute size of the investment index is therefore not comparable across different samples or estimations with different dependent variables.

Table 2.5 reports the results of the regressions of the difference between a parent's and a child's attitude (risk and trust) on the investment the parent made in the upbringing of the child. All the investment indices used in the four displayed regressions are constructed using the Lubotsky-Wittenberg method. This also means that actual investment index is different for every column. We find point estimates for parental investment that are larger than the estimates for the PCA investment index and statistically highly significant in all four scenarios (risk/trust, mother/father). Apart from the change in the point estimates for the investment index the regression output stays largely similar to the output of our earlier analysis, the correlation coefficients of the control variables stay unchanged, while the total explained variance increases slightly. Given the noisy nature of the proxy variables and the fact that this is only a small selection of possible investments ${ }^{16}$ the results of this analysis are likely to still underestimate the true effect.

Since all the dependent variables as well as the investment variables are standardized, it is hard to grasp the economic significance of our findings. In Table 2.6 we therefore present our main results in absolute points on the risk and trust scale. A change from the 5th to the 95th percentile in mother's investment, for example, relates to a decrease in difference in willingness to take risks of 0.596 points on the risk scale that ranges from 0 to 10 . To get a better understanding for the economic meaning of this effect we compare it to the gender difference in willingness to take risks. The mentioned effect of a change from the 5th to the 95th percentile in mother's investment almost matches the difference in willingness to take risks between men and women in our sample, which amounts to 0.664

\subsubsection{Robustness checks}

While the theory of cultural transmission by Bisin and Verdier (2001) assumes that parents invest in their children to enhance the probability that the children will become more similar to them, we can also imagine a reversed scenario where parents who are more similar to their children are (emotionally) closer to them and thus invest more. We address this problem by adding information on the relationship between a child and parent in our model. If investment is indeed just a function of the relationship between parents and children, then the impact of investment on similarity should disappear (or at least

\footnotetext{
${ }^{16}$ There are many other investment options, such as choice of place of residence or excursions with the children, just mention some.
} 
Table 2.5: Measurement error correction: Lubotsky-Wittenberg. The impact of parental investments on differences in risk and trust attitudes

\begin{tabular}{|c|c|c|c|c|}
\hline \multirow[b]{2}{*}{ VARIABLES } & \multicolumn{2}{|l|}{ Risk } & \multicolumn{2}{|l|}{ Trust } \\
\hline & $\Delta_{R}^{M C}$ & $\Delta_{R}^{F C}$ & $\Delta_{T}^{M C}$ & $\Delta_{T}^{F C}$ \\
\hline Investment Mother/Father (LW) & $\begin{array}{c}-0.091 * * * \\
(0.019)\end{array}$ & $\begin{array}{c}-0.096 * * * \\
(0.020)\end{array}$ & $\begin{array}{c}-0.085 * * * \\
(0.023)\end{array}$ & $\begin{array}{c}-0.093 * * \\
(0.021)\end{array}$ \\
\hline 1 if $\Delta_{R}^{M F}>$ median & $\begin{array}{l}0.485 * * * \\
(0.048)\end{array}$ & $\begin{array}{l}0.235 * * * \\
(0.047)\end{array}$ & & \\
\hline 1 if $\Delta_{T}^{M F}>$ median & & & $\begin{array}{l}0.266 * * * \\
(0.058)\end{array}$ & $\begin{array}{l}0.561 * * * \\
(0.059)\end{array}$ \\
\hline No. of kids in family & $\begin{array}{c}0.005 \\
(0.021)\end{array}$ & $\begin{array}{c}-0.016 \\
(0.019)\end{array}$ & $\begin{array}{c}-0.014 \\
(0.025)\end{array}$ & $\begin{array}{r}-0.036 * \\
(0.021)\end{array}$ \\
\hline Age & $\begin{array}{c}0.002 \\
(0.017)\end{array}$ & $\begin{array}{c}0.011 \\
(0.020)\end{array}$ & $\begin{array}{c}-0.002 \\
(0.020)\end{array}$ & $\begin{array}{c}0.004 \\
(0.020)\end{array}$ \\
\hline 1 if female & $\begin{array}{l}-0.201 * * * \\
(0.041)\end{array}$ & $\begin{array}{c}-0.067 \\
(0.043)\end{array}$ & $\begin{array}{c}0.034 \\
(0.050)\end{array}$ & $\begin{array}{c}0.075 \\
(0.052)\end{array}$ \\
\hline Mother's years of education & $\begin{array}{c}-0.005 \\
(0.011)\end{array}$ & $\begin{array}{c}-0.001 \\
(0.012)\end{array}$ & $\begin{array}{c}0.013 \\
(0.013)\end{array}$ & $\begin{array}{c}0.016 \\
(0.013)\end{array}$ \\
\hline Father's years of education & $\begin{array}{c}0.001 \\
(0.011)\end{array}$ & $\begin{array}{c}-0.002 \\
(0.011)\end{array}$ & $\begin{array}{c}-0.016 \\
(0.012)\end{array}$ & $\begin{array}{c}-0.012 \\
(0.013)\end{array}$ \\
\hline 1 if no migration background & $\begin{array}{c}-0.168 * * * \\
(0.057)\end{array}$ & $\begin{array}{c}-0.072 \\
(0.063)\end{array}$ & $\begin{array}{c}0.069 \\
(0.070)\end{array}$ & $\begin{array}{c}-0.052 \\
(0.076)\end{array}$ \\
\hline Age difference MC & $\begin{array}{c}-0.001 \\
(0.007)\end{array}$ & $\begin{array}{c}-0.003 \\
(0.007)\end{array}$ & $\begin{array}{c}-0.002 \\
(0.008)\end{array}$ & $\begin{array}{c}0.010 \\
(0.008)\end{array}$ \\
\hline Age difference FC & $\begin{array}{c}0.003 \\
(0.006)\end{array}$ & $\begin{array}{c}0.006 \\
(0.006)\end{array}$ & $\begin{array}{c}0.003 \\
(0.007)\end{array}$ & $\begin{array}{c}-0.007 \\
(0.007)\end{array}$ \\
\hline $\mathrm{HH}$-income vigintile & $\begin{array}{c}0.000 \\
(0.005)\end{array}$ & $\begin{array}{c}-0.003 \\
(0.005)\end{array}$ & $\begin{array}{c}-0.002 \\
(0.006)\end{array}$ & $\begin{array}{c}-0.001 \\
(0.005)\end{array}$ \\
\hline Constant & $\begin{array}{r}-10.179 \\
(17.560)\end{array}$ & $\begin{array}{r}-16.634 \\
(18.132)\end{array}$ & $\begin{array}{r}-11.031 \\
(23.219)\end{array}$ & $\begin{array}{l}-7.053 \\
(24.002)\end{array}$ \\
\hline Observations & 2,187 & 2,187 & 1,466 & 1,466 \\
\hline R-squared & 0.082 & 0.027 & 0.028 & 0.089 \\
\hline $\begin{array}{l}\text { Notes: The dependent variables are the s } \\
\text { in Column(1) and father and child in Col } \\
\text { mother and child in Column(3) and father } \\
\text { is described in Section } 2.2 .1 \text {. Our variab } \\
\text { variable that differs between the four colun } \\
\text { parental investment, using the method by } \\
\text { minimizing weights. The variable " } 1 \text { if } \Delta \\
\text { heterogeneous in their risk attitudes. We re } \\
\text { the estimation procedure (1000 repetitions }\end{array}$ & $\begin{array}{l}\text { ardized differenc } \\
\text { 2), and the stan } \\
\text { hild in Column( } \\
\text { interest, "Inves } \\
\text { It is constructed } \\
\text { otsky and Witte } \\
\text { median" is a } \\
\text { robust standard e } \\
\text { significant at } 10 \%\end{array}$ & $\begin{array}{l}\text { ce in risk attitudes } \\
\text { dardized differenc } \\
\text { 4). The measurem } \\
\text { tment mother/fatl } \\
\text { as a weighted aver } \\
\text { nberg (2006) to e } \\
\text { binary variable th } \\
\text { rrror in parenthese } \\
\% \text {; }{ }^{* *} \text { significant at }\end{array}$ & $\begin{array}{l}\text { es between mothe } \\
\text { nce in trust attitude } \\
\text { nent of risk and tru } \\
\text { ther (LW)", is a c } \\
\text { erage of } 13 \text { proxy } \\
\text { estimate the atten } \\
\text { hat indicates parer } \\
\text { es, retrieved by bo } \\
\text { tt } 5 \% \text {; } * * \text { significar }\end{array}$ & $\begin{array}{l}r \text { and child } \\
\text { es between } \\
\text { ust attitudes } \\
\text { constructed } \\
\text { variables of } \\
\text { uation bias } \\
\text { nts that are } \\
\text { otstrapping } \\
\text { nt at } 1 \% \text {. }\end{array}$ \\
\hline
\end{tabular}


Table 2.6: Impact of an increase in investment on the difference in attitude

\begin{tabular}{lcccc} 
Risk: Mother-Child $\left(\Delta_{R}^{M C}\right)$ & \multicolumn{2}{c}{ PCA investment index } & \multicolumn{2}{c}{ LW investment index } \\
A change from the & std & abs & std & abs \\
\hline 25th - 75th percentile in investment & -0.064 & -0.126 & -0.125 & -0.247 \\
5th - 95th percentile in investment & -0.161 & -0.319 & -0.301 & -0.596 \\
\hline
\end{tabular}

Trust: Mother-Child $\left(\Delta_{T}^{M C}\right)$

\begin{tabular}{lcccc} 
& \multicolumn{2}{c}{ PCA investment index } & \multicolumn{2}{c}{ LW investment index } \\
A change from the & std & abs & std & abs \\
\hline 25th - 75th percentile in investment & -0.050 & -0.021 & -0.111 & -0.046 \\
5th - 95th percentile in investment & -0.127 & -0.053 & -0.280 & -0.116 \\
\hline
\end{tabular}

Risk: Father-Child $\left(\Delta_{R}^{F C}\right)$

\begin{tabular}{lcccc} 
& \multicolumn{2}{c}{ PCA investment index } & \multicolumn{2}{c}{ LW investment index } \\
A change from the & std & abs & std & abs \\
\hline 25th - 75th percentile in investment & -0.047 & -0.087 & -0.129 & -0.237 \\
5th - 95th percentile in investment & -0.120 & -0.221 & -0.318 & -0.584 \\
\hline
\end{tabular}

Trust: Father-Child $\left(\Delta_{T}^{F C}\right)$

\begin{tabular}{lcccc} 
& \multicolumn{2}{c}{ PCA investment index } & \multicolumn{2}{c}{ LW investment index } \\
A change from the & std & abs & std & abs \\
\hline 25th - 75th percentile in investment & -0.069 & -0.029 & -0.124 & -0.053 \\
5th - 95th percentile in investment & -0.174 & -0.074 & -0.306 & -0.130 \\
\hline
\end{tabular}

Notes: We report the change in difference in attitude between parent and child, resulting from an increase in investment from the 25th to the 75th percentile (and 5th to 95th percentile respectively). For each of the four specifications (attitude and parent combination) we report standardized and attitude-point effects based on the results of the estimation with both investment indices. 
drop significantly) once we include previously omitted variables on relationship. Adding two control variables on how often a child argues with a parent and how important the parent is in the child's life, we do not find that the impact of investments fades away. This finding (presented in detail in the Appendix in Tables A2.1 and A2.2) supports our hypothesis that parental investments influence the similarity between children and parents independently of the relationship between them.

Willingness to take risks decreases with age (Dohmen et al., 2011). Also trust attitudes depend on age: Older people have less trust in strangers (Alesina and La Ferrara, 2002). This may introduce a bias, since we use the absolute difference between the attitudes of parents and children and the distributions of the children's attitudes are shifted to the right due to the age effect (young people are more willing to take risks and to trust strangers). To be confident that our results are not driven by this age difference, we introduce a new set of dependent variables that are not dependent on age. We construct the age-independent difference in attitudes by regressing the individual attitude variables (of parents and children) on age dummies. For these regressions we use the complete SOEP sample, and not just our smaller sample of parents and children. We split this larger sample by gender and into a parent sample (age range of parents) and a children sample (age range of children) to allow for gender-specific age effects and to avoid introducing a bias by estimating a parent's and her child's age-independent attitude in the same regression. We then take the residual from these regressions as the age-adjusted attitude and use these new attitude measures to construct the new dependent variable. The resulting similarity variable measures the absolute difference of the age-adjusted attitudes between parent and child. The estimation with the new dependent variable leads to a very similar correlation coefficient for the investment index in particular for the more efficient LW-investment indices, thus supporting our previous results. We report the results in the Appendix in Tables A2.3 and A2.4. For both risk and trust attitudes, parental investment retains a strongly significant negative impact on the difference between parent and child.

\subsection{Conclusion}

We investigate whether parents are equipped with a technology that would allow them to deliberately shape the preferences of their children. In particular, we focus on the link between parental involvement and parent-child similarity in risk and trust attitudes and find that parents who invest more effort by being more involved in the lives of their children have children who are more similar to them. This holds for mothers and fathers and for both risk and trust attitudes.

Our results are important for at least two reasons: First, answering the question whether parents can purposefully affect the economic preferences of their children generates new insights for social scientists and policy makers alike. Having shown that a mechanism exists which enables parents to affect the transmission of preferences by investments, such as parental involvement, indicates that preferences are malleable during childhood and can be targeted. As it is very likely that other investment opportunities, beyond the ones documented in this paper (e.g. the choice of neighborhood in which the 
child grows up), exist that allow parents to directly or indirectly affect their children's attitudes, beliefs, and preferences, we interpret our findings as a lower bound for the effect of parental investments on the intergenerational transmission of risk and trust attitudes. While the malleability of preferences suggests scope for policy intervention, we deliberately have not indicated whether policy makers should aim at affecting preference formation, and if so in what directions. In fact, it is not obvious what bundles of preferences are superior in different conditions, and we want to caution policy makers to jump to conclusions too quickly.

Second, we test a central assumption of several theoretical models on cultural transmission, namely, that parents can purposefully invest to shape the preferences of their children. Our findings support the assumption that investments made by parents have a significant positive impact on the intergenerational transmission of preferences and attitudes.

More generally, our findings provide evidence that socialization is crucial for the transmission of preferences from one generation to the next. This result is of great consequence for our understanding of intergenerational mobility and for the design and appraisal of policies that affect social mobility. 


\subsection{Appendix}

Table A2.1: Robustness check: controlling for the relation between mother and child

VARIABLES

$\Delta_{R}^{M C}$

(2)

$\Delta_{T}^{M C}$

(1)

(3)

(4)

\begin{tabular}{|c|c|c|c|c|}
\hline Investment mother (PCA) & $\begin{array}{r}-0.044 * \\
(0.023)\end{array}$ & & $\begin{array}{c}-0.027 \\
(0.027)\end{array}$ & \\
\hline Investment mother (LW) & & $\begin{array}{c}-0.088 * * * \\
(0.020)\end{array}$ & & $\begin{array}{c}-0.082 * * \\
(0.023)\end{array}$ \\
\hline Mother important & $\begin{array}{c}-0.031 \\
(0.045)\end{array}$ & $\begin{array}{c}-0.033 \\
(0.044)\end{array}$ & $\begin{array}{r}-0.066 \\
(0.054)\end{array}$ & $\begin{array}{c}-0.064 \\
(0.055)\end{array}$ \\
\hline Argue with mother & $\begin{array}{c}-0.001 \\
(0.024)\end{array}$ & $\begin{array}{c}-0.016 \\
(0.025)\end{array}$ & $\begin{array}{c}0.031 \\
(0.031)\end{array}$ & $\begin{array}{c}0.039 \\
(0.033)\end{array}$ \\
\hline Constant & $\begin{array}{c}0.209 \\
(0.461)\end{array}$ & $\begin{array}{c}-12.324 \\
(17.946)\end{array}$ & $\begin{array}{c}0.036 \\
(0.512)\end{array}$ & $\begin{array}{c}-10.547 \\
(23.642)\end{array}$ \\
\hline Observations & 2,180 & 2,180 & 1,462 & 1,462 \\
\hline R-squared & 0.079 & 0.082 & 0.024 & 0.030 \\
\hline \multicolumn{5}{|c|}{$\begin{array}{l}\text { Notes: The dependent variables are the standardized difference in risk attitudes between mother and } \\
\text { child in Columns(1-2) and the standardized difference in trust attitudes between mother and child } \\
\text { in Columns(3-4). The regressor "Investment mother (PCA)" is the first principal component of the } \\
\text { investment proxies. The variable "Investment mother (LW)" is constructed as a weighted average of } \\
13 \text { proxy variables of mother's investments, using the Lubotsky-Wittenberg method to estimate the } \\
\text { attenuation bias minimizing weights. Other controls include: No. of kids in family, year of birth, } 1 \\
\text { if female, household income (vigintile), mother's years of education, father's years of education, } 1 \text { if } \\
\text { no migration background, } 1 \text { if } \Delta_{R}^{M F}>\text { median, age difference MC, age difference FC and year of the } \\
\text { attitude elicitation. Clustered, robust standard error in parentheses, the standard errors for Column(2) } \\
\text { and (4) are bootstrapped. }{ }^{*} \text { significant at } 10 \% ;{ }^{* *} \text { significant at } 5 \% \text {; }{ }^{* *} \text { significant at } 1 \% \text {. }\end{array}$} \\
\hline
\end{tabular}


Table A2.2: Robustness check: controlling for the relation between father and child

\begin{tabular}{|c|c|c|c|c|}
\hline \multirow[t]{2}{*}{ VARIABLES } & \multicolumn{2}{|c|}{$\Delta_{R}^{F C}$} & \multicolumn{2}{|c|}{$\Delta_{T}^{F C}$} \\
\hline & (1) & (2) & (3) & (4) \\
\hline Investment father (PCA) & $\begin{array}{c}-0.018 \\
(0.027)\end{array}$ & & $\begin{array}{r}-0.059 * \\
(0.032)\end{array}$ & \\
\hline Investment father (LW) & & $\begin{array}{c}-0.092 * * * \\
(0.020)\end{array}$ & & $\begin{array}{c}-0.102 * * \\
(0.023)\end{array}$ \\
\hline Father important & $\begin{array}{c}-0.081 * * \\
(0.038)\end{array}$ & $\begin{array}{c}-0.085 * * \\
(0.039)\end{array}$ & $\begin{array}{c}0.015 \\
(0.045)\end{array}$ & $\begin{array}{c}0.027 \\
(0.046)\end{array}$ \\
\hline Argue with father & $\begin{array}{c}0.002 \\
(0.024)\end{array}$ & $\begin{array}{c}0.007 \\
(0.024)\end{array}$ & $\begin{array}{c}0.052 * \\
(0.027)\end{array}$ & $\begin{array}{l}0.070 * * \\
(0.030)\end{array}$ \\
\hline Constant & $\begin{array}{c}0.372 \\
(0.447)\end{array}$ & $\begin{array}{c}-15.797 \\
(18.117)\end{array}$ & $\begin{array}{c}-0.649 \\
(0.489)\end{array}$ & $\begin{array}{l}-0.428 \\
(22.414)\end{array}$ \\
\hline Observations & 2,180 & 2,180 & 1,462 & 1,462 \\
\hline R-squared & 0.024 & 0.029 & 0.084 & 0.092 \\
\hline \multicolumn{5}{|c|}{$\begin{array}{l}\text { Notes: The dependent variables are the standardized difference in risk attitudes between father and } \\
\text { child in Columns(1-2) and the standardized difference in trust attitudes between father and child } \\
\text { in Columns(3-4). The regressor "Investment father (PCA)" is the first principal component of the } \\
\text { investment proxies. The variable "Investment father (LW)" is constructed as a weighted average of } \\
13 \text { proxy variables of father's investments, using the Lubotsky-Wittenberg method to estimate the } \\
\text { attenuation bias minimizing weights. Other controls include: No. of kids in family, year of birth, } 1 \\
\text { if female, household income (vigintile), mother's years of education, father's years of education, } 1 \text { if } \\
\text { no migration background, } 1 \text { if } \Delta_{R}^{M F}>\text { median, age difference MC, age difference FC and year of the } \\
\text { attitude elicitation. Clustered, robust standard error in parentheses, the standard errors for Column( } 2 \text { ) } \\
\text { and (4) are bootstrapped. * significant at } 10 \% \text {; }{ }^{*} \text { significant at } 5 \% \text {; }{ }^{* * *} \text { significant at } 1 \% \text {. }\end{array}$} \\
\hline
\end{tabular}


Table A2.3: Robustness check: using age adjusted preference differences mother and child

\begin{tabular}{|c|c|c|c|c|}
\hline \multirow[t]{2}{*}{ VARIABLES } & \multicolumn{2}{|c|}{$\Delta_{R_{a d j}}^{M C}$} & \multicolumn{2}{|c|}{$\Delta_{T_{a d j}}^{M C}$} \\
\hline & (1) & (2) & (3) & (4) \\
\hline Investment mother (PCA) & $\begin{array}{r}-0.014 \\
(0.022)\end{array}$ & & $\begin{array}{r}-0.048 * \\
(0.026)\end{array}$ & \\
\hline Investment mother (LW) & & $\begin{array}{c}-0.060 * * * \\
(0.018)\end{array}$ & & $\begin{array}{c}-0.088 * * x \\
(0.023)\end{array}$ \\
\hline Constant & $\begin{array}{c}0.280 \\
(0.395)\end{array}$ & $\begin{array}{l}-5.776 \\
(16.989)\end{array}$ & $\begin{array}{c}0.003 \\
(0.422)\end{array}$ & $\begin{array}{c}-15.760 \\
(23.291)\end{array}$ \\
\hline Observations & 2,180 & 2,180 & 1,462 & 1,462 \\
\hline R-squared & 0.035 & 0.034 & 0.022 & 0.028 \\
\hline \multicolumn{5}{|c|}{$\begin{array}{l}\text { Notes: The dependent variables are the standardized age adjusted difference in risk attitudes between } \\
\text { mother and child in Columns(1-2) and the standardized difference in trust attitudes between mother } \\
\text { and child in Columns(3-4). The construction of age adjusted differences is discussed in Section } \\
\text { 2.3.2. The regressor "Investment mother (PCA)" is the first principal component of the investment } \\
\text { proxies. The variable "Investment mother (LW)" is constructed as a weighted average of } 13 \text { proxy } \\
\text { variables of mother's investments, using the Lubotsky-Wittenberg method to estimate the attenuation } \\
\text { bias minimizing weights. Other controls include: No. of kids in family, year of birth, } 1 \text { if female, } \\
\text { household income (vigintile), mother's years of education, father's years of education, } 1 \text { if no migration } \\
\text { background, } 1 \text { if } \Delta_{R}^{M F}>\text { median, age difference MC, age difference FC and year of the attitude } \\
\text { elicitation. Clustered, robust standard error in parentheses, the standard errors for Column(2) and (4) } \\
\text { are bootstrapped. * significant at } 10 \% \text {; ** significant at } 5 \% ;{ }^{* * *} \text { significant at } 1 \% \text {. }\end{array}$} \\
\hline
\end{tabular}


Table A2.4: Robustness check: using age adjusted preference differences father and child

\begin{tabular}{|c|c|c|c|c|}
\hline \multirow[t]{2}{*}{ VARIABLES } & \multicolumn{2}{|c|}{$\Delta_{R_{a d j}}^{F C}$} & \multicolumn{2}{|c|}{$\Delta_{T_{a d j}}^{F C}$} \\
\hline & (1) & (2) & (3) & (4) \\
\hline Investment father (PCA) & $\begin{array}{r}-0.039 \\
(0.024)\end{array}$ & & $\begin{array}{c}-0.058 * \\
(0.031)\end{array}$ & \\
\hline Investment father (LW) & & $\begin{array}{c}-0.113 * * * \\
(0.020)\end{array}$ & & $\begin{array}{c}-0.085 * * * \\
(0.021)\end{array}$ \\
\hline Constant & $\begin{array}{r}-0.158 \\
(0.396)\end{array}$ & $\begin{array}{c}-12.311 \\
(18.006)\end{array}$ & $\begin{array}{c}-0.209 \\
(0.442)\end{array}$ & $\begin{array}{l}-3.530 \\
(24.058)\end{array}$ \\
\hline Observations & 2,180 & 2,180 & 1,462 & 1,462 \\
\hline R-squared & 0.031 & 0.038 & 0.081 & 0.086 \\
\hline \multicolumn{5}{|c|}{$\begin{array}{l}\text { Notes: The dependent variables are the standardized age adjusted difference in risk attitudes between } \\
\text { father and child in Columns(1-2) and the standardized difference in trust attitudes between father and } \\
\text { child in Columns(3-4). The construction of age adjusted differences is discussed in Section 2.3.2. } \\
\text { The regressor "Investment father (PCA)" is the first principal component of the investment proxies. } \\
\text { The variable "Investment father (LW)" is constructed as a weighted average of } 13 \text { proxy variables of } \\
\text { father's investments, using the Lubotsky-Wittenberg method to estimate the attenuation bias minimizing } \\
\text { weights. Other controls include: No. of kids in family, year of birth, } 1 \text { if female, household income } \\
\text { (vigintile), mother's years of education, father's years of education, } 1 \text { if no migration background, } 1 \text { if } \\
\Delta_{R}^{M F}>\text { median, age difference MC, age difference FC and year of the attitude elicitation. Clustered, } \\
\text { robust standard error in parentheses, the standard errors for Column }(2) \text { and (4) are bootstrapped. }{ }^{*} \\
\text { significant at } 10 \% ;{ }^{* *} \text { significant at } 5 \% ;{ }^{* * *} \text { significant at } 1 \% \text {. }\end{array}$} \\
\hline
\end{tabular}




\section{Chapter 3}

\section{A model of negative reciprocity on relationship formation}

\subsection{Introduction}

The inclination of individuals to punish unkind actions by others is an important factor in establishing and maintaining cooperation. This negative reciprocal behavior has been repeatedly shown in lab experiments (for surveys see e.g. Fehr et al., 2002; Gächter and Herrmann, 2009). There is evidence that a significant share of individuals behaves strongly negatively reciprocal, punishing others at personal costs even in one shot games where no strategic motives exist or if they were not the harmed party themselves. Gürerk et al. (2006) and Gintis (2000) consider negative reciprocity as a crucial factor for the development of human societies that fosters cooperation amongst humans, and thus provides the basis for our modern society with division of labor. Negative reciprocity plays an important role in keeping cooperation at a high level through punishment and exclusion of not cooperating individuals. While the impact of negative reciprocity on cooperation within (existing) groups or partnerships is well established, especially in multi-player games in laboratory settings (see e.g. Fehr et al., 2002 and Fehr and Gächter, 2000 for strong reciprocity or Herrmann et al., 2008 for cross-cultural evidence), its impact on the formation of partnerships has received less attention so far. ${ }^{1}$

I analyze theoretically how the interplay between own and potential partners' negative reciprocal inclinations affect the formation and stability of partnerships. I then test the implications of the model using data from the German Socio-Economic Panel Study (SOEP). For simplicity I frame the model in a marriage market setting, with two partners with equal decision power. I model the decision of two agents, who meet randomly, to

\footnotetext{
${ }^{1}$ Page et al. (2005) allow their subjects in a laboratory experiment to endogenously form groups and find that the subjects sort with respect to their willingness to contribute to the public goods game. In a control treatment the subjects can also punish, however the selection process doesn't allow to select on negative reciprocity, since punishment is not common knowledge.
} 
form and maintain a partnership. The agents are heterogeneous in the degree to which they punish others for exposing them to negative externalities. This willingness to punish is captured by the negative reciprocity parameter. Assuming imperfect information at first encounter, I model how the expected level of negative reciprocity and uncertainty about the true value of the other's reciprocity parameter affect the decision to form a couple. I then study how the partnership evolves if partners learn about each other's true reciprocity parameter once they are married, i.e. have engaged in the partnership. ${ }^{2}$ I follow Becker's (1974) model on marriage, in which each agent compares the expected utility of being married with the outside option of staying single; and the extension of this model (Becker et al., 1977) for the decision to get divorced. A first general prediction of my model is that agents prefer to form partnerships with partners who are similar with respect to negative reciprocal inclinations, leading to positive assortative mating in negative reciprocity. Under type uncertainty there are two potential ways that lead to a positive correlation between the spouses' negative reciprocity parameters: 1) positive assortative matching, i.e. homogeneous couples are more likely to form a partnership, 2) selective divorce, i.e. heterogeneous couples are more likely to separate once they receive full information. ${ }^{3}$ The importance of either of the pathways depends on the degree of uncertainty about types.

To test these hypotheses of assortative mating and the importance of the two pathways I empirically analyze marriage and divorce decisions, using data on the marital history and negative reciprocal inclinations of couples from the SOEP. The overall tendency of positive assortative mating in negative reciprocity is supported by the data. The correlation in negative reciprocity is around 0.4 for all couples in the SOEP. ${ }^{4}$ This general finding of positive assortative mating does not allow to discriminate between the cases of complete and incomplete information. However I show in the empirical section that the sorting process does not only take place at once, but goes on in the following periods. This is supportive of the incomplete information case. Hence I focus mainly on assortative mating under incomplete information in the empirical part of this study by testing the hypotheses of positive assortative marriage and selective divorce. A potential caveat of my model is the assumption of stability of preferences. In the empirical analysis I also relax this assumption and investigate the evidence for assimilation.

The paper is organized as follows. In Section 2 I lay out a model of how the match in negative reciprocity between two partners influences the willingness of both involved agents to enter a partnership in a marriage market setting. I model the decision to get married under imperfect information and the decision to divorce once the agents update their information about their partner's negative reciprocity parameters. In Section 3 I

\footnotetext{
${ }^{2}$ The model is based on the assumption that prior to forming a relationship individuals are agnostic about their potential partners' negative reciprocity. This does not hold for the marriage decision in the empirical analysis, but we can assume that there is still learning after the marriage decision, in particular if the marriage decision is taken in order to start a family.

${ }^{3}$ In my model I assume that preferences are stable over time. This leads to the exclusion of a third possible pathway, the assimilation of preferences within couples over time. In the empirical part I however do show that assimilation is not the driver of the pattern of positive assortative mating in negative reciprocity that I find.

${ }^{4}$ This is comparable to results for the correlation of other economic preferences, e.g. by Dohmen et al. (2012) for risk and trust or Lundberg (2012) for personality traits.
} 
test the hypotheses of positive assortative marriage in negative reciprocity and divorce empirically. I also provide evidence that assimilation does not drive my results. Finally in Section 4 I conclude and discuss the implications of my result.

\subsection{Model}

Consider an agent $i$ with a negative reciprocity parameter $\gamma_{i}$ that captures agent $i$ 's willingness to punish unkind actions of others. ${ }^{5}$ This reciprocity parameter does not directly influence a person's utility function, but it has an impact on the actions of a potential partner: In particular, the willingness to punish at own costs can constitute a credible threat that prevents a partner from engaging in actions that impose negative externalities on the spouse. Hence the own negative reciprocity parameter enters an agent's utility function indirectly through its impact on the partner's behavior. In case the agent stays single, the negative reciprocity parameter does not enter the agent's own utility function.

Let the utility of an agent who is single, $U_{i}^{S}$, consist of two parts. There is utility from actions which are completely independent from any potential partner - i.e. this part of the utility function is not influenced by a partner's actions, and does not impose any externalities on a partner's utility neither. Additionally there is also utility that comes from actions that impose negative externalities to a potential partner. I define these actions as $A_{i}$. Since the independent part of utility occurs both in the utility function of married and single agents we can disregard it. The utility function of an agent who is single thus reads:

$$
U_{i}^{S}=A_{i}^{S}=1,
$$

where $A_{i}^{S}$ is the engagement in action $A_{i}$ when being single. For simplicity I assume that the utility agent $i$ derives from the action $A_{i}$ is one. Since negative externalities do not matter if the agent stays single, the agent will always get the full utility $A_{i}^{S}=1$ when being single. Let the utility function of a married agent be

$$
U_{i}^{M}=B_{i j}+\left(1-\gamma_{j}\right) A_{i}^{M}-A_{j}^{M},
$$

where $B_{i j}$ is the benefit that both agents $i$ and $j$ receive from a partnership. ${ }^{6}$ Being aware of the externalities of action $A_{i}^{M}$ any married agent $i$ has to decide on the consumption of action $A_{i}^{M}$. Accordingly $A_{i}^{M}$ is $i$ 's engagement in action $A_{i}$ when being married and lies between 0 and 1 . The individual decision follows from an optimization process that takes the partner's negative reciprocity parameter into account. While the agent can still receive utility from engaging in action $A_{i}$, she is punished by her partner $j$ for doing

\footnotetext{
${ }^{5}$ While this parameter itself could result from an optimization process over fairness concerns, I treat it here as a constant, individual preference parameter. See Rabin (1993) for an explicit modeling of reciprocity, or Sobel (2005) for a review of theoretical models of reciprocity.

${ }^{6}$ Models of marital dissolution often consider shocks in the benefit parameter $B_{i j}$, e.g. Weiss and Willis (1997) who investigate shocks in the earnings capacity of either of the spouses. In this model I make the assumption that the benefits are randomly distributed but known to the couples and constant over time.
} 
so and experiences a disutility of $\left(-\gamma_{j} A_{i}^{M}\right)$ from the punishment. If this punishment is sufficiently strong, she might consider to reduce action $A_{i}^{M}$ or even abandon it altogether. In terms of this simple model this amounts to

$$
A_{i}^{M}= \begin{cases}1 & \text { for } \gamma_{j}<1 \\ 0 & \text { for } \gamma_{j} \geq 1\end{cases}
$$

This means that the agent $i$ will always fully engage in the action $A_{i}^{M}$ if the partner's reciprocity parameter $\gamma_{j}$ is smaller than the threshold value of 1 and never if it is larger than 1.

Now let every agent $i$ be randomly matched with an agent $j$ who has the same utility function but may differ in the reciprocity parameter $\gamma$. The two agents decide about the formation of the partnership by maximizing their expected utilities. The marriage decision has to be made unanimously for the partnership to be formed, (ex post) utility transfers are not possible.

\section{Hypothesis 1 POSITIVE ASSORTATIVE MATING}

Given complete information about the potential partner's negative reciprocity parameter, a couple is more likely to be formed if both partners are similar in terms of negative reciprocity.

To see this, note that it is always the partner with the smaller negative reciprocity parameter who receives less utility from the union. It is now easy to show that for an agent $i$ for whom $\gamma_{i}<\gamma_{j}$, the utility of being married decreases in the absolute difference in negative reciprocity between the two partners, denoted as $\Delta \gamma^{7}$

$$
\frac{\partial U_{i}^{M}}{\partial \Delta \gamma}=-A_{i}^{M}+\left(1-\gamma_{i}-\Delta \gamma\right) \frac{\partial A_{i}^{M}}{\partial \Delta \gamma} \leq 0
$$

While under complete information it is easy to show that there is positive assortative mating, the situation becomes more complex under incomplete information. In the following I model how and when positive assortative mating results if the information about the partner's negative reciprocity - the signal each agent receives about their partner - is imperfect.

\section{Hypothesis 2 POSITIVE ASSORTATIVE MARRIAGE}

Provided with a sufficiently accurate signal about their partner's type, agents are more likely to marry agents that are similar to themselves.

When deciding to get married both agents compare their utility of being single with their expected utility of being married. For each agent we can calculate a marriage

\footnotetext{
${ }^{7}$ Since I define agent $i$ and agent $j$ such that $\gamma_{i}<\gamma_{j}$, the absolute difference in negative reciprocity between the two partners, $\Delta \gamma$, equals to $\gamma_{j}-\gamma_{i}$.
} 
Table 3.1: Joint marriage benefit threshold $B_{i j}^{M^{*}}$

\begin{tabular}{cl|cc|cc|c}
\multirow{2}{*}{ True $\gamma$} & & \multicolumn{2}{|c|}{$\gamma_{j}$ low } & \multicolumn{2}{|c|}{$\gamma_{j}$ high } & \\
& Signal $\tilde{\gamma}$ & $\tilde{\gamma}_{j}$ low & $\tilde{\gamma}_{j}$ high & $\tilde{\gamma}_{j}$ low & $\tilde{\gamma}_{j}$ high & \\
\hline \multirow{2}{*}{$\gamma_{i}$ low } & $\tilde{\gamma}_{i}$ low & $2-s$ & $1+s$ & $2-s$ & $1+s$ & $\mathrm{p}$ \\
& $\tilde{\gamma}_{i}$ high & $1+s$ & $1+s$ & $2-s$ & $1+s$ & $1-\mathrm{p}$ \\
\hline \multirow{2}{*}{$\gamma_{i}$ high } & $\tilde{\gamma}_{\text {low }}$ low & $2-s$ & $2-s$ & $1-s$ & $s$ & $1-\mathrm{p}$ \\
& $\tilde{\gamma}_{i}$ high & $1+s$ & $1+s$ & $s$ & $s$ & $\mathrm{p}$ \\
\hline & & $\mathrm{p}$ & $1-\mathrm{p}$ & $1-\mathrm{p}$ & $\mathrm{p}$ &
\end{tabular}

This table shows the marriage benefit threshold of the partner with the higher and thus binding threshold for each combination of partner's true types and perceived signals. The last column, and row respectively, shows the probability that a certain signal is sent, given the true type.

threshold benefit $B_{i j}^{M^{*}}$ that is needed for the agent to enter a marriage. Both agents make their decision simultaneously. A marriage is only established if the actual benefit is larger than both benefit thresholds.

$$
B_{i j}^{M^{*}}=\max \left[1+A_{j}^{M}-E\left[\left(1-\gamma_{j}\right) A_{i}^{M}\right], 1+A_{i}^{M}-E\left[\left(1-\gamma_{j}\right) A_{j}^{M}\right]\right]
$$

I now introduce some simplifying assumptions in order to be able to derive the predictions on marriage and divorce behavior of homogeneous and heterogeneous couples. I start with the assumption that there are two types of agents: high negative reciprocity types with $\gamma^{h}: \gamma=1$ and a low types with $\gamma^{l}: \gamma=0$. Every agent $i$ receives a signal $\tilde{\gamma}_{j}^{l}$ or $\tilde{\gamma}_{j}^{h}$ upon being matched with an agent $j$. The signal $\tilde{\gamma}_{j}$ is correct with probability $p$. The agents assume with a subjective probability $s$ that their information is correct. However, this probability does not need to match the true probability $p$. In this simplified world we can define the marriage benefit threshold of $i$ as

$$
B_{i}^{M^{*}}=1+\left(1-\gamma_{i}\right)-\left[\left(1-\tilde{\gamma}_{j}\right) s+\tilde{\gamma}_{j}(1-s)\right] .
$$

Table 3.1 shows the binding marriage benefit threshold for each type of couple (by types and information).

From these threshold values it is obvious that homogeneous couples that are high negative reciprocity types have the smallest thresholds, independent of the objective or subjective probabilities of the signal correctness. This means that couples of two strongly negative reciprocal types are willing to marry at lower levels of benefits. To be able to make a prediction about assortative mating, we thus have to compare heterogeneous couples with homogeneous couples that are both low types.

Comparing the benefit thresholds of mixed and low-low type couples we can conclude that there is positive assortative marriage in negative reciprocity as long as $p^{2}>1-p$ holds, i.e. if the objective probability $p$ for the signal to be correct is larger than $0.618 .^{8}$

\footnotetext{
${ }^{8}$ Due to the lower thresholds for high-high type couples positive assortative marriage in negative reciprocity might appear also at lower levels of certainty, but for $p>0.618$ every type of homogeneous couple is more likely to form a union than a heterogeneous couple.
} 


\section{Hypothesis 3 SELECTIVE DIVORCE}

Couples who are heterogeneous with respect to their negative reciprocity parameters are more likely to get divorced.

If two agents agree to marry, they learn about their partner's true reciprocity parameter, update the parameters in their utility functions and decide whether they want to stay married or not. If the benefit the agents receive from the marriage is below the updated benefit threshold of one or both of the two agents, the couple gets divorced. ${ }^{9}$ I hence define the divorce benefit threshold as

$$
B_{i j}^{D^{*}}=\min \left[1-\left(1-\gamma_{j}\right) A_{i}^{M}+A_{j}^{M}, 1-\left(1-\gamma_{j}\right) A_{j}^{M}+A_{i}^{M}\right]
$$

Using the marriage and the divorce thresholds I define the divorce rate as

$$
D=\frac{\int_{i j}^{B_{i j}^{M^{*}}} \rho\left(B_{i j}\right) \mathrm{d} B_{i j}}{\int_{B_{i j}^{M^{*}}}^{\infty} \rho\left(B_{i j}\right) \mathrm{d} B_{i j}},
$$

with the share of all couples who get married and then divorced in the numerator and the share of all couples who get married in the denominator. For any combination of negative reciprocity parameters $\gamma_{i}$ and $\gamma_{j}$ the share of couples that get married is equal to the area of the integral over all possible benefit parameters $B_{i j}$ (with $\rho\left(B_{i j}\right)$ being the probability density function of the distribution of benefits) that are larger than the marriage benefit threshold $B_{i j}^{M^{*}}$. The share of couples who get married and divorced is the integral over all possible benefit parameters that are larger than the marriage benefit threshold, but smaller than the divorce benefit threshold $B_{i j}^{D^{*}}$.

In the model with only two types of agents I can state $i$ 's threshold benefit for divorce, i.e. the minimal benefit $i$ needs to stay married with $j$ :

$$
B_{i}^{D^{*}}=1+\left(1-\gamma_{i}\right)-\left(1-\gamma_{j}\right)
$$

We only observe a divorce if the marriage benefits of a couple are large enough to pass the marriage benefit threshold, but smaller than the divorce threshold, $B_{i j}^{M^{*}}<B_{i j}<B_{i j}^{D^{*}}$. Table 3.2 summarizes the cases in which couples divorce.

Since homogeneous couples of low-low types can only make mistakes that lead to a too high marriage threshold, they never have a reason to divorce, even if they learn that their information was incorrect. For the selective divorce hypothesis we have to compare the mixed type couples with the high-high type couples.

To analyze the conditions under which the selective divorce hypothesis holds, I make the simplifying assumption that $s=1$, which means that the agents trust the signal they

\footnotetext{
${ }^{9}$ This is in line with an extension of the marriage model by Becker et al. (1977), however at this point we do not allow for the option of any utility transfers within a couple.
} 
Table 3.2: Joint marriage and divorce benefit thresholds, $\left[B_{i j}^{M^{*}}, B_{i j}^{D^{*}}\right]$

\begin{tabular}{ll|cc|cc|c}
\multirow{2}{*}{ True $\gamma$} & \multirow{2}{*}{ low } & \multicolumn{3}{|c}{ high } \\
& Signal $\tilde{\gamma}$ & low & high & low & high & \\
\hline \multirow{2}{*}{ low } & low & & & {$[2-s, 2]$} & {$[1+s, 2]$} & $\mathrm{p}$ \\
& high & & & {$[2-s, 2]$} & {$[1+s, 2]$} & $1-\mathrm{p}$ \\
\hline \multirow{2}{*}{ high } & low & {$[2-s, 2]$} & {$[2-s, 2]$} & {$[1-s, 1]$} & {$[s, 1]$} & $1-\mathrm{p}$ \\
& high & {$[1+s, 2]$} & {$[1+s, 2]$} & {$[s, 1]$} & {$[s, 1]$} & $\mathrm{p}$ \\
\hline \multirow{2}{*}{} & & $\mathrm{p}$ & $1-\mathrm{p}$ & $1-\mathrm{p}$ & $\mathrm{p}$ &
\end{tabular}

This table shows the intervals of benefit thresholds within which couples get married and divorced, for each combination of partner's true types and perceived signals. The last column, and row respectively, shows the probability that a certain signal is sent, given the true type.

receive. There is selective divorce if

$$
\frac{(1-p) \int_{1}^{2} \rho\left(B_{i j}\right) \mathrm{d} B_{i j}}{(1-p) \int_{1}^{2} \rho\left(B_{i j}\right) \mathrm{d} B_{i j}+\int_{2}^{\infty} \rho\left(B_{i j}\right) \mathrm{d} B_{i j}}>\frac{(1-p)^{2} \int_{0}^{1} \rho\left(B_{i j}\right) \mathrm{d} B_{i j}}{(1-p)^{2} \int_{0}^{1} \rho\left(B_{i j}\right) \mathrm{d} B_{i j}+\int_{1}^{\infty} \rho\left(B_{i j}\right) \mathrm{d} B_{i j}}
$$

The term on the left-hand side is the divorce rate of heterogeneous couples, the amount of divorcing couples divided by the total number of marriages. The term on the right-hand side constitutes the divorce rate of homogeneous, high-high type couples.

This inequality holds for any normal distribution of $B_{i j}$ with strictly positive variance, as I show in the proof in the appendix.

The model predicts that agents prefer to be in a partnership with a partner that is similar to them with respect to negative reciprocity. If at first they do not have full information but a sufficiently informative signal they will engage in positive assortative marriage in negative reciprocity. Further, selective divorce increases the correlation in negative reciprocity among observed couples, because heterogeneous couples are more likely to get divorced and thus drop out of the pool of observed couples.

\subsection{Empirical Analysis}

In the following section I assess the hypotheses of positive assortative marriage in negative reciprocity and divorce empirically. I will also address the issue of assimilation within partnerships. ${ }^{10}$ I use data from the SOEP, ${ }^{11}$ a large representative household panel survey

\footnotetext{
${ }^{10}$ In the model I take the assumption that preferences are stable over time. If this assumption does not hold, the findings of positive assortative mating in negative reciprocity could also be induced by assimilation. I address the issue of assimilation in this section to show that this is not the case.

${ }^{11}$ Socio-economic Panel (SOEP), Data for years 1984-2012, Version 29, SOEP, 2013, doi:10.5684/soep.v29.
} 
which runs since $1984 .{ }^{12}$ It contains detailed data on individuals' marriage biographies, as well as measures for economic attitudes and traits, including negative reciprocity. My measure of negative reciprocity, $\gamma$, is based on 3 survey questions on negatively reciprocal inclinations taken from the personal norm of reciprocity questionnaire by Perugini et al. (2003). Respondents have to rate their willingness to retaliate in the following conditions on a 7-point scale: (1) "If I suffer a serious wrong, I will take revenge as soon as possible, no matter what the cost." (2) "If somebody puts me in a difficult position, I will do the same to him/her." (3) "If somebody offends me, I will offend him/her back." I use the average of the responses to these 3 questions as a proxy to $\gamma .{ }^{13}$

The decision to get married and divorced occur at different points in time. This implies that I can not analyze the two decisions for the same sample, but have to construct different samples to analyze the different decisions. Table A3.1 in the appendix provides descriptive statistics on the 3 samples that I introduce in more detail in the relevant subsections.

\subsubsection{Positive assortative marriage}

The hypothesis on assortative marriage states that agents are more likely to marry partners that are similar to them with respect to negative reciprocity. This leads to positive assortative marriage patterns. I use data on newly married couples to analyze this hypothesis. Since the reciprocity questions have been asked in 2005 and 2010 I construct an estimation sample which consists of all couples who got married between 2003 and 2005 and answered the negative reciprocity question in 2005, and those who got married between 2008 and 2010 and answered the question in 2010. The sample contains information on 508 couples. The average age when getting married is 33.2 years for women and 36.5 years for men. ${ }^{14}$

A first glance at the data supports the hypothesis of positive assortative marriage in negative reciprocity. There is a positive and significant correlation between the levels of negative reciprocity of the two partners as can be seen in Figure 3.1. The corresponding correlation coefficient amounts to 0.32 . Just looking at the raw data we can thus say that individuals that are strongly negatively reciprocal are more likely to have a partner who is also strongly negatively reciprocal, while individuals that score low on negatively reciprocity on average also have partners that have weak negatively reciprocal inclinations.

This correlation, however, does not show that couples do indeed select on negative reciprocity. It could also be driven through selection on other characteristics that are correlated to negative reciprocity, such as age or years of education. To account for that I

\footnotetext{
${ }^{12}$ Schupp and Wagner (2002) give detailed information on the construction and maintenance of the SOEP.

${ }^{13}$ Using the same measure of negative reciprocity in the SOEP Dohmen et al. (2009) show that the relation between reciprocity and labor market behavior and life outcomes is in line with experimental evidence.

${ }^{14}$ Note that this sample includes all marriages, not just first marriages, which increases the age at marriage. The average age at first marriage in Germany in 2009 was 30.2 for women and 33.1 for men (Destatis Statistisches Bundesamt, 10.07.2014, retrieved from: https://www.destatis.de/DE/ZahlenFakten/ GesellschaftStaat/Bevoelkerung/Eheschliessungen/Tabellen/EheschliessungenHeiratsalter.html). This corresponds to the average age of the 365 women in the sample who marry for the first time, 29.6 and to the 327 men who marry for the first time at age 32.6.
} 


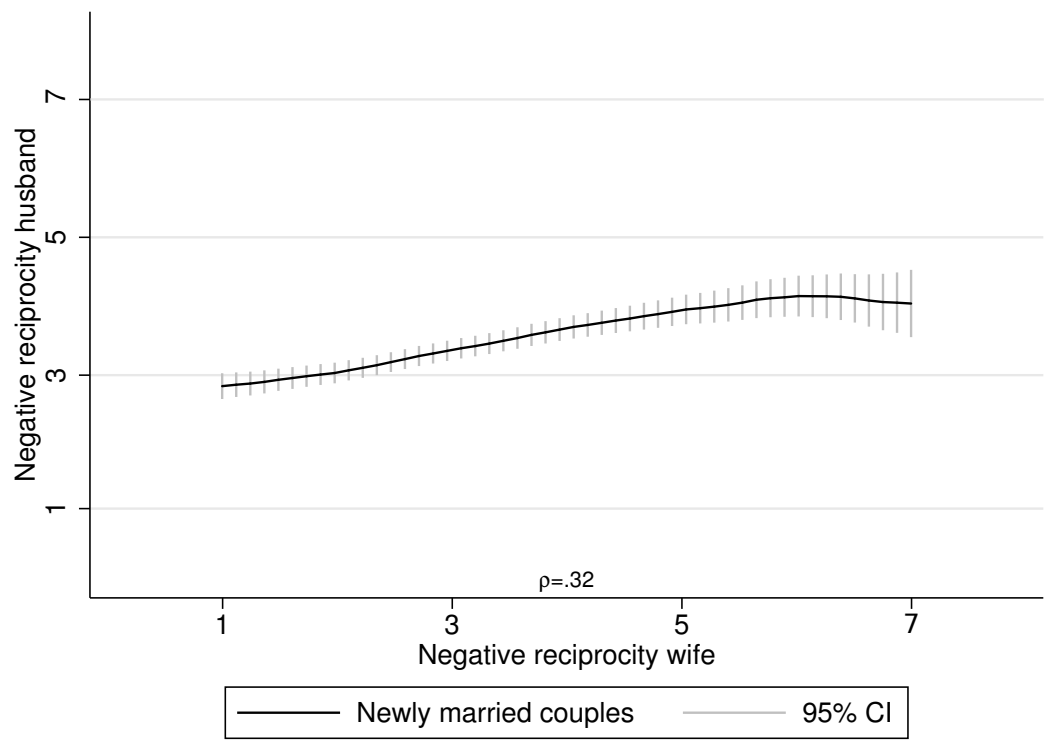

Figure 3.1: Assortative marriage on negative reciprocity

Local polynomial fit. Data source: SOEP v29.

now control for such characteristics. In Table 3.3 I report the results of OLS estimations of the negative reciprocity of one partner on the negative reciprocity of the other, ${ }^{15}$ controlling for age and years of education of both partners, as well as for the year of the reciprocity elicitation and two dummies for 1 and 2 years of marriage duration. Column 1 shows the results of the regression of the negative reciprocity of the wife on her husband's negative reciprocity parameter and the controls. In Column 2 I report the same for the negative reciprocity of the husband. The coefficients for the partner's negative reciprocity of 0.320 and 0.297 respectively are both highly statistically significant. The age of the husband and the years of education of the wife relate to a lower degree of negative reciprocity of the wife, holding everything else constant. The age of the wife herself and the years of education of the husband do not relate statistically significant to the negative reciprocity of the wife. The husband's negative reciprocity is not related to neither his own nor the wife's age on any conventional level of statistical significance. The years of education of the husband relates strongly to his negative reciprocity parameter, decreasing it, while the wife's education relates to a slightly higher level of the husband's negative

\footnotetext{
${ }^{15}$ Using single reciprocity questions in this estimation, instead of the index, leads to very similar results. The results are available from the author upon request.
} 
Table 3.3: Assortative marriage on negative reciprocity

\begin{tabular}{lcc}
\hline & $(1)$ & $(2)$ \\
VARIABLES & neg. reciprocity wife & neg. reciprocity husband \\
\hline neg. reciprocity wife & & \\
& & $0.297 * * *$ \\
neg. reciprocity husband & $0.320 * * *$ & $(0.043)$ \\
& $(0.044)$ & \\
age wife & 0.008 & -0.003 \\
& $(0.011)$ & $(0.012)$ \\
age husband & $-0.025 * *$ & 0.010 \\
& $(0.010)$ & $(0.011)$ \\
education wife & $-0.063 * *$ & $0.046 *$ \\
& $(0.026)$ & $(0.027)$ \\
education husband & -0.013 & $-0.099 * * *$ \\
& $(0.025)$ & $(0.025)$ \\
Constant & 59.836 & -8.634 \\
& $(50.173)$ & $(48.365)$ \\
& & 508 \\
Observations & 508 & 0.135 \\
R-squared & 0.144 & \\
\hline Notes: Education is in years of education. Robust standard errors in parentheses; ${ }^{*}$ significant at $10 \%$; \\
** significant at $5 \% ; * *$ significant at $1 \%$.
\end{tabular}

reciprocity. The wave in which the reciprocity was elicited and whether the marriage started one or two years before the preference elicitation does not matter.

Controlling for age and years of education in a linear regression model could still be insufficient to disentangle selection on these characteristics and negative reciprocity. I therefore construct a placebo marriage sample in which every woman is matched with a random male partner that is similar to her real partner in terms of age and years of education. In this placebo sample the correlation between the negative reciprocity of a wife and her randomly matched partner is 0.08 and significant at a $10 \%$ level. Controlling for age and years of education of both partners, as well as for year and marriage duration leads to coefficients for negative reciprocity of 0.04 and 0.036 respectively, both statistically insignificant at any conventional level. This shows that the results are not driven by non-linearities in the control variables, and thus supports the hypothesis of positive assortative mating in negative reciprocity.

\subsubsection{Selective divorce}

According to the hypothesis of selective divorce heterogeneous couples are more likely to get divorced if there is imperfect information about the partner's preference at the time the marriage decision is taken. In the model it is assumed that the couple decides upon their first encounter whether to engage in a marriage or not. This does of course not hold 


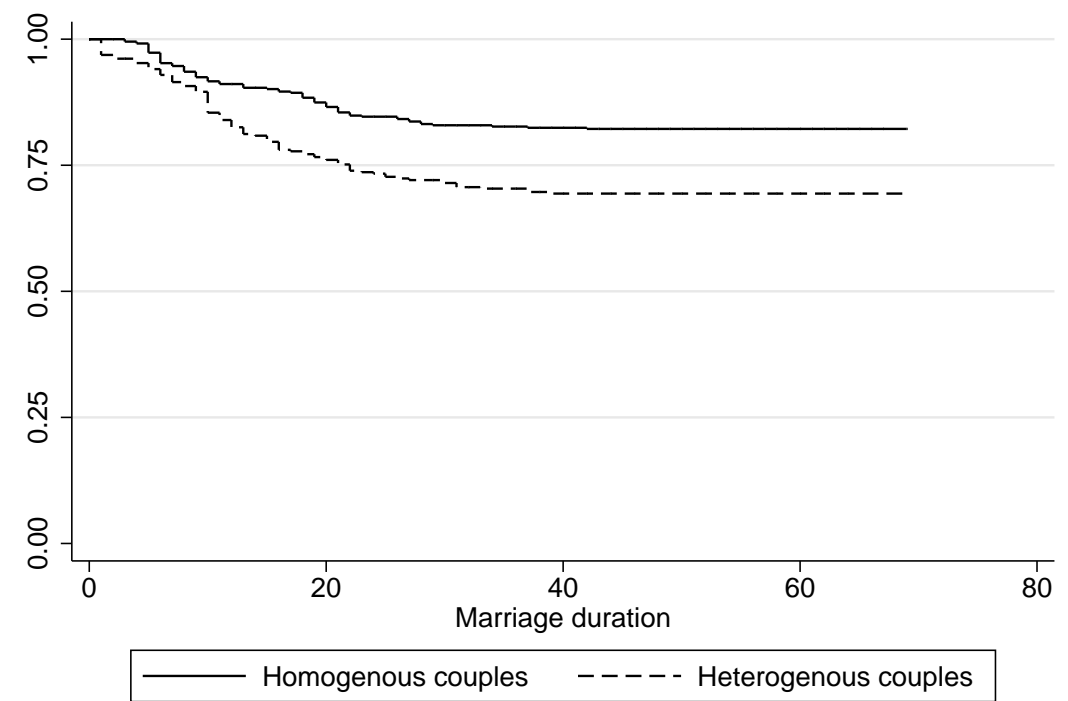

Figure 3.2: Kaplan-Meier survival estimates for marriages by difference in negative reciprocity

Homogeneous if below, heterogeneous if above mean difference in negative reciprocity. Data source: SOEP v29.

in the real world, however, it is sufficient for the prediction to hold if the information is still imperfect at the time the marriage decision is taken.

I construct a sample that contains the couples in the SOEP that are observed between 2005 and 2012, and for which I have information on the negative reciprocity parameter for both, wife and husband. To analyze the impact of the difference in negative reciprocity on the likelihood to get divorced, I create the variable " $|\Delta|$ negative reciprocity" which is the distance between the two partners' negative reciprocity parameters. In total there are 6141 couples in the data set for which we can observe the negative reciprocity parameter of both partners, beginning and end year (or right censoring) of their marriage spell, and the control variables.

Table A3.1 Column 2 in the appendix reports the mean and standard deviation of negative reciprocity for both wives and husbands, and of the distance between the two. The average distance is 1.176 with a standard deviation of 1.072.

First evidence of higher divorce rates among heterogeneous couples is provided by the Kaplan Meier survival estimates for marriages in Figure 3.2. I split the sample into couples who are at least as similar in terms of negative reciprocity than the average (homogeneous couples) and heterogeneous couples that are more different than the average. The figure shows that the survival rates are lower for heterogeneous couples, 
Table 3.4: Selective divorce on negative reciprocity

\begin{tabular}{|c|c|c|}
\hline VARIABLES & \multicolumn{2}{|c|}{ divorce hazard } \\
\hline$|\Delta|$ neg. reciprocity & $\begin{array}{l}1.173 * * \\
(0.076)\end{array}$ & $\begin{array}{c}1.156 * \\
(0.089)\end{array}$ \\
\hline neg. reciprocity wife $* I^{w}$ & & $\begin{array}{c}1.015 \\
(0.075)\end{array}$ \\
\hline neg. reciprocity husband $* I^{h}$ & & $\begin{array}{l}1.022 \\
(0.073)\end{array}$ \\
\hline$|\Delta|$ age & $\begin{array}{r}1.033 * \\
(0.019)\end{array}$ & $\begin{array}{r}1.033 * \\
(0.019)\end{array}$ \\
\hline age wife & $\begin{array}{c}0.987 \\
(0.011)\end{array}$ & $\begin{array}{c}0.988 \\
(0.011)\end{array}$ \\
\hline$|\Delta|$ education & $\begin{array}{l}1.024 \\
(0.047)\end{array}$ & $\begin{array}{l}1.025 \\
(0.047)\end{array}$ \\
\hline$|\Delta|$ education missing & $\begin{array}{l}4.677 * * * \\
(1.062)\end{array}$ & $\begin{array}{l}4.645 * * * \\
(1.069)\end{array}$ \\
\hline 1 if kids under 16 in $\mathrm{HH}$ & $\begin{array}{l}0.622 * * \\
(0.145)\end{array}$ & $\begin{array}{l}0.624 * * \\
(0.147)\end{array}$ \\
\hline $\log \mathrm{HH}$ income & $\begin{array}{l}0.223 * * * \\
(0.037)\end{array}$ & $\begin{array}{l}0.224 * * * \\
(0.037)\end{array}$ \\
\hline full time empl. wife & $\begin{array}{l}2.825 * * * \\
(0.509)\end{array}$ & $\begin{array}{l}2.823 * * * \\
(0.507)\end{array}$ \\
\hline Observations & 30,030 & 30,030 \\
\hline Number of subjects & 6141 & 6141 \\
\hline Number of divorces & 150 & 150 \\
\hline Log likelihood & -872.8 & -872.7 \\
\hline
\end{tabular}

Notes: Cox proportional hazard model. $|\Delta|$ denotes the absolute difference between the spouses in the values of the respective variable. $I^{w}$ and $I^{h}$ respectively are indicator functions, taking the value of one if the wife, or the husband respectively, is the partner with the lower negative reciprocity preferences. Education is in years of education. Robust standard errors in parentheses; ${ }^{*}$ significant at $10 \% ;{ }^{* *}$ significant at 5\%; *** significant at $1 \%$.

with a gap that increases over the first years of marriage and stays relatively stable after that. $^{16}$

To look closer at these first results and to control for some potentially problematic other correlates of the probability to divorce, I now turn to survival analysis. Table 3.4 reports the Cox proportional hazard rates for getting divorced, controlling for the age and the age difference of the partners, the years of education and the difference therein, for having children below the age of 16 in the household, the log household income and the

\footnotetext{
${ }^{16}$ If this drift mainly takes place in the first years of the marriage, the picture could be even more pronounced if we were to observe the start of the relation, instead of the start of the marriage.
} 


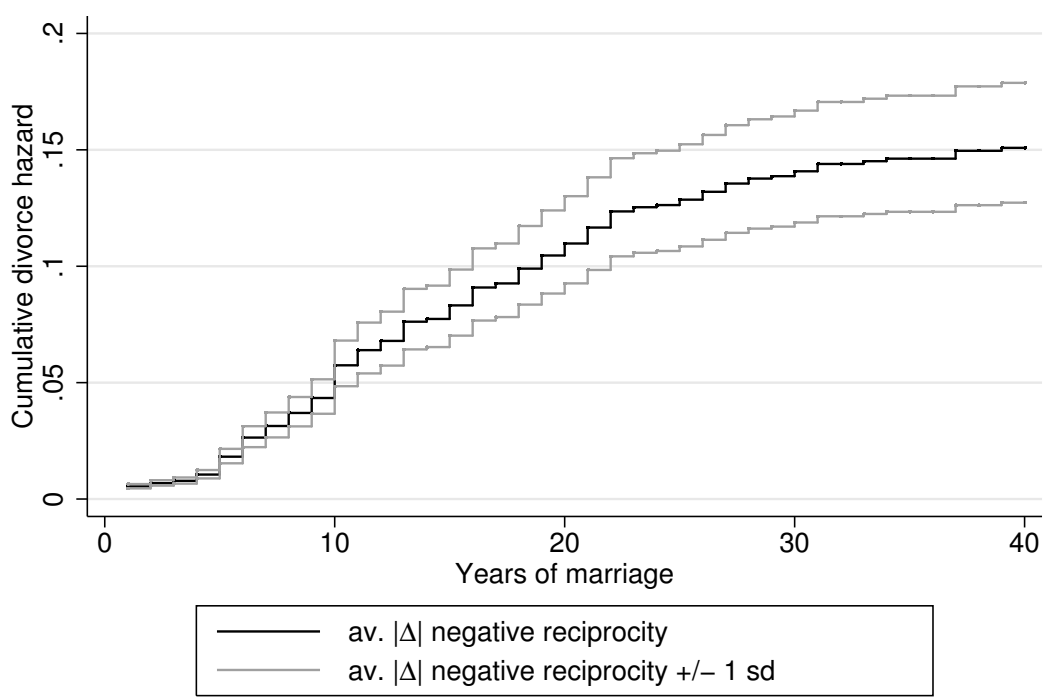

Figure 3.3: Cox proportional hazard by $|\Delta|$ negative reciprocity

Cumulative divorce hazard at average levels of $|\Delta|$ negative reciprocity (1.17), plus/minus one standard deviation in $|\Delta|$ negative reciprocity (1.07). Estimation results are reported in Column (1) of Table 3.4. Data source: SOEP v29.

employment status of the wife. There is a strong relation between the divorce hazard and the within couple heterogeneity in negative reciprocity, significant at the 5\% level. A one point increase in the difference between the two partners is associated with a $17 \%$ higher divorce probability, holding everything else constant. Figure 3.3 illustrates the differences in divorce hazard by different levels of negative reciprocity. From this graph we can see that a couple with average characteristics in our sample has a probability of around $15 \%$ to be divorced 40 years after marrying. A similar couple that differs only in being one standard deviation more different in negative reciprocity has a divorce probability of around $18 \%$.

This relation also holds when controlling for the level of negative reciprocity of the partners; shown in Column (2). In order not to introduce a problem of multicollinearity I control only for the level of negative reciprocity of the partner with the lower level. The level of negative reciprocity of each partner is interacted with an indicator on whether this partner's negative reciprocity level is lower. The actual level of negative reciprocity of the partners is not driving the results from the first specification. It does not matter if it is the wife or the husband who is less negatively reciprocal, the level of reciprocity is not statistically significantly related to the probability of getting divorced. Meanwhile the hazard ratio of the match in reciprocity stays similar, significant at the $10 \%$ level now. 
Turning to the other correlates we see that a larger age gap between the wife and the husband relates to a slightly higher divorce probability, independent of the wife's age. For a number of couples the information on education of one or both of the partners is missing. I set the difference in education to the sample average and add a dummy for missing education. The results don't change if I drop the observations. While not fully reporting the education of both partners seems to be more frequent among couples who later get divorced, the difference in years of education itself doesn't seem to be related to divorcing. Log household income, full time employment status of the wife and the presence of children younger than 16 in the household are statistically as well as economically strongly related to the divorce hazard. While a higher household income and young children are negatively associated with the divorce probability, the employment status of the wife is positively related. These variables however are highly endogenous since income and demographics as well as the labor supply decision are influenced by a physical separation of the household. The variable "kids" is less subject to endogeneity problems, since I define the household of the wife as the main household, and most children in the sample live in their mother's household after a divorce. Using lagged values of the other two endogenous variables solves the problem partially (if the physical separation of the households does not occur before the time of the lag) but decreases the sample size. As expected, the hazard ratios for log household income and full time employment become closer to one, but the direction stays the same and they are still economically and statistically highly significant. Since these control variables are not crucial for my research question, and since using lags rather than the actual levels does not change the results but decreases the sample size, I report the specifications with the contemporaneous levels.

A problem that could arise in the dataset is selective attrition. It is likely that couples who split up also leave the dataset. I run a robustness check in which I code each couple that leaves the sample before 2012, with the exception of couples who leave the sample because of the death of one of the partners. This clearly overstates the number of divorces, since also couples who drop out of the SOEP without separating will be coded as divorced. Table A3.2 in the appendix reports the results for this robustness check. A one point difference in negative reciprocity relates to a 3 percent higher probability to get divorced or leave the sample, significant at the $15 \%$ level. If I use the binary measure for heterogeneity in negative reciprocity I find that heterogeneous couples have a 8 percent higher chance of failure (dropping out of the sample or getting divorced), significant at the $10 \%$ level. This robustness check gives a lower bound to the relation between divorce hazard and heterogeneity in negative reciprocity.

\subsubsection{Assimilation}

In the model, and also in the empirical analyses above I assume that preferences are stable over time. If this was not the case, it could be that the results discussed above are a mere product of the assimilation in preferences of the partners, i.e. that the partners are becoming more similar the longer they are together. In this case we would get positive 


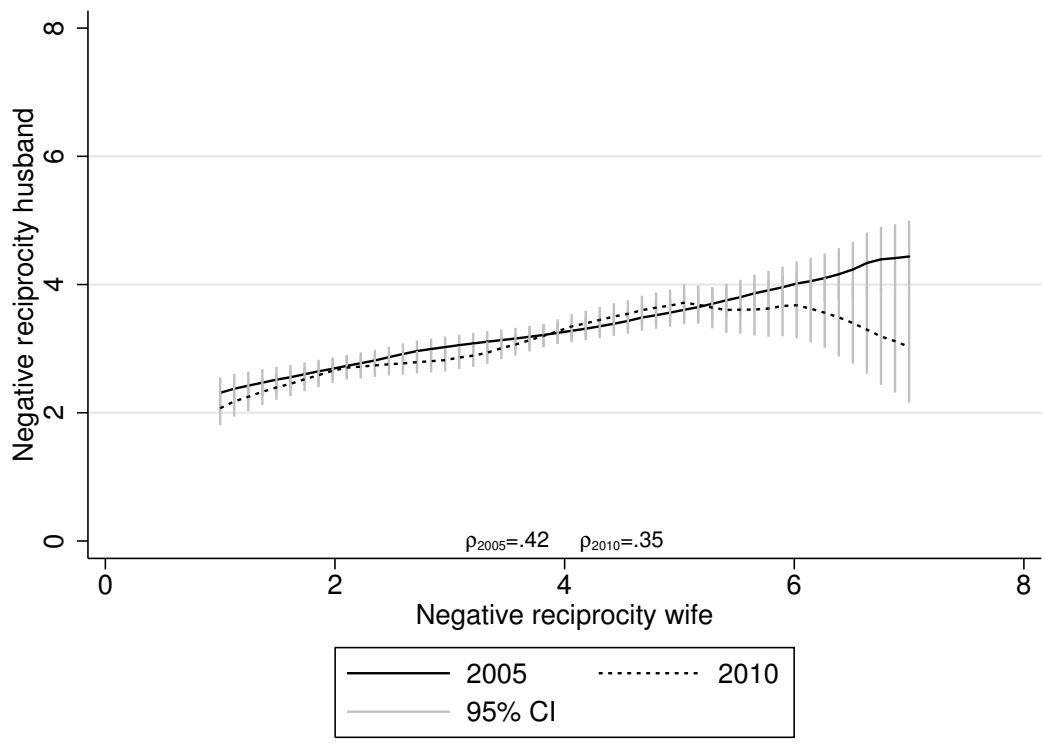

Figure 3.4: Stability in negative reciprocity correlation within couples

Local polynomial fit. Data source: SOEP v29.

results on the match in negative reciprocity and the risk to divorce, even if the two variables would be orthogonal to each other. I therefore investigate if there is evidence that partners become more similar over time in this last part of the empirical analysis.

For this part of the analysis I use data of couples who answered the negative reciprocity questions in both waves, 2005 and 2010. Since assimilation is likely to be more pronounced at the beginning of the relationship I restrict the sample to couples who got married between 2000 and 2005. ${ }^{17}$ Column (3) of Table A3.1 in the appendix reports descriptive statistics for the 384 couples in the sample.

A first graphical check of the data indicates that our previous results are not challenged by assimilation in negative reciprocity. Figure 3.4 shows the relation of negative reciprocity of both partners in 2005 and 2010. The distribution of negative reciprocity of the husbands, conditional on the wives' negative reciprocity, seems remarkably similar over the years. The within couple correlations of negative reciprocity support this impression. The correlation coefficients of 0.42 in 2005 and 0.34 in 2010 are statistically not significantly different from each other as Fisher's Z-test shows. There is no evidence for assimilation during the first 5 to 10 years of marriage. This result also doesn't change if I compare the correlations between the two years for marriage cohorts of one year.

\footnotetext{
${ }^{17}$ Results for older cohorts of couples are similar.
} 


\subsection{Discussion and Conclusion}

The model in this paper captures how the negative reciprocal inclinations of two agents can influence their decision to form or dissolve a partnership. While for cooperation within groups the level of negative reciprocity of the agents plays an important role, I show in the model that for the formation and stability of a group the conformity in negative reciprocal inclinations could be more important than their level. I extend the model to show that under initial uncertainty about the partner's negative reciprocity parameter the assortative matching happens in two steps, at first encounter through assortative grouping, and through selective separating after updating with the full information. I apply the model on empirical data from the SOEP on marriage and divorce. There is evidence for both assortative mating upon marriage and selective divorce throughout the course of the marriage. I find a positive correlation of negative reciprocity parameters within a couple at the start of a marriage and also an increased divorce risk for heterogeneous couples. The confounding hypothesis of assimilation of preferences during the marriage finds little support in my dataset.

While my model focuses on the role of negative reciprocity in the formation of couples, parts of the analysis could equally well be used to analyze other preferences. There is evidence of positive assortative mating with respect to other economic preferences and attitudes, such as risk or trust (Dohmen et al., 2012) or personality traits (Lundberg, 2012). While the mechanism through which assortative mating comes about might be different (the utility functions of the partners in my model are specific to negative reciprocity), the analysis of assortative marriage and selective divorce could be used for other preferences, with different levels of uncertainty at the beginning, since some economic preferences are easier to observe than others. ${ }^{18}$

The application to the marriage market is a straight forward example on how the match in negative reciprocity influences the formation of a partnership, however it is by far not the only interesting setting in which this question is relevant. Matches on the labor market, with the agents being employees and employers or team members, could be similarly investigated. This might lead to new insights on differences in unemployment and wages between workers with different negative reciprocity parameters, as well as on firm culture, adding to the literature on the role of reciprocity on the labor market (Dohmen et al., 2009; Micevski, 2013).

Finally the implications of the empirical results are interesting for the discussion on intergenerational mobility. There is evidence that parents transmit their economic preferences and attitudes to their children (e.g. Dohmen et al., 2012; Cesarini et al., 2009). The economic preferences contribute to shaping the child's economic outcomes (see e.g. Dohmen et al., 2009) for the relation between negative reciprocity and economic outcomes). The finding of positive assortative mating plays an important role in the transmission, since similar parents don't mitigate each other's impact on the child and

\footnotetext{
${ }^{18}$ Preliminary empirical results for assortative marriage and divorce with respect to other preferences show similar patterns, though in most cases there is more initial sorting and less sorting through separation.
} 
can hence transmit their own preferences stronger. This insight might help us better understand frictions in social and economic mobility across generations. 


\subsection{Appendix}

\section{Proof for selective divorce}

In the following I deliver the mathematical proof for the hypothesis of selective divorce, that the divorce ratio of heterogeneous couples is larger than the divorce ratio among homogeneous couples.

$$
\frac{(1-p) \int_{1}^{2} \rho\left(B_{i j}\right) \mathrm{d} B_{i j}}{(1-p) \int_{1}^{2} \rho\left(B_{i j}\right) \mathrm{d} B_{i j}+\int_{2}^{\infty} \rho\left(B_{i j}\right) \mathrm{d} B_{i j}}>\frac{(1-p)^{2} \int_{0}^{1} \rho\left(B_{i j}\right) \mathrm{d} B_{i j}}{(1-p)^{2} \int_{0}^{1} \rho\left(B_{i j}\right) \mathrm{d} B_{i j}+\int_{1}^{\infty} \rho\left(B_{i j}\right) \mathrm{d} B_{i j}}
$$

Assuming that $B i j$ is normally distributed I rewrite inequality A3.1 in terms of cumulative distribution functions $\Phi$ and bring both terms on one side.

$$
\begin{aligned}
& \frac{(\Phi(2)-\Phi(1))\left[(1-p)^{2}(\Phi(1)-\Phi(0))+(1-\Phi(1))\right]}{[(1-p)(\Phi(2)-\Phi(1))+(1-\Phi(2))]\left[(1-p)^{2}(\Phi(1)-\Phi(0))+(1-\Phi(1))\right]} \\
& -\frac{(1-p)(\Phi(1)-\Phi(0))[(1-p)(\Phi(2)-\Phi(1))+(1-\Phi(2))]}{[(1-p)(\Phi(2)-\Phi(1))+(1-\Phi(2))]\left[(1-p)^{2}(\Phi(1)-\Phi(0))+(1-\Phi(1))\right]}>0
\end{aligned}
$$

Since the common denominator is positive, I only have to show that the numerator $N$ is positive.

$$
\begin{aligned}
N & =(\Phi(2)-\Phi(1))\left[(1-p)^{2}(\Phi(1)-\Phi(0))\right. \\
& +(1-\Phi(1))]-(1-p)(\Phi(1)-\Phi(0))[(1-p)(\Phi(2)-\Phi(1))+(1-\Phi(2))]>0
\end{aligned}
$$

$N$ is strictly increasing in $\mathrm{p}$

$$
\frac{\partial N}{\partial p}=(\Phi(0)-\Phi(1))(\Phi(2)-1)>0,
$$

and since $\mathrm{p}$ is between 0.5 and 1 , the numerator $N$ will be smallest at $\mathrm{p}=0.5$. Hence I replace $\mathrm{p}$ with 0.5 . Rewriting the numerator in terms of error functions gives,

$$
N=\operatorname{Erfc}(x)^{2}-\frac{1}{2}[\operatorname{Erfc}(x)+\operatorname{Erfc}(x-z)] \operatorname{Erfc}(x+z),
$$

where I have introduced $x=1 / \sqrt{2 \sigma^{2}}+\mu$ and $z=1 / \sqrt{2 \sigma^{2}}$. Taking the derivative with respect to $\mathrm{z}$ yields

$$
\frac{\partial N}{\partial z}=\operatorname{Erfc}(x)+\operatorname{Erfc}(x-z)-e^{4 x z} \operatorname{Erfc}(x+z) .
$$


To determine that this term is positive I take its partial derivative with respect to $x$, showing that the equation A3.6 is decreasing in $\mathrm{x}$.

$$
\frac{\partial N / \partial z}{\partial x}=-\frac{2 e^{-x^{2}}}{\sqrt{\pi}}-4 e^{4 x z} z \operatorname{Erfc}(x+z)<0
$$

I can now show that equation A3.6 approaches 0 if $x$ approaches $\infty$. Thus the derivative of $N$ with respect to $z$ is positive. I now plug the smallest possible value for $z$ which is $z=0$ in equation A3.5, which leads to $N=0$. Thus for any $z>0$ the inequality in equation A3.1 holds. 
Table A3.1: Descriptive statistics for all 3 samples

\begin{tabular}{|c|c|c|c|}
\hline & $\begin{array}{r}\text { (1) } \\
\text { marriage }\end{array}$ & $\begin{array}{r}(2) \\
\text { divorce }\end{array}$ & $\begin{array}{r}\text { (3) } \\
\text { assimilation }\end{array}$ \\
\hline$\Delta$ neg. reciprocity & $\begin{array}{c}1.346 \\
(1.064)\end{array}$ & $\begin{array}{c}1.178 \\
(1.073)\end{array}$ & $\begin{array}{c}1.209 \\
(0.998)\end{array}$ \\
\hline neg. reciprocity wife & $\begin{array}{c}3.096 \\
(1.485)\end{array}$ & $\begin{array}{c}2.895 \\
(1.411)\end{array}$ & $\begin{array}{c}3.085 \\
(1.450)\end{array}$ \\
\hline neg. reciprocity husband & $\begin{array}{c}3.362 \\
(1.422)\end{array}$ & $\begin{array}{c}3.210 \\
(1.443)\end{array}$ & $\begin{array}{c}3.286 \\
(1.427)\end{array}$ \\
\hline$\Delta$ age & $\begin{array}{c}4.717 \\
(4.862)\end{array}$ & $\begin{array}{c}3.720 \\
(3.653)\end{array}$ & $\begin{array}{c}4.279 \\
(4.274)\end{array}$ \\
\hline age wife & $\begin{array}{l}33.213 \\
(9.459)\end{array}$ & $\begin{array}{c}51.992 \\
(13.823)\end{array}$ & $\begin{array}{c}34.607 \\
(9.247)\end{array}$ \\
\hline age husband & $\begin{array}{c}36.516 \\
(10.054)\end{array}$ & $\begin{array}{c}54.740 \\
(13.963)\end{array}$ & $\begin{array}{l}37.583 \\
(9.727)\end{array}$ \\
\hline$\Delta$ education & $\begin{array}{c}1.833 \\
(1.915)\end{array}$ & $\begin{array}{c}1.689 \\
(1.918)\end{array}$ & $\begin{array}{c}1.720 \\
(1.834)\end{array}$ \\
\hline education wife & $\begin{array}{l}12.841 \\
(2.660)\end{array}$ & $\begin{array}{l}12.055 \\
(2.656)\end{array}$ & $\begin{array}{c}12.774 \\
(2.495)\end{array}$ \\
\hline education husband & $\begin{array}{l}12.864 \\
(2.827)\end{array}$ & $\begin{array}{l}12.544 \\
(2.875)\end{array}$ & $\begin{array}{l}12.785 \\
(2.857)\end{array}$ \\
\hline 1 if kids under 16 in $\mathrm{HH}$ & & $\begin{array}{c}0.328 \\
(0.470)\end{array}$ & \\
\hline $\log \mathrm{HH}$ income & & $\begin{array}{c}7.488 \\
(0.487)\end{array}$ & \\
\hline full time empl. wife & & $\begin{array}{c}0.205 \\
(0.403)\end{array}$ & \\
\hline Observations & 508 & 6141 & 384 \\
\hline
\end{tabular}


Table A3.2: Selective divorce on negative reciprocity - all drop-outs are considered to be divorced

\begin{tabular}{|c|c|c|}
\hline VARIABLES & $\begin{array}{c}(1) \\
\text { divorce ha }\end{array}$ & ard \\
\hline 1 if heterogeneous in neg. rec. & & $\begin{array}{c}1.083 * \\
(0.047)\end{array}$ \\
\hline$|\Delta|$ neg. reciprocity & $\begin{array}{c}1.029 \\
(0.020)\end{array}$ & \\
\hline$|\Delta|$ age & $\begin{array}{c}1.003 \\
(0.006)\end{array}$ & $\begin{array}{c}1.003 \\
(0.006)\end{array}$ \\
\hline age wife & $\begin{array}{l}0.990 * * \\
(0.004)\end{array}$ & $\begin{array}{l}0.990 * * \\
(0.004)\end{array}$ \\
\hline$|\Delta|$ education & $\begin{array}{c}1.002 \\
(0.012)\end{array}$ & $\begin{array}{c}1.002 \\
(0.012)\end{array}$ \\
\hline$|\Delta|$ education missing & $\begin{array}{l}1.591 * * * \\
(0.152)\end{array}$ & $\begin{array}{l}1.593 * * * \\
(0.152)\end{array}$ \\
\hline 1 if kids under 16 in $\mathrm{HH}$ & $\begin{array}{c}0.977 \\
(0.072)\end{array}$ & $\begin{array}{c}0.978 \\
(0.072)\end{array}$ \\
\hline $\log \mathrm{HH}$ income & $\begin{array}{l}0.816 * * * \\
(0.041)\end{array}$ & $\begin{array}{l}0.815 * * * \\
(0.041)\end{array}$ \\
\hline full time empl. wife & $\begin{array}{c}0.973 \\
(0.060)\end{array}$ & $\begin{array}{c}0.973 \\
(0.060)\end{array}$ \\
\hline Observations & 29,873 & 29,873 \\
\hline Number of subjects & 6109 & 6109 \\
\hline Number of divorces & 2063 & 2063 \\
\hline Log likelihood & -12772 & -12772 \\
\hline
\end{tabular}





\section{Chapter 4}

\section{Stability of self-stated risk preferences and media coverage of economic news}

\subsection{Introduction}

In economic theory it is often assumed that risk preferences are stable personal characteristics. Many empirical studies however find evidence for within-individual variation in risk attitudes over time and show that changes in risk attitudes are related to changes in personal economic circumstances or demographics (see e.g. Andersen et al., 2008, Cho et al., 2013, Jung and Treibich, 2014) and changes in the macroeconomic environment (Bucciol and Miniaci, 2013, Sahm, 2012).

In this paper we investigate whether self-stated risk attitudes are affected by changes in media coverage of economic news, a particularly interesting and diverse proxy for changes in the economic environment. The media continuously conveys information about economic events in a multitude of areas to a broad audience. In contrast to changes in news coverage of other subject areas that are difficult to evaluate or of interest only for a subsection of society, changes in the economy affect virtually everyone and an increase in the amount of bad economic news can be interpreted as a worsening of the economic situation. While several studies focus on how risk attitudes are affected by rare extreme events like the financial crisis (e.g. Guiso et al., 2013) or natural catastrophes (e.g. Hanaoka et al., 2014), economic news have the advantage that they allow to capture more than one event and also provide an inherent metric for weighting the event's significance. In contrast to conventional aggregate economic indexes like changes in GDP, news capture more detailed information about the economy that is conveyed to individuals on a daily base. They therefore constitute a continuous and overarching measure for changes

\footnotetext{
$\stackrel{\ddagger}{\ddagger}$ Joint work with Franziska Tausch (Max Planck Institute for Research on Collective Goods, Bonn).
} 
in the economy, which allows individuals to infer and regularly update their own risk exposure, e.g. income or unemployment risk, from the information they receive.

Empirical evidence suggests that the media has a crucial influence on individuals' formation of risk beliefs (see Wahlberg and Sjoberg, 2000). In an economic context Garz (2012), e.g., finds that individuals' perception of job security decreases in years with an increase of news coverage about labor market policy. The precision of the news measure that we employ allows us to relate changes in risk attitudes solely to changes in the economic environment that occur in the time before risk attitudes are elicited. We can further distinguish the effects of long lasting and short term changes in news in the analysis, which helps to shed some light on the mechanism that mediates the relation between risk attitudes and news coverage.

Previous studies have tried to identify determinants of risk attitudes using cross sectional analysis. Empirical evidence shows that the spectrum of how people deal with risk is broad and that considerable heterogeneity in risk attitudes among individuals exists (see e.g. Barsky et al., 1997 or Dohmen et al., 2011). Individual attributes are frequently investigated as influencing factors. Often confirmed findings are that the willingness to take risk is negatively correlated with being female and age and positively with income, wealth, height and education (see Donkers et al., 2001, Hartog et al., 2002, Dohmen et al., 2011). ${ }^{1}$

Personal experience is another factor identified to play a role for risk taking behavior. Malmendier and Nagel (2011) find that individuals who experienced periods of low stock market returns report lower willingness to take financial risk and are less likely to participate in the stock market. Estimations show that the influence of recent experiences on risk taking behavior is stronger than the influence of distant experiences.

A further strand of literature suggests that risk attitudes depend on individuals' emotions at the moment the attitudes are accessed, thus capturing immediate effects. Most relevant for our context is the finding that individuals that are subjected to a treatment which induces an anxious mood are more risk averse as compared to participants that are untreated or are induced a neutral mood (Raghunathan and Pham, 1999, Guiso et al., 2013). Lerner and Keltner $(2000,2001)$ find that dispositional fear, which also predicts state fear, is positively related to the risk assessment of causes of death and negatively related to risk taking behavior when deciding about the abatement of a deadly disease.

Due to the cross-sectional nature of the underlying data, the preceding studies are however not well suited to contribute to the understanding of within-individual variation in risk attitudes over time. Only few studies apply panel data analysis to investigate what factors are related to this variation. One line of research investigates the effects of changes in individuals' personal circumstances. Using the risk measure from the American National Longitudinal Survey of Youth 79, that is hypothetical gambles over lifetime income, Cho et al. (2013) estimate a fixed effects model and show that risk aversion changes with personal economic circumstances. The authors find that an increase in net family income comes along with increased risk aversion. Further, risk aversion increases in the duration of employment or time spent out of the labor force

\footnotetext{
${ }^{1}$ Some of these correlations are however not consistently supported by empirical evidence.
} 
and decreases with the duration of unemployment. Jung and Treibich (2014) observe correlations between self-stated risk attitudes and shocks in income, labor and health using the Japanese Osaka Panel Survey. ${ }^{2}$

To the best of our knowledge only few papers investigate how risk attitudes are related to changes in the general economic conditions. Using different risk attitude measures of the Dutch Household Survey, Bucciol and Miniaci (2013) estimate a fixed effects model and find that individuals are generally more willing to take risk in periods of economic growth and less so in periods of recessions. Business cycle periods are defined based on the time trend in annual variation in real GDP, AEX stock price index and the NVM house price index. In Sahm (2012) economic conditions are measured on a monthly base by the Index of Consumer Sentiment which is then combined with the risk measure from the Health and Retirement Study. The estimation of a correlated random effects model reveals that risk tolerance is significantly positively related to the Index of Consumer Sentiment.

For our analysis we combine daily economic news data from the media research institute Media Tenor with survey data from seven waves of the SOEP on individuals' self-stated willingness to take risks. We tailor our news measures to the date of the SOEP interview on which the risk attitudes are assessed. Forming a moving average of daily economic news reports in the year preceding the risk attitude elicitation we investigate whether long lasting exogenous changes have effects on individuals' self-stated risk attitudes. At the same time we take short term changes in news coverage into account by including the deviation between the yearly news measure and the moving average of the number of news reports in the month before the risk attitude elicitation in the analysis. As news can further be distinguished based on their valuation, we create those measures separately for bad, good and ambiguous news.

Our analysis reveals that part of the within-individual variation in risk attitudes over time can be explained by changes in media coverage of economic news. Making use of the panel structure of our data we estimate the impact of bad, good and ambiguous economic news on the willingness to take risks with a fixed effects regression. We find that irrespective of their valuation news are negatively related to individuals' willingness to take risk in the long run. When considering short term changes the same holds for bad and good news reports, while for ambiguous news the relation is insignificant. We show that in particular the strength of the adjustment of risk attitudes resulting from long lasting changes in news depends on individual demographics and personality traits. Using the short and long-term news measures together with the conventional GDP measure for macroeconomic shocks to explain variation in risk attitudes yields that news have explanatory power on top of GDP. The short term findings appear not to be driven by media induced changes in mood. Using one month short term measures explains our model better than using one week or two days measures. Instead, we suggest another channel through which news might influence risk preferences. We show that negative

\footnotetext{
${ }^{2}$ Another study that does not focus on exogenous shocks but that is still interesting for the discussion of the stability of risk preferences is Brachert and Hyll (2014). They use panel data from the German Socio-economic Panel (SOEP) and find that becoming self-employed is associated with a relative increase in risk attitudes as a result of entrepreneurial learning.
} 
news coverage is related to an increase in perceived risk, which we proxy by individuals' worries about job security, the economic development and the economic situation. Finally we also investigate nonlinear relations between news and risk preferences by aggregating the news and controlling for the relation between good and bad news. We find that with a short term news measure the relation between news and risk attitudes is negative when bad news predominate but turns positive when good news predominate. No such change in the direction of the relation is found when considering the long-term measure.

Our results are informative with respect to changes in risk attitudes that are measured based on how individuals rank their own willingness to take risks. How these changes are related to changes in actual risk preferences and changes in behavior under risk is yet unclear. There are three scenarios why individuals may adjust their ranking. 1) Individuals are stable in their behavior and preferences, but they perceive a change in others' risk attitudes and rank themselves differently relative to others. 2) Individuals change their behavior without changing the underlying preferences, e.g. because they perceive the economic environment as riskier and adjust their behavior accordingly. 3) Individuals change their actual preferences. Further investigation is required to evaluate which of the scenarios drives our results. ${ }^{3}$

The remainder of this paper is structured as follows. Section 2 introduces our data and explains the choice of the main variables. In section 3 we introduce the empirical strategy and discuss the results. Section 4 concludes the paper.

\subsection{Data Description}

To address the question whether within-individual variation of risk attitudes is systematically related to economic news coverage, we construct a panel data set combining information from the SOEP and information on economic news coverage provided by the media research institute Media Tenor.

\subsubsection{Risk Attitudes and Risk Perception}

The SOEP is a large longitudinal representative panel data set (for details see Schupp and Wagner, 2002, Wagner et al., 1993). Starting in the year 2004, seven waves of the SOEP contain a question on the general risk attitude of the respondents. The respondents are asked to assess their willingness to take risks on a 11 point scale, from 'not at all willing to take risks' to 'very willing to take risks'. The survey question is experimentally validated and found to be a good predictor for a number of risky decisions (see Dohmen et al., 2011). For the years that are included in our analysis, the standard deviation of self-stated risk preferences across individuals amounts to 2.01 while the within-individual standard deviation is 1.41 . Given the relatively high within-individual variation, an investigation of whether changes are systematic or pure measurement error suggests itself.

\footnotetext{
${ }^{3}$ We are currently working on an extension, in which we attempt to use insurance data to establish the link between changes in news and actual behavior under risk on an aggregate level.
} 
In order to obtain more insights about the mechanism that determines the relation between news coverage and risk attitudes, we make use of another item in the SOEP that elicits to what extent respondents are concerned about various issues. The areas that are relevant for our analysis are the respondent's economic situation and job security as well as the general economic development. The respondents answer on a three points Likert scale with the choices 'not concerned at all', 'somewhat concerned' or 'very concerned'. We use these questions on worries as proxies for individuals' risk perception in the different areas.

The SOEP further contains a variety of personal and household information that we use as control variables. We include information on whether a child below age sixteen is part of the household, the employment status, household income (adjusted by CPI and the size of the household ${ }^{4}$ ), marriage status and health status. Tables 4.1 and 4.2 provide detailed information on the data that we use for our main analysis, as well as additional background information that is constant over time (such as gender or year of birth) and that can therefore only enter fixed effects regressions through interactions.

\subsubsection{News Coverage}

The news coverage data are provided by the media research institute Media Tenor. The institute analyzes TV news reports as well as newspaper and magazine articles on a diverse range of topics by applying media content analysis. The evaluation is done by professionally trained analysts who identify and categorize on a daily basis each report according to a set of criteria, among others its content and valuation. ${ }^{5}$

Our analysis focuses on news coverage of economic topics in the following leading German newscasts and newspapers: ARD Tagesschau, ARD Tagesthemen, RTL Aktuell, ZDF heute, ZDF heute journal and Bild-Zeitung. ${ }^{6}$ More specifically, we make use of the information on the daily number of news reports in the topic group 'economic situation/economic policies', to which we will from now on refer to as 'economics'. ${ }^{7}$ Our media data covers daily reports between January 1, 2001 and August 31, 2012. Media Tenor further provides information on the valuation of the report. The valuation indicates whether the discussed economic topic is in a bad, good or in an ambiguous context. A judgmental representation (bad, good) is existent if the topic is mentioned in a positive or negative context, or if circumstances are reported in words that have a clear positive or

\footnotetext{
${ }^{4}$ The data appendix, Section 4.5.1, provides more detailed information on the construction of the income variable.

${ }^{5} \mathrm{http}: / /$ www.mediatenor.com

${ }^{6}$ For more detailed information on the different news see the Data Appendix. We exclude the news coverage data of the weekly journals Focus and Spiegel as the exact day on which individuals are exposed to the journal content is unknown.

${ }^{7}$ Each news report is further classified into subtopics of economics. One report can be classified as several of the subtopics, but for each report one main topic is defined. In order to avoid a biased representation on news coverage due to multiple classification we focus on those observations that are evaluated to be the main topic of the underlying news report. An overview of all subtopics in economics and the according daily average number of reports and their valuation are reported in Appendix 4.5.
} 


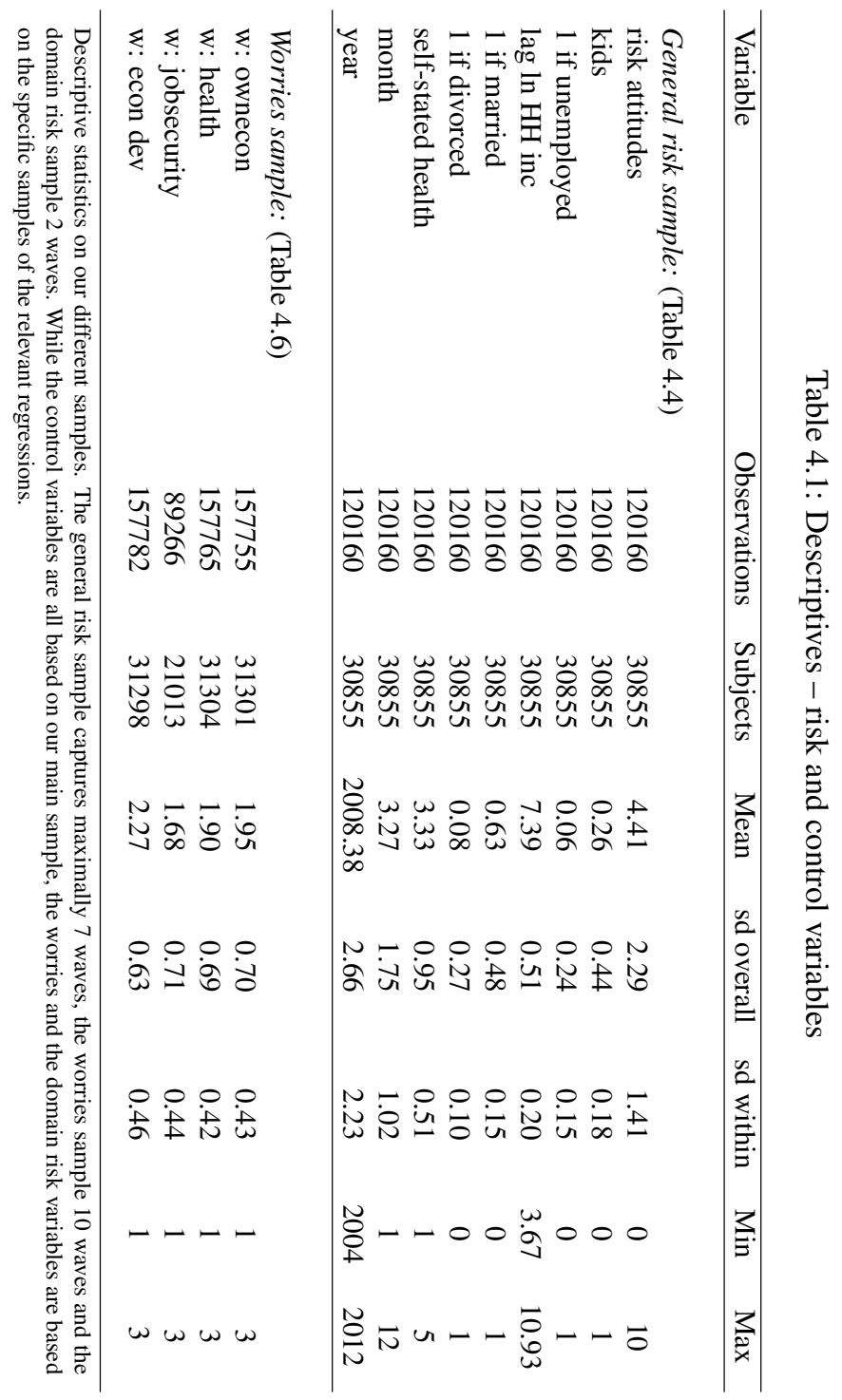


Table 4.2: Descriptives - demographics and personality traits

\begin{tabular}{lccccc}
\hline Variable & Mean & sd & Min & Max & Subjects \\
\hline female & 0.52 & 0.50 & 0 & 1 & 30855 \\
birth year & 1959.14 & 18.37 & 1905 & 1994 & 30855 \\
education & 12.21 & 2.71 & 7 & 18 & 29383 \\
Big5 O & 4.44 & 1.15 & 1 & 7 & 24771 \\
Big5 C & 5.84 & 0.89 & 1 & 7 & 24757 \\
Big5 E & 4.80 & 1.08 & 1 & 7 & 24827 \\
Big5 A & 5.40 & 0.91 & 1 & 7 & 24829 \\
Big5 N & 3.90 & 1.14 & 1 & 7 & 24837 \\
\hline
\end{tabular}

Descriptive statistics on our main sample. The Big 5 were elicited in 2005 and 2009. For individuals that took part in the elicitation in both years we form the average of the two values.

negative meaning according to general understanding. Only clearly identifiable valuations are coded as bad or good; news without clear judgment are coded as ambiguous.

\subsubsection{Combined data set}

While the news coverage information is available on a daily basis, we also know the date of the SOEP interview for each participant. We can thus link the two data sets on the exact date. We construct moving averages of the daily number of economic news reports during the year (364 days) and the month (28 days) preceding the day of the SOEP interview. For the analysis we combine the long-term yearly news measure with a short term deviation measure that is the difference between the monthly and the yearly moving average in news. That way we can capture long-term developments in news coverage as well as rather immediate changes in our analysis.

Table 4.3 provides information on observation numbers, means and standard deviations of both, the year and the month measure for negative, ambiguous and positive news in our regression sample. Overall, the average number of good news reports is relatively small. For the yearly news measure the average of good news reports is 2.58 , whereas ambiguous and bad news are more frequent, with an average daily number of 4.71 and 4.44 news reports respectively. Also the variance of good news reports is lower with 0.48 than those of ambiguous and negative reports ( 0.63 and 0.78 respectively). For the monthly news measure qualitatively the same differences are observed. However, the variance of ambiguous and bad news is even higher than for the yearly news measures (1.02 and 1.11 respectively), while the variance of good news is very similar for both measures ( 0.51 for the yearly news measure). In 2009 with the beginning of the financial crisis, the average bad economic news coverage increased. The number of bad news is high in that particular year with a monthly average of 6.15 reports per day. Also the yearly measure has the highest averages in 2009 and 2010. 

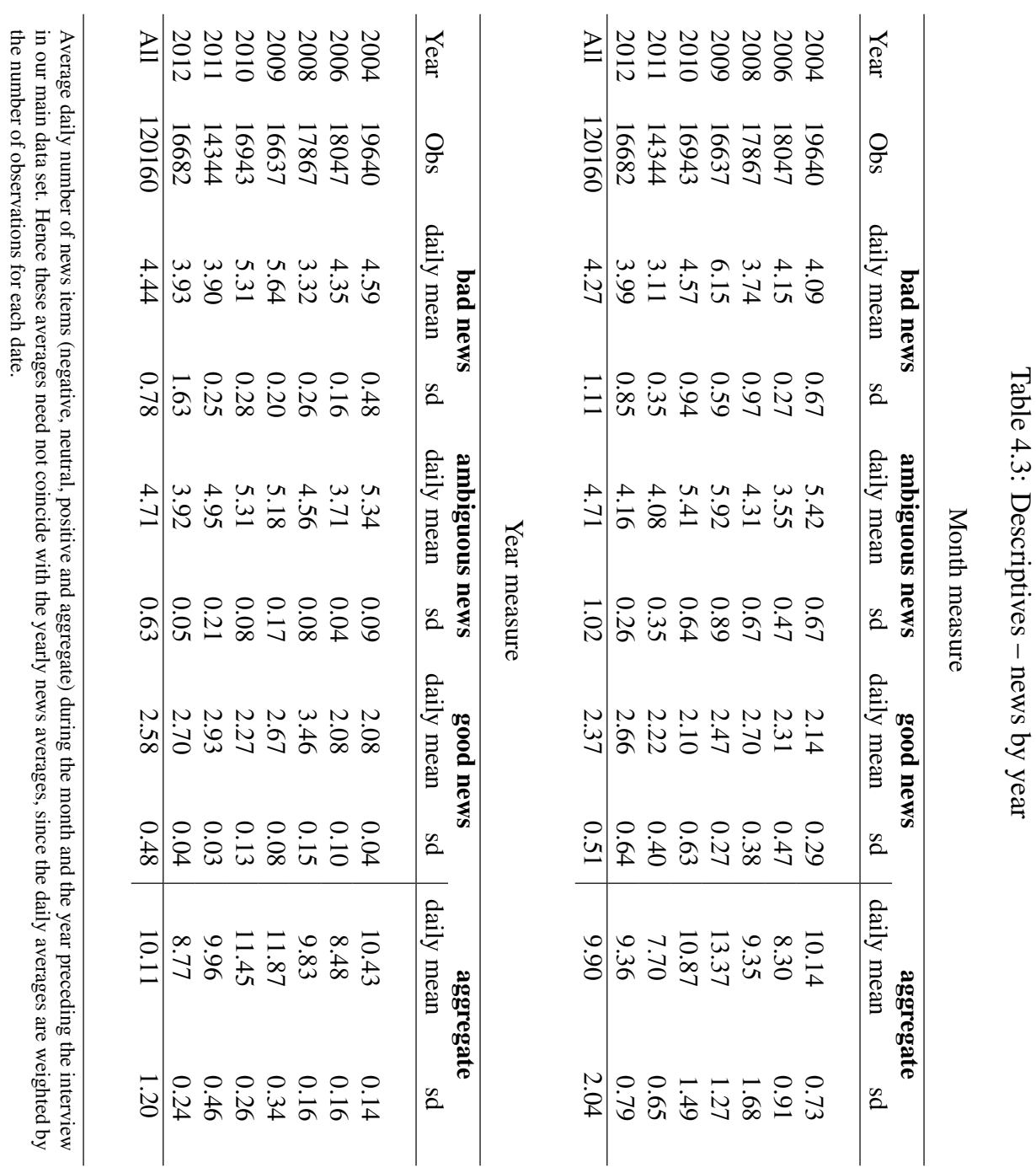

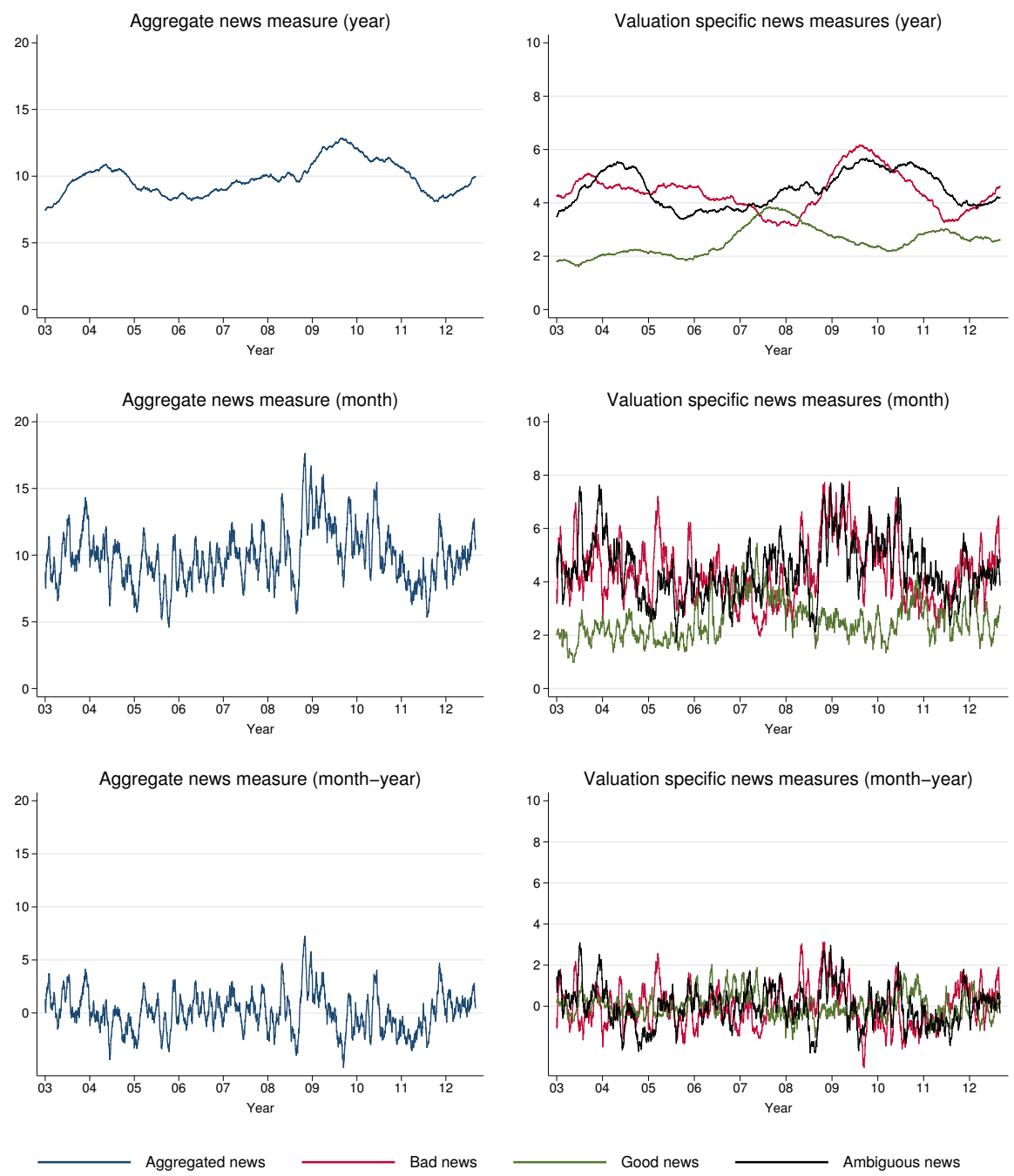

Figure 4.1: News - year measure, month measure and deviation measure

Note: Daily number of news reports averaged over different time-spans. Data for the years 2001-2012 from Media Tenor. 
Figure 4.1 shows the variation in the number of economic news reports over time. The two graphs on the top row provide information on the yearly news measure. The left panel displays aggregate news coverage and the right panel divides the news according to their valuation. The second row shows the same graphs for the monthly news measures and the third row those for the deviation measures. The yearly (monthly) news measure has an average aggregated news coverage of approximately 9.01 (9.23) reports per day and a standard deviation of $2.18(2.55){ }^{8}$

\subsection{Results}

\subsubsection{News Coverage and Risk Attitudes}

In a first step we investigate how exogenous changes in individuals' economic environments influence the temporal stability of general risk attitudes. We apply a fixed effects (FE) model, making use of the panel structure of our data. We regress the risk attitude measure at different points in time on the three yearly news measures (bad, good and ambiguous) which we combine in the vector News $t_{t^{*}}^{Y}$, the deviations between the yearly and the monthly news measures $\left(\operatorname{News}_{t^{*}}^{M}-\operatorname{News}_{t^{*}}^{Y}\right.$ ), and a vector of control variables $\left(X_{i t}\right)$ that includes information on personal changes in life and the year and month of the interview. $u_{i}$ denotes an individual fixed effect and $\varepsilon_{i t}$ stands for a time variant idiosyncratic error term. The personal changes in life include changes in the household composition, in the marital status, in the employment status and the household income, and in the subjective health of the individual.

$$
\text { riskattitude }_{i t}=\alpha+\beta^{\prime} \operatorname{News}_{t^{*}}^{Y}+\gamma^{\prime}\left(\operatorname{News}_{t^{*}}^{M}-\operatorname{News}_{t^{*}}^{Y}\right)+\delta^{\prime} X_{i t}+u_{i}+\varepsilon_{i t}
$$

While our news measures do not differ between individuals on any given day, there is heterogeneity in news coverage across the sample within one time unit $t$ since we adjust the news measures to the interview date, rather than using a coarse yearly average.

Table 4.4 shows the results from estimating the FE model described in equation 4.1. In Column (4) we estimate the full model; the preceding columns report the results of additional FE regressions with limited inclusion of the variables of interest. In Column (1) we first regress the risk attitude measure only on personal changes to get a baseline for understanding how much additional within-individual variance can be explained by adding changes in news coverage. Many of the personal changes are endogenous, either directly chosen by the individual (such as getting married) or influenced by earlier decisions of the individual (i.e. those who choose to work on a job with a higher unemployment risk are more likely to become unemployed). While any interpretation of the coefficient other than being a simple correlation is not possible, it is still interesting to briefly look at the relations. Adults are significantly less willing to take risks if there are children below

\footnotetext{
${ }^{8}$ These values are based on the complete Media Tenor data set for the time period 2001 to 2012, as is shown in Figure 4.1. If we take our regression sample instead (as reported in Table 4.3) where some days are represented several times and others not at all, we get a daily average of $10.11(9.90)$ news items with a standard deviation of 1.20 (2.04).
} 
Table 4.4: Risk preference - News on willingness to take risks (FE)

\begin{tabular}{|c|c|c|c|c|}
\hline VARIABLES & $\begin{array}{r}(1) \\
\text { risk att. }\end{array}$ & $\begin{array}{r}(2) \\
\text { risk att. }\end{array}$ & $\begin{array}{r}(3) \\
\text { risk att. }\end{array}$ & $\begin{array}{r}(4) \\
\text { risk att. }\end{array}$ \\
\hline year: bad news & & $\begin{array}{c}-0.455 * * * \\
(0.011)\end{array}$ & & $\begin{array}{c}-0.426 * * * \\
(0.013)\end{array}$ \\
\hline year: good news & & $\begin{array}{c}-0.607 * * * \\
(0.017)\end{array}$ & & $\begin{array}{c}-0.602 * * * \\
(0.022)\end{array}$ \\
\hline year: ambiguous news & & $\begin{array}{c}-0.061 * * * \\
(0.010)\end{array}$ & & $\begin{array}{c}-0.101 * * * \\
(0.012)\end{array}$ \\
\hline month: bad news & & & $\begin{array}{c}-0.111 * * * \\
(0.006)\end{array}$ & \\
\hline month: good news & & & $\begin{array}{c}-0.006 \\
(0.011)\end{array}$ & \\
\hline month: ambiguous news & & & $\begin{array}{c}-0.165 * * * \\
(0.006)\end{array}$ & \\
\hline month dev: bad news & & & & $\begin{array}{c}-0.028 * * * \\
(0.008)\end{array}$ \\
\hline month dev: good news & & & & $\begin{array}{c}-0.071 * * * \\
(0.013)\end{array}$ \\
\hline month dev: ambig. news & & & & $\begin{array}{c}-0.008 \\
(0.009)\end{array}$ \\
\hline 1 if children in $\mathrm{HH}$ & $\begin{array}{r}-0.052 * \\
(0.028)\end{array}$ & $\begin{array}{c}-0.063 * * \\
(0.028)\end{array}$ & $\begin{array}{c}-0.057 * * \\
(0.028)\end{array}$ & $\begin{array}{c}-0.062 * * \\
(0.028)\end{array}$ \\
\hline 1 if unemployed & $\begin{array}{c}0.043 \\
(0.035)\end{array}$ & $\begin{array}{c}0.041 \\
(0.034)\end{array}$ & $\begin{array}{c}0.047 \\
(0.034)\end{array}$ & $\begin{array}{c}0.040 \\
(0.034)\end{array}$ \\
\hline lag $\ln \mathrm{HH}$ inc & $\begin{array}{c}0.028 \\
(0.024)\end{array}$ & $\begin{array}{c}-0.026 \\
(0.024)\end{array}$ & $\begin{array}{c}0.002 \\
(0.024)\end{array}$ & $\begin{array}{c}-0.026 \\
(0.024)\end{array}$ \\
\hline 1 if married & $\begin{array}{c}-0.096 * * \\
(0.042)\end{array}$ & $\begin{array}{c}-0.108 * * \\
(0.042)\end{array}$ & $\begin{array}{c}-0.100 * * \\
(0.042)\end{array}$ & $\begin{array}{c}-0.108 * * \\
(0.042)\end{array}$ \\
\hline 1 if divorced & $\begin{array}{c}0.015 \\
(0.068)\end{array}$ & $\begin{array}{c}0.006 \\
(0.067)\end{array}$ & $\begin{array}{c}0.011 \\
(0.067)\end{array}$ & $\begin{array}{c}0.005 \\
(0.067)\end{array}$ \\
\hline self-stated health & $\begin{array}{l}0.096 * * * \\
(0.010)\end{array}$ & $\begin{array}{l}0.093 * * * \\
(0.010)\end{array}$ & $\begin{array}{l}0.094 * * * \\
(0.010)\end{array}$ & $\begin{array}{l}0.094 * * * \\
(0.010)\end{array}$ \\
\hline month & $\begin{array}{c}-0.000 \\
(0.005)\end{array}$ & $\begin{array}{l}0.015 * * * \\
(0.005)\end{array}$ & $\begin{array}{c}-0.007 \\
(0.005)\end{array}$ & $\begin{array}{l}0.019 * * * \\
(0.005)\end{array}$ \\
\hline year & $\begin{array}{c}-0.028 * * * \\
(0.002)\end{array}$ & $\begin{array}{l}0.013 * * * \\
(0.003)\end{array}$ & $\begin{array}{c}-0.035 * * * \\
(0.002)\end{array}$ & $\begin{array}{l}0.008 * * * \\
(0.003)\end{array}$ \\
\hline Constant & $\begin{array}{l}60.023 * * * \\
(4.746)\end{array}$ & $\begin{array}{c}-17.529 * * * \\
(5.405)\end{array}$ & $\begin{array}{l}75.540 * * * \\
(4.790)\end{array}$ & $\begin{array}{c}-6.922 \\
(5.749)\end{array}$ \\
\hline Observations & 120,160 & 120,160 & 120,160 & 120,160 \\
\hline Number of individuals & 30,855 & 30,855 & 30,855 & 30,855 \\
\hline Adjusted R-squared & 0.004 & 0.045 & 0.032 & 0.046 \\
\hline
\end{tabular}

Note: Fixed effects regressions. The variable 'year: bad news' stands for the average of bad news reports per day over the past year, while 'month: bad news' analogously represents the average over the last month. 'month dev: bad news' captures the difference between the yearly and the monthly average in bad news. ' 1 if children in HH' captures if there are any children under 16 in the household. 'lag $\ln \mathrm{HH}$ income' captures the CPI and household size adjusted log household income. Robust standard errors in parentheses, ${ }^{*}$ significant at $10 \%$; ${ }^{* *}$ significant at $5 \%$; ${ }^{* * *}$ significant at $1 \%$. 
age sixteen living in the same household. Also when getting married individuals are less willing to take risk than if they are not (yet or anymore) married. We do not find any relation between changes in and out of unemployment as well as changes in household income and individual risk attitudes. Finally, changes in reported health are significantly related to within-individual changes in risk attitudes, with better health being associated with a higher willingness to take risks.

We additionally control for the month and the year of the SOEP interview. The control for the timing of the interview within a wave is to deal with heterogeneity in availability of the individuals. More busy individuals could be harder to reach by the interviewer and thus interviewed later in the calendar year. The year trend captures age effects as well as a general development over the years that is not captured by the news. ${ }^{9}$ The year trend in this first specification is negative, as can be expected due to the age effect. ${ }^{10}$ The coefficients of personal changes are robust to the inclusion of exogenous changes in the model, as can be seen across the specifications.

In Column (2) we add the yearly news measures for bad, good and ambiguous reports. An increase in the average number of economic news reports, irrespective of the valuation of the news, appears to be negatively related to the willingness to take risks. ${ }^{11}$ One additional bad news item in the daily average is related to a 0.455 points decrease in a person's general willingness to take risks while the according decrease for an additional report of good news is 0.607 . For ambiguous news the coefficient is much smaller with 0.061 , but still highly statistically significant and negative.

In Column (3) instead of the yearly news measures we include the monthly news measures. Here we also find a significant relation between the willingness to take risk and bad and ambiguous news. The coefficients are 0.11 and 0.165 respectively. For good news the relation between self-stated risk preferences and the monthly news measure is not statistically significant. The explained variance of the model is higher when we include the year measures than when we use the month measures $(0.045$ versus 0.032$)$.

The analysis in Column (4) finally combines the long and short term measures. We regress the willingness to take risks on the year measures and additionally include the deviations between the year and the month measures. We confirm the significant negative relation between the willingness to take risk and news for our long-term yearly news measure, irrespective of the valuation of the news. The coefficient for the short-term deviation is significantly negative for bad and good news, but insignificant for ambiguous news.

\footnotetext{
${ }^{9}$ See Dohmen et al. (2014) for a discussion of age and cohort effects. They show that individuals do become more risk averse over time.

${ }^{10}$ When including the yearly average of news in the analysis, the year trend turns positive. This is strange, but may be an artifact of the correlation between the year trend and economic news over the period we observed.

${ }^{11}$ While it is unlikely that individual risk attitudes have an impact on the national news, we cannot completely exclude that a third, independent event (such as a sporting event) leads to an aggregate change of the populations risk attitudes, which influences the real economy and by that also the news. See Dohmen et al. (2006) for such an example.
} 
We find that both, persistent and temporary changes in news, affect individuals' willingness to take risks. These effects constitute a small but systematic part of the variance in individual risk attitudes over time. ${ }^{12}$

\subsubsection{Explanatory Value of News}

An alternative and conventional proxy for exogenous changes in individuals' environments are yearly changes in the regional gross domestic product. However, the GDP as indicator for changes in the macroeconomic conditions only allows to relate coarse yearly averages to the risk preference measure. In the following analysis we show the explanatory value that our short and long-term news measures have on changes in risk preferences on top of the conventional measure for an exogenous change in the economic situation. ${ }^{13}$

Column (1) of Table 4.5 shows the FE regression of the general risk attitude on GDP change and control variables. A positive change in GDP is associated with a higher willingness to take risks, meaning that in times of economic upswings people are more willing to take risks. This effect is in line with the interpretation of our media coverage data. The coefficient of GDP amounts to 0.070 and the model has an adjusted $\mathrm{R}^{2}$ of 0.024. Column (2) in Table 4.5 shows the FE regressions of the individuals' willingness to take risk on GDP change, the yearly news measures and the short term deviations in news. We can observe a doubling in the adjusted $\mathrm{R}^{2}$ between Columns (1) and (2), reaching an $\mathrm{R}^{2}$ of 0.046 when the news measures are included. This shows the additional explanatory value of the news data on top of the macroeconomic indicator GDP. This additional predictive power could be due to higher precision in the measurement of news coverage. Our measures allow to adjust the year moving averages of news reports to the date of the SOEP interview. Further they also capture more than just information about GDP fluctuation as can be seen in the overview of subtopics within the main topic of economic that is displayed in Table A4.1. Relevant changes in the economic situation can therefore be captured in much more detail by economic news reports as compared to the GDP measure.

\footnotetext{
${ }^{12}$ Analyzing the effect of news coverage on risk taking in domains that are unrelated to an economic context is currently not feasible with the SOEP data but very interesting for future research. Respondents of the SOEP were asked about their domain specific risk attitude in the years 2004 and 2009. The questions apply the same wording and scale as the general risk question, but are more specific with respect to the risk taking context. Using the domain specific willingness to take risks instead of the general one yields results for the long-term news measures that are largely in line with our general results. For the short term news measures the interpretation of the results is less clear. These findings are not explicitly discussed here, since the analysis with only two waves of the domain specific risk attitudes is not sufficiently robust to derive meaningful conclusions. The results are available upon request from the authors.

${ }^{13}$ We use statistics on the changes in GDP for all German regions provided by the Federal and State Statistical Offices and adjust GDP for inflation.
} 
Table 4.5: Risk preference - News and GDP on willingness to take risks (FE)

\begin{tabular}{|c|c|c|}
\hline VARIABLES & $\begin{array}{r}(1) \\
\text { risk att. }\end{array}$ & $\begin{array}{r}(2) \\
\text { risk att. }\end{array}$ \\
\hline GDP change & $\begin{array}{l}0.070 * * * \\
(0.002)\end{array}$ & $\begin{array}{l}0.015 * * * \\
(0.002)\end{array}$ \\
\hline year: bad news & & $\begin{array}{c}-0.377 * * * \\
(0.015)\end{array}$ \\
\hline year: good news & & $\begin{array}{c}-0.513 * * * \\
(0.026)\end{array}$ \\
\hline year: ambiguous news & & $\begin{array}{c}-0.108 * * * \\
(0.012)\end{array}$ \\
\hline month dev: bad news & & $\begin{array}{c}-0.019 * * \\
(0.009)\end{array}$ \\
\hline month dev: good news & & $\begin{array}{c}-0.050 * * * \\
(0.013)\end{array}$ \\
\hline month dev: ambig. news & & $\begin{array}{c}-0.005 \\
(0.009)\end{array}$ \\
\hline Constant & $\begin{array}{l}49.172 * * * \\
(4.745)\end{array}$ & $\begin{array}{c}0.972 \\
(5.876)\end{array}$ \\
\hline Controls & yes & yes \\
\hline Observations & 120,160 & 120,160 \\
\hline Number of individuals & 30,855 & 30,855 \\
\hline Adjusted R-squared & 0.024 & 0.046 \\
\hline \multicolumn{3}{|c|}{$\begin{array}{l}\text { Note: Fixed effects regressions. 'GDP change' denotes the inflation } \\
\text { adjusted yearly changes in the German GDP. The variable 'years: } \\
\text { bad news' stands for the average of bad news reports per day over } \\
\text { the past year, while 'month dev: bad news' captures the difference } \\
\text { between the yearly and the monthly average in bad news. Controls } \\
\text { include children in the HH, unemployed, HH income, marital status, } \\
\text { self-stated health, month and year of the interview. Robust standard } \\
\text { errors in parentheses, * significant at } 10 \% ;{ }^{* *} \text { significant at } 5 \% \text {; } \\
{ }^{* * *} \text { significant at } 1 \% \text {. }\end{array}$} \\
\hline
\end{tabular}




\subsubsection{Risk perception}

There are several ways how news could potentially influence risk attitudes. One of them is that news coverage has an influence on individuals' risk perception. ${ }^{14}$ In this subsection we show how news relate to changes in risk perception that are proxied by information on how worried people are about various issues. The SOEP provides yearly information on how worried individuals are about 1) their own economic situation, 2) their job security (information available only for employed people), and 3) the economic development. The scale ranges from 1 'not worried at all' to 3 'very worried'.

Similar to the first part of the analysis, described in equation 4.1 we apply fixed effects regressions to estimate how changes in individuals' economic environments are related to within-individual changes in worries. Table 4.6 shows the fixed effects regressions of worries on the long-term and short-term measures of news, as well as personal and time control variables.

Column (1) of Table 4.6 shows the relation between news and worries about the economic development. Bad news are positively related to individuals' worries, both in the short and in the long run. That means the more bad news individuals encounter over the year, the more worried they are about the economic development. The relation between good news and worries about the economic development is statistically significantly negative, i.e. more good news over the year relate to less worries. For ambiguous news both relations are statistically insignificant. In Column (2) we report FE regressions with worries about the own economic situation as dependent variable. The short and long run effects of bad news are in line with the previous findings. However, both good news measures are insignificant, while ambiguous news are negatively related to the worries in the long run but positively in the short run.

Column (3) reports - for all respondents who are currently in the labor force - how worries about job security relate to changes in news coverage. Here only the year measure of bad news relates significantly positively to job worries. While the positive news measure is not significantly related to the worries, for ambiguous news we find the same pattern as in Column (2): in the short run news are positively related to worries and in the long run negatively.

Overall, bad news are related to an increase in individuals' worries in the short as well as in the long run, while the relations for good news tend to go in the opposite direction or to be insignificant. Ambiguous news instead increase worries in the short run, but lead to a decrease in worries in the long run.

Concerning the personal changes, we find robustly over all regression specifications that changing into a household with a child below the age of sixteen, becoming unemployed, a decrease in household income or a decrease in subjective health relate significantly to an increase in individuals' concerns.

The results presented in this section indicate that economic news do indeed influence individuals' concerns and thus their risk perceptions. We suggest that risk perception

\footnotetext{
${ }^{14}$ Alternative explanations could be that the salience of economic risks is increased, or that individuals perceive themselves differently in their risk attitudes relative to others after learning about the risk-taking behavior of others through the news (e.g. about bankers in the financial crisis).
} 
Table 4.6: Risk perception - News on worries (FE)

\begin{tabular}{|c|c|c|c|}
\hline VARIABLES & $\begin{array}{l}\text { (1) } \\
\text { ec. development }\end{array}$ & $\begin{array}{l}(2) \\
\text { orries about: } \\
\text { own ec. sit. }\end{array}$ & $\begin{array}{c}\text { (3) } \\
\text { jobsecurity }\end{array}$ \\
\hline year: bad news & $\begin{array}{l}0.092 * * * \\
(0.003)\end{array}$ & $\begin{array}{l}0.036 * * * \\
(0.003)\end{array}$ & $\begin{array}{l}0.053 * * * \\
(0.004)\end{array}$ \\
\hline year: good news & $\begin{array}{c}-0.127 * * * \\
(0.004)\end{array}$ & $\begin{array}{c}-0.003 \\
(0.004)\end{array}$ & $\begin{array}{c}0.005 \\
(0.006)\end{array}$ \\
\hline year: ambiguous news & $\begin{array}{c}-0.004 \\
(0.003)\end{array}$ & $\begin{array}{c}-0.017 * * * \\
(0.003)\end{array}$ & $\begin{array}{c}-0.027 * * * \\
(0.004)\end{array}$ \\
\hline month dev: bad news & $\begin{array}{l}0.034 * * * \\
(0.002)\end{array}$ & $\begin{array}{l}0.004 * * \\
(0.002)\end{array}$ & $\begin{array}{c}0.001 \\
(0.002)\end{array}$ \\
\hline month dev: good news & $\begin{array}{c}-0.025 * * * \\
(0.003)\end{array}$ & $\begin{array}{c}0.003 \\
(0.003)\end{array}$ & $\begin{array}{c}-0.002 \\
(0.004)\end{array}$ \\
\hline month dev: ambig. news & $\begin{array}{c}-0.000 \\
(0.002)\end{array}$ & $\begin{array}{l}0.010 * * * \\
(0.002)\end{array}$ & $\begin{array}{l}0.012 * * * \\
(0.003)\end{array}$ \\
\hline 1 if children in $\mathrm{HH}$ & $\begin{array}{c}-0.001 \\
(0.007)\end{array}$ & $\begin{array}{l}0.016 * * \\
(0.008)\end{array}$ & $\begin{array}{c}-0.005 \\
(0.009)\end{array}$ \\
\hline 1 if unemployed & $\begin{array}{l}0.073 * * * \\
(0.008)\end{array}$ & $\begin{array}{l}0.199 * * * \\
(0.008)\end{array}$ & $\begin{array}{l}0.122 * * * \\
(0.025)\end{array}$ \\
\hline lag $\ln \mathrm{HH}$ inc & $\begin{array}{c}-0.015 * * \\
(0.006)\end{array}$ & $\begin{array}{c}-0.048 * * * \\
(0.006)\end{array}$ & $\begin{array}{c}-0.013 \\
(0.009)\end{array}$ \\
\hline 1 if married & $\begin{array}{c}0.018 * \\
(0.011)\end{array}$ & $\begin{array}{c}0.005 \\
(0.012)\end{array}$ & $\begin{array}{c}-0.016 \\
(0.016)\end{array}$ \\
\hline 1 if divorced & $\begin{array}{c}0.023 \\
(0.016)\end{array}$ & $\begin{array}{c}-0.013 \\
(0.018)\end{array}$ & $\begin{array}{c}-0.019 \\
(0.024)\end{array}$ \\
\hline self-stated health & $\begin{array}{c}-0.011 * * * \\
(0.003)\end{array}$ & $\begin{array}{c}-0.048 * * * \\
(0.003)\end{array}$ & $\begin{array}{c}-0.039 * * * \\
(0.004)\end{array}$ \\
\hline month & $\begin{array}{c}0.000 \\
(0.001)\end{array}$ & $\begin{array}{c}0.001 \\
(0.001)\end{array}$ & $\begin{array}{c}-0.006 * * * \\
(0.002)\end{array}$ \\
\hline year & $\begin{array}{c}-0.031 * * * \\
(0.001)\end{array}$ & $\begin{array}{c}-0.018 * * * \\
(0.001)\end{array}$ & $\begin{array}{c}-0.037 * * * \\
(0.001)\end{array}$ \\
\hline Constant & $\begin{array}{l}64.247 * * * \\
(1.493)\end{array}$ & $\begin{array}{l}38.208 * * * \\
(1.514)\end{array}$ & $\begin{array}{l}75.700 * * * \\
(2.187)\end{array}$ \\
\hline Observations & 157,782 & 157,755 & 89,266 \\
\hline Number of individuals & 31,298 & 31,301 & 21,013 \\
\hline Adjusted R-squared & 0.105 & 0.023 & 0.040 \\
\hline
\end{tabular}

Note: Fixed effects regressions. The dependent variables are 'worries about the economic development' in Column (1), 'worries about the own economic environment' in Column (2) and worries about the jobsecurity' in Column (3). Only respondents who are employed are asked about the jobsecurity. The variable 'year: bad news' stands for the average of bad news reports per day over the past year, while 'month: bad news' analogously represents the average over the last month. 'month dev: bad news' captures the difference between the yearly and the monthly average in bad news. ' 1 if children in HH' captures if there are any children under 16 in the household. 'lag $\ln \mathrm{HH}$ income' captures the CPI and household size adjusted log household income. Robust standard errors in parentheses, ${ }^{*}$ significant at $10 \% ;{ }^{* *}$ significant at $5 \%$; ${ }^{* * *}$ significant at $1 \%$. 
could be a possible channel through which economic news influence individuals' willingness to take risks. At this point however we have to suffice with the suggestive evidence discussed above, since our risk perception variables are too coarsely measured to explain sufficient variance in the willingness to take risk in order to make a structural analysis possible. ${ }^{15}$

\subsubsection{Affective reaction}

As pointed out in the introduction, empirical studies show that risk attitudes may be influenced by individuals' moods the moment they are assessed. In our context bad (good) economic news may trigger (alleviate) anxiety or fear about the general economic situation and in turn influence risk taking behavior. Such an emotion-driven reaction would suggest that the news coverage just before the risk attitude elicitation has a particularly strong effect on risk attitudes.

We investigate whether the effect of changes in economic news coverage is rather related to news induced emotional changes or whether it is mainly rooted in a long-term adjustment of individuals' economic risk perception. The strong results for the yearly news measures that we show above already indicate that our results are likely not driven by an emotional reaction. However, one could still argue that more prompt measures of news would perform better. To address this concern we construct additional short-term news measures that capture the average daily number of economic news reports during the week and the two days preceding the day of the SOEP interview.

In Table 4.7 we present the results of fixed effects regressions of risk preferences on bad, good and ambiguous news measures for different time spans. We include average daily news measures over the timespan of one year, one month, one week and two days. We use standardized values in order to make the results comparable across the different specifications. This is necessary, as one news item more on average per day over the span of a complete month needs a more fundamental event than a similar increase for just two days.

Going from Column (1) to Column (4) we see that the effects of bad news become smaller in magnitude, the shorter the time frame of the news measure. For good news we observe that while in the long run the effect on the willingness to take risk is negative, it turns positive in the short run. The time span does not seem to play much of a role for the effect of ambiguous news. Overall, the news measure for the shorter time spans perform worse in terms of explained variance. ${ }^{16}$

In general our analyses show that emotion-related effects are not a main determinant of the relation between economic news and risk attitudes.

\footnotetext{
${ }^{15}$ The results of the regressions of risk preferences on worries are available from the authors upon request.

${ }^{16}$ If we control for the yearly level of news and investigate the effect of different short-term measures included as deviations from the yearly measures, we get similar results. For good and bad news the monthly deviation has an additional impact, while the deviation of one week or two days has a less or even statistically not significant effect. This does not hold for ambiguous news for which no clear trend can be observed. Results are available upon request.
} 
Table 4.7: Affect - Impact of different time-spans in news on risk

\begin{tabular}{|c|c|c|c|c|}
\hline VARIABLES & $\begin{array}{r}(1) \\
364 \text { days } \\
\text { risk att. }\end{array}$ & $\begin{array}{l}\quad(2) \\
28 \text { days } \\
\text { risk att. }\end{array}$ & $\begin{array}{r}\text { (3) } \\
7 \text { days } \\
\text { risk att. }\end{array}$ & $\begin{array}{r}(4) \\
2 \text { days } \\
\text { risk att. }\end{array}$ \\
\hline std. bad news & $\begin{array}{c}-0.408 * * * \\
(0.010)\end{array}$ & $\begin{array}{c}-0.141 * * * \\
(0.007)\end{array}$ & $\begin{array}{c}-0.098 * * * \\
(0.006)\end{array}$ & $\begin{array}{c}-0.085 * * * \\
(0.006)\end{array}$ \\
\hline std. good news & $\begin{array}{c}-0.353 * * * \\
(0.010)\end{array}$ & $\begin{array}{c}-0.005 \\
(0.008)\end{array}$ & $\begin{array}{l}0.014 * * \\
(0.007)\end{array}$ & $\begin{array}{l}0.041 * * * \\
(0.006)\end{array}$ \\
\hline std. ambiguous news & $\begin{array}{c}-0.060 * * * \\
(0.010)\end{array}$ & $\begin{array}{c}-0.199 * * * \\
(0.007)\end{array}$ & $\begin{array}{c}-0.157 * * * \\
(0.007)\end{array}$ & $\begin{array}{c}-0.110 * * * \\
(0.006)\end{array}$ \\
\hline Constant & $\begin{array}{c}-21.155 * * * \\
(5.427)\end{array}$ & $\begin{array}{l}74.364 * * * \\
(4.791)\end{array}$ & $\begin{array}{l}70.849 * * * \\
(4.772)\end{array}$ & $\begin{array}{l}68.662 * * * \\
(4.767)\end{array}$ \\
\hline Controls & yes & yes & yes & yes \\
\hline Observations & 120,160 & 120,160 & 120,160 & 120,160 \\
\hline Number of individuals & 30,855 & 30,855 & 30,855 & 30,855 \\
\hline Adjusted R-squared & 0.045 & 0.032 & 0.021 & 0.014 \\
\hline
\end{tabular}

\subsubsection{Heterogeneity based on demographics and personality traits}

News may affect different types of people to a different extent or even in different ways. Therefore, we investigate how demographics and personality traits influence the relation between changes in economic news coverage and changes in general risk attitudes. We investigate the interaction effects of gender, birth year, education and the "Big Five" personality traits with the news measures. The captured personality traits are openness, conscientiousness, extroversion, agreeableness, and neuroticism. The different traits are in further detail discussed in the Data Appendix. Summary statistics for the demographic and personality trait variables are reported in Table 4.2.

For each characteristic $\mathrm{v}_{i}$ we estimate a fixed effects regression as follows.

$$
\begin{aligned}
\text { riskattitude }_{i t}= & \alpha+\beta^{\prime} \operatorname{News}_{t^{*}}^{Y}+\gamma^{\prime}\left(\operatorname{News}_{t^{*}}^{M}-\operatorname{News}_{t^{*}}^{Y}\right)+\pi^{\prime}\left(\operatorname{News}_{t^{*}}^{Y} \mathrm{v}_{i}\right) \\
& +\lambda^{\prime}\left(\operatorname{News}_{t^{*}}^{M}-\operatorname{News}_{t^{*}}^{Y}\right) \mathrm{v}_{i}+\delta^{\prime} X_{i t}+u_{i}+\varepsilon_{i t},
\end{aligned}
$$

where $\operatorname{News}_{t^{*}}^{Y}$ is the vector containing the year measures of bad news, good news and ambiguous news. News $t_{t^{*}}^{M}$ is its month equivalent. The time-constant variable $\mathrm{v}_{i}$ is always normed to the sample average in order to make the interpretation of the interaction terms easier.

Table 4.8 shows the results of the regression stated in equation 4.2. Each specification includes the interaction terms with one of the above mentioned demographic or personality variables. Concerning the effect of long-lasting changes in news we find that for higher 


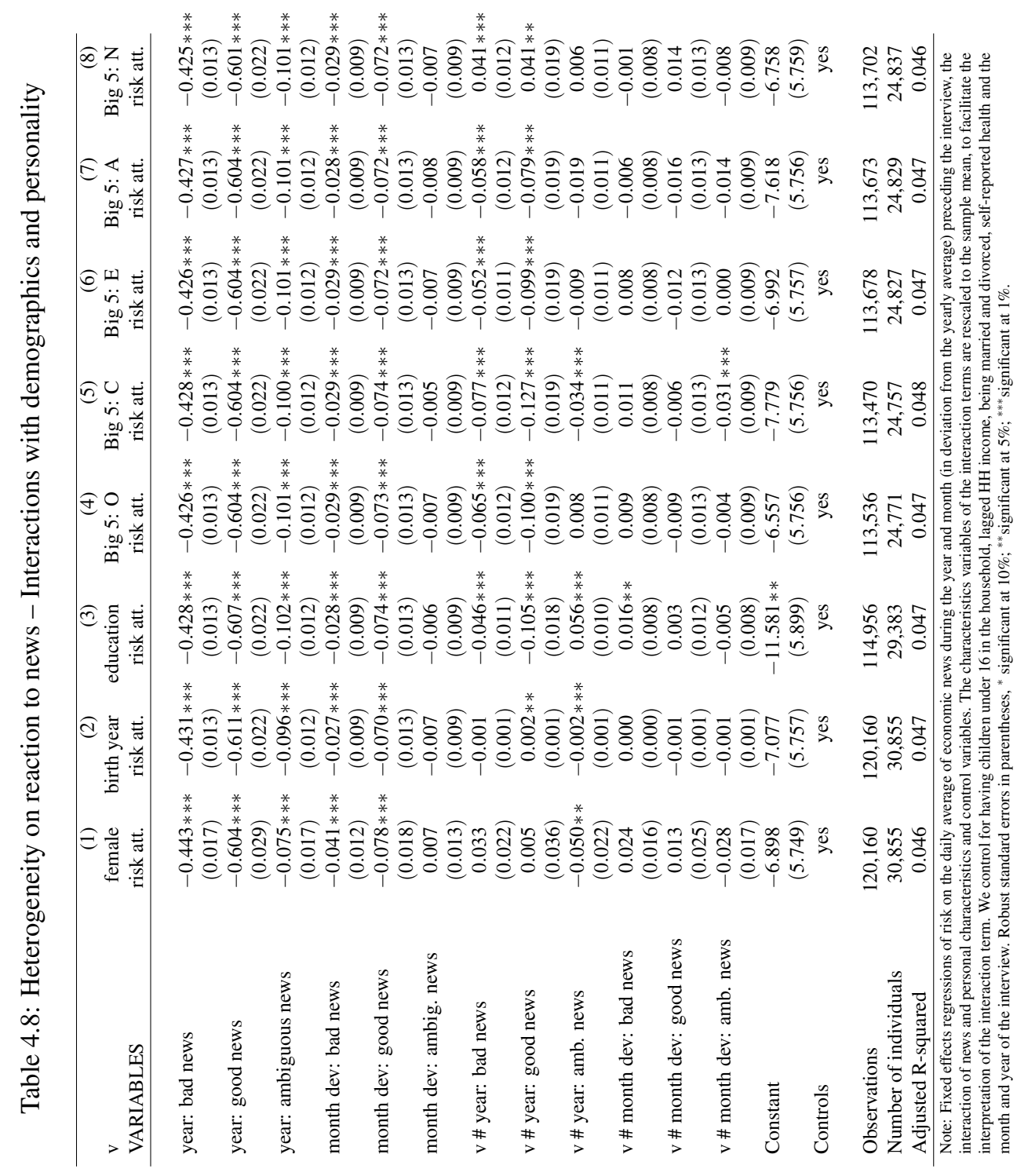


educated people and those that score high on openness, conscientiousness, extroversion and agreeableness the relation between news coverage and willingness to take risk is more negative for bad news and good news. This means that those individuals react stronger to economic news with respect their risk preferences. For younger people the effect of good news is less negative. People that score high on the neuroticism scale are a particular case, as they react less strongly on negative news. This might be due to the fact that neurotic people are in general more risk averse and bad news might just confirm what they expected, so that they do not need to update their risk attitudes. The effect of long lasting changes in ambiguous news is more negative for females, younger people and people that score high on consciousness, whereas it is less negative for higher educated people.

Concerning the effect of short term changes in news we find much less differences in how people's risk attitudes are influenced by news. A short term increase in bad news is less negatively related to the willingness to take risk for higher educated people. For people that score high on consciousness, a short term increase in ambiguous news is more negatively related to risk attitudes.

Overall we find that while there is evidence for significant heterogeneity in the magnitude of the impact of long-lasting changes in news on risk attitudes, the general results discussed in the previous sections still hold. The magnitude of the effects of short term changes in news instead appears quite stable among individuals with different characteristics.

\subsubsection{The good news share}

In the previous analysis we only focus on the absolute amount of the different types of news, thus capturing linear effects. However, it is also important to take into account that a given amount of e.g. bad news may have a different effect depending on how many good news are published at the same time. Also, the different types of news measures are correlated. Therefore, we create variables that capture the relation between the good and bad news measures. The share of good news for a particular news measure, share $_{t^{*}}^{j}$, is specified as follows:

$$
\text { share }_{t^{*}}^{j}=\frac{\text { goodnews }_{t^{*}}^{j}}{\text { goodnews }_{t^{*}}^{j}+\text { badnews }_{t^{*}}^{j}} \quad \text { for } \quad j=Y, M
$$

In addition we create an aggregate yearly news measure (news $t_{t^{*}}^{Y}$ ) and an aggregate monthly news measure $\left(\right.$ news $_{t^{*}}^{M}$ ). These measures are the moving averages of the sums of bad, good and ambiguous news in the year and in the month before the risk attitudes are elicited. We then apply a FE estimation of risk attitudes on the particular aggregate new measure, the according share and the interaction of the share and the news measure.

$$
\begin{aligned}
& \text { risk-attitude }{ }_{i t}=\alpha+\beta \text { news }_{t^{*}}^{j}+\gamma \text { share }_{t^{*}}^{j}+\lambda\left(\text { news }_{t^{*}}^{j} \text { share }_{t^{*}}^{j}\right) \\
& +\delta^{\prime} \mathrm{X}_{i t}+u_{i}+\varepsilon_{i t} \quad \text { for } \quad j=Y, M
\end{aligned}
$$


Table 4.9: Good/Bad news ratio - News on willingness to take risks and good news share

\begin{tabular}{|c|c|c|}
\hline VARIABLES & $\begin{array}{r}(1) \\
\text { year } \\
\text { risk att. }\end{array}$ & $\begin{array}{r}(2) \\
\text { month } \\
\text { risk att. }\end{array}$ \\
\hline year: aggregate news & $\begin{array}{c}-0.219 * * * \\
(0.042)\end{array}$ & \\
\hline year: good news share & $\begin{array}{c}0.403 \\
(1.250)\end{array}$ & \\
\hline yearly news \# yearly share & $\begin{array}{c}-0.081 \\
(0.125)\end{array}$ & \\
\hline month: aggregate news & & $\begin{array}{c}-0.391 * * * \\
(0.015)\end{array}$ \\
\hline month: good news share & & $\begin{array}{c}-7.951 * * * \\
(0.443)\end{array}$ \\
\hline monthly news \# monthly share & & $\begin{array}{l}0.852 * * * \\
(0.045)\end{array}$ \\
\hline Constant & $\begin{array}{l}44.047 * * * \\
(5.240)\end{array}$ & $\begin{array}{l}41.988 * * * \\
(4.911)\end{array}$ \\
\hline Controls & yes & yes \\
\hline Observations & 120,160 & 120,160 \\
\hline Number of individuals & 30,855 & 30,855 \\
\hline Adjusted R-squared & 0.039 & 0.035 \\
\hline \multicolumn{3}{|c|}{$\begin{array}{l}\text { Note: Fixed effects regressions. The variable 'years: aggregate news' } \\
\text { stands for the average of all news reports per day over the past year. 'year: } \\
\text { good news share' captures the ratio between good and bad news during the } \\
\text { past year. Controls include children in the HH, unemployed, HH income, } \\
\text { marital status, self-stated health, month and year of the interview. Robust } \\
\text { standard errors in parentheses, }{ }^{*} \text { significant at } 10 \% \text {; }{ }^{* *} \text { significant at } 5 \% \text {; } \\
{ }^{* * * *} \text { significant at } 1 \% \text {. }\end{array}$} \\
\hline
\end{tabular}

With this analysis we investigate how aggregate news perform as predictor of risk preferences and importantly, whether the predictive power of the aggregate measure depends on the share of good news relative to bad ones. This approach is motivated by the idea that the effect of e.g. bad news may be less strong if individuals are at the same time exposed to a lot of good news that may consequently outweigh the bad news and vice versa. Table 4.9 Column (1) shows the results of regressing the individuals' risk attitudes on the aggregate year measure and the according share of good news, the interaction of the two and control variables. In line with our previous findings we find that aggregate news are significantly negatively related to individuals' willingness to take risks. The interaction of the news measure and the share however is insignificant. This means that the effect of the aggregate yearly news measure on risk attitudes does not depend on the share of good news.

Column (2) reports the same analysis with the aggregate month measure and the month share. Also for this more temporary news measure we find that an increase in 
Total yearly news and share of positive news



(a) Yearly news measure

Total monthly news and share of positive news

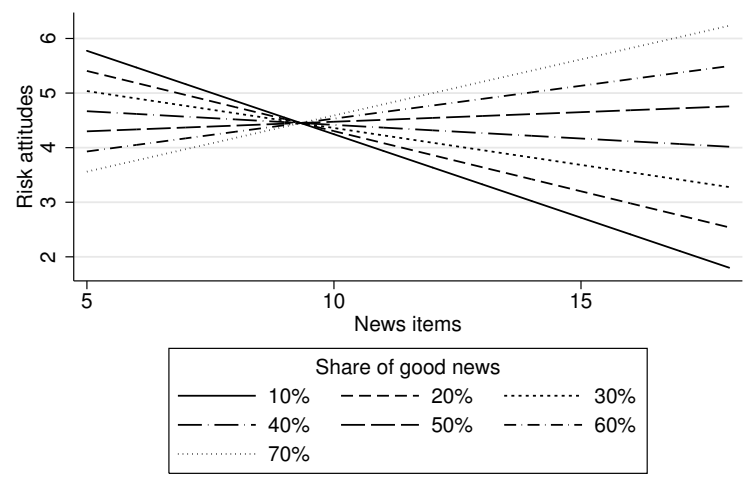

(b) Monthly news measure

Figure 4.2: News and share of positive news

Note: These graphs illustrate the impact of one additional news item per day by the share of good news. The values are computed from the coefficients of the aggregate news and the interaction term of aggregate news and share of good news that we report in Table 4.9. The share of good news, as well as the amount of news item per day cover the range of values in our dataset.

aggregate news is related to a decrease in willingness to take risks. For the short term measure however, the interaction term of aggregate news and the share of positive news is positive and highly statistically significant. Thus, in this case the relation of an increase in news and the willingness to take risks depends on the composition of the news. 
Figure 4.2 displays the graphical interpretation of the relation between additional news in the year or the month before the risk attitude elicitation, their composition, and the willingness to take risks. Panel a) shows the relation between the year moving average and the risk attitude measure for shares of good news ranging from 20 percent to 50 percent. ${ }^{17}$ Clearly, the share does not have an influence on how the two measures are related. Panel $b$ ) of the Figure shows the relation between the month measure and the risk attitude measure for shares of good news ranging from 10 percent to 70 percent. Up to a share of 40 percent the relation is negative. As of a share of 50 percent, however, the slope of the regression line turns positive: an increase in the number of aggregate news in the month preceding the SOEP interview is now associated with an increase in the willingness to take risk.

We conclude that while in the long run the constitution of news with respect to their valuation does not influence how news are related to risk attitudes, in the short run the direction of the relation depends on whether good or bad news predominate.

\subsection{Conclusion}

This paper examines whether within-individual variations in self-stated risk preferences over time are related to long and short term changes in individuals' economic environments. Using panel data from the SOEP and the media research institute Media Tenor over an eight year span, we find that self-stated risk preferences vary systematically with the amount of economic news coverage in the year and in the month before risk attitudes are elicited. A high number of bad, good and ambiguous news reports, not taking into account their relative occurrence, is associated with a low willingness to take risks both in the short and in the long run. We show that in particular the strength of the relations with the long-lasting changes in news depends on individual demographics and personality traits. Using the short and long term news measures together with the conventional GDP measure for macroeconomic shocks to explain variation in risk attitudes yields that news coverage has explanatory power on top of GDP.

As our FE regression model is better explained when taking news coverage during the month preceding the risk attitude elicitation into account as compared to the week or the two days before, we may exclude that our results are driven by state emotions induced by the exposure to economic news reports. A positive relation between bad news coverage and individuals' worries about economic issues instead suggests that an underlying mechanism explaining our results is a media induced change in individuals' risk perception. Further research is however necessary to clearly identify the mechanism behind the relation. A more precise measure of risk perception would be helpful to understand the effect that economic news have on individuals' assessment of economic risk exposure.

When aggregating the news and controlling for the share of good news, we find that when considering short term deviations, the relation between news and risk attitudes is negative when bad news predominate but turns positive when good news predominate.

\footnotetext{
${ }^{17}$ The range of shares as well as the range of the amount of news items cover our complete sample distribution.
} 
No such change in the direction of the relation is found when considering the effects of long lasting changes in news.

Our results show that the presentation of a bad economy in the news affects individuals' economic risk perception and their self-stated willingness to take risks. The findings are important to understand within individual variation in risk preference measures over time, as they show that it is at least partly systematic. How changes in self-stated risk preferences are related to changes in actual risk preferences and whether they translate into changes in revealed risk taking behavior requires further investigation. 


\subsection{Data Appendix}

\subsubsection{SOEP Data}

Risk attitudes are measured in 7 waves of the SOEP, in 2004, 2006, 2008, 2009, 2010, 2011 and 2012. The wording of the question is: "How do you see yourself: Are you generally a person who is fully prepared to take risks or do you try to avoid taking risks? - Please tick a box on the scale, where the value 0 means: 'risk averse' and the value 10 means: 'fully prepared to take risks'. You can use the values in between to make your estimate."

Our proxy for risk perception, worries, is based on yearly repeated questions in the SOEP about the respondents' concerns. We chose the 3 concerns that are related to economics and that are available for the complete time span of our sample. The wording of the question is: "What is your attitude towards the following areas - are you concerned about them?" 'General economic development', 'Your own economic situation' and 'If you are employed: Your job security'. The answer is given in 3 options: 'Very concerned', 'Somewhat concerned' and 'Not concerned at all'.

Among other control variables we include lagged household income in the main regression. We construct adjusted household income as CPI adjusted, log of the household income, after adjusting it for the household size by dividing the total household income by the square root of the number of household members. We use the CPI provided by the German Federal Statistical Office Destatis; the base year is 2010.

The Big5 personality traits are elicited twice in the SOEP, in 2005 and 2009. The captured personality traits are openness, conscientiousness, extroversion, agreeableness, and neuroticism. The Big Five domains were assessed using the BFI-S psychology questionnaire, a 15-item subset of the NEO-FFI version (see Gerlitz and Schupp, 2005). For the assessment of each personality trait individuals indicate on a seven-point scale to what extent they agree with three statements. Averaging over the three responses yields the score for the particular trait. For each individual we take the average over time of the available information.

\subsubsection{Media Tenor Data}

\section{Newscasts}

- Tagesschau is one of Germany's main daily television newscasts produced by the consortium of public broadcasters in Germany (ARD). It is aired several times a day on the principal publicly owned television channel in Germany Das Erste. It's main edition is currently aired at 8:00 PM and is additionally broadcasted at the regional television programs of ARD (exclusive BR and MDS) as well as at Phoenix, 3sat, EinsPLus and tagesschau24.

- Tagesthemen is the second of ARD's most important newscast and currently aired Mondays to Thursdays at 10:15 PM, Fridays at 10:15 PM, Saturdays at varying times after the 20:15 program and Sundays at 10:45 PM. In contrast to the 
Table A4.1: Subtopics

\begin{tabular}{l|ccc}
\hline Subtopics & \multicolumn{3}{|c}{ Average daily news coverage } \\
& Bad & Neutral & Good \\
\hline national budget & 1.91 & 1.73 & 1.26 \\
business cycle & 1.76 & 1.50 & 1.56 \\
economic climate & 1.09 & 0.85 & 1.21 \\
economic situation of firms & 0.65 & 0.63 & 0.58 \\
mining & 0.07 & 0.10 & 0.03 \\
agriculture & 0.25 & 0.32 & 0.07 \\
markets & 0.05 & 0.04 & 0.02 \\
labor costs & 0.59 & 0.65 & 0.28 \\
labor market & 1.99 & 2.04 & 1.63 \\
tax policy & 1.41 & 1.76 & 0.88 \\
consumer protection & 0.45 & 0.71 & 0.24 \\
economic demand & 0.57 & 0.54 & 0.85 \\
economic policy & 1.30 & 1.62 & 0.96 \\
national HH policy comparison & 0.13 & 0.12 & 0.08 \\
industrial location & 1.10 & 1.11 & 0.91 \\
\hline aggregated economic news & 4.22 & 4.22 & 2.42
\end{tabular}

Tagesschau, Tagesthemen provides the viewer with more information, context and background.

- RTL Aktuell is the news broadcast of the German commercial television station RTL. It is currently aired daily at 6:45 PM.

- Heute is the news broadcast of one of the biggest German public-service television broadcasters ZDF. It is currently aired daily at 7:00 PM.

- Heute journal is another newscast of ZDF, comparable to the ARD Tagesthemen. It is currently aired Mondays to Wednesdays and Fridays at 10:45 PM, Thursdays and Sundays at 21:45 PM and Saturdays at 11:15 PM.

- Bild-Zeitung is a German tabloid published by Axel Springer AG. The paper is published daily from Mondays to Saturdays. It is Germany's top high-circulating newspaper. $^{18}$

\section{Content}

Table A4.1 shows the average number of economic news in the different subtopics, separated by valuation and in aggregation.

\footnotetext{
${ }^{18}$ All newscasts are further available online as live-streams or podcasts.
} 


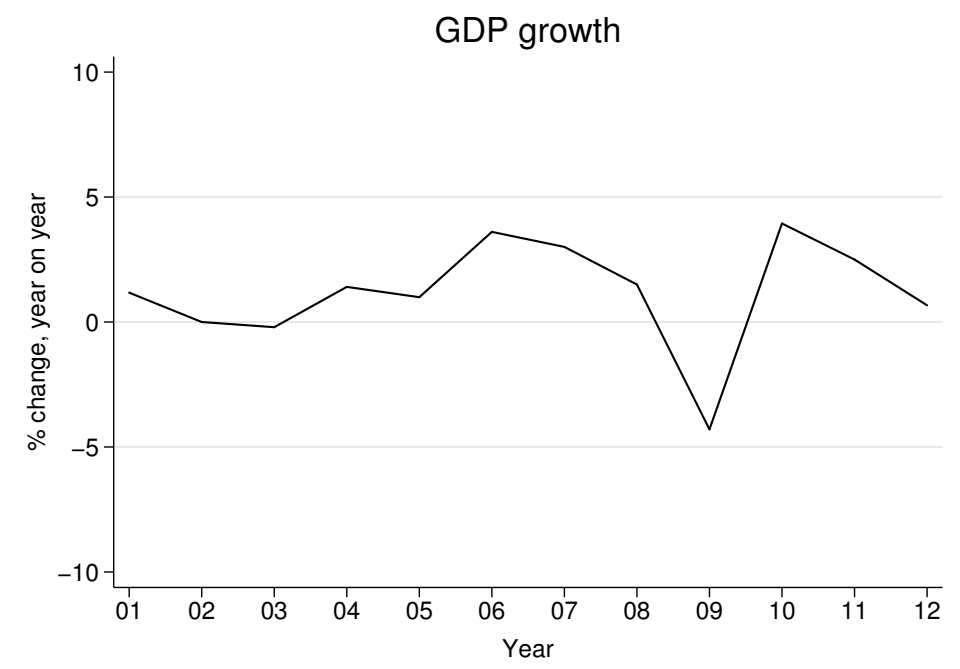

Figure A4.1: GDP growth

Note: Change in inflation adjusted GDP for Germany. Data for the years 2001-2012 from Destatis.

\subsubsection{GDP}

Statistics on the changes in GDP per citizen for all German regions for the years 2003 to 2013 are provided by the Federal and State Statistical Offices. The yearly measure is interlinked and adjusted for inflation. Figure A4.1 shows the GDP change measure for each year between 2003 and 2012 in aggregation for all sixteen regions. Evidently, as with the economic news measures, the harshest decrease can be observed in 2009, the year of the financial crisis. 



\section{Chapter 5}

\section{Introspection, focal points and measurement errors in survey questions $^{\star}$}

\subsection{Introduction}

In recent decades a massive amount of data became available through large-scale household and other surveys around the world. These data differ from census or experimental data in that they mainly contain answers to questions that are not (and often cannot) be incentivized in the usual way economists prefer. Information gathered this way provides unparalleled flexibility for accessing concepts or quantities that are difficult to measure otherwise. Surveys also include questions that are simpler for the respondent to answer and less costly for the researcher to ask, since they do not rely on complex incentive structures. But how precise are the data obtained by simply asking people, i.e. how close are their answers to their true preferences? ${ }^{1}$

On average people seem to answer well in surveys. Hudomiet and Willis (2013) show that the average responses to survival probabilities are remarkably accurate. Dohmen et al. (2011) find that measurements of risk attitudes that are elicited by survey methods not only correlate strongly with experimental measures of risk preferences, but also predict real economic outcomes that relate to risk taking rather well.

While the average information from survey questions may be precise, individual responses are often subject to substantial measurement error, which is unlikely to be

\footnotetext{
${ }^{\star}$ Joint work with Nicolas Salamanca (University of Melbourne).

${ }^{1}$ The psychometrics literature demands that survey questions adhere to both, (construct) validity and reliability (Crocker and Algina, 1986). When testing for construct validity, psychologists examine whether a question really measures what it claims to. To test the reliability of answers, to exclude that the answers contain but noise, they often apply a test-retest procedure and compare the two answers. While we take the construct validity as given in our investigation, we are interested in the reliability of the answers.
} 
classical (i.e., independently distributed and homoscedastic). Hoderlein and Winter (2010) show that the limited recall ability of subjects will likely lead to non-classical and differential measurement error. ${ }^{2}$ They suggest a test statistic to identify information reduction and bounds to account for the effects of recall errors in dependent variables.

One way in which this non-classical measurement error can be seen is the unusually large probability mass on focal points - points that naturally attract the respondent's attention, such as multiples of five when reporting numbers or midpoints on intensity scales. There is evidence that the likelihood of giving a focal answer to a probability question is dependent on the personal characteristics of the respondent such as education, but also on how informed the respondent is about the topic of the question (Manski and Molinari, 2010; Hudomiet and Willis, 2013; Kleinjans and Soest, 2014). A recent experimental study by Ruud et al. (2013) shows that subjects round more if they are provided with noisier information about the target variable.

In this paper we investigate focal answers to survey questions, with particular attention on how to correctly estimate population parameters when there are such focal answers in the dependent variable. We examine how the propensity to give a focal answer relates to characteristics of the respondents and the situation, and how we can use the information in focal answers more efficiently. There is a growing literature that deals with this particular kind of measurement error.

Manski and Molinari (2010) show that, under minimal assumptions, population parameters are often only partially identified when there is interval censoring. They then turn to calculating the bounds of these partially identified parameters. Our approach is somewhat different. We start from a behavioral model of survey response that structures our believes about the nature of focal responses. This behavioral model implies that we can correct for the effect focal points in a survey-measured dependent variable and at the same time investigate the determinants of this focality using a simple modification of an interval regression. ${ }^{3}$ This interval regression identifies the main population parameters of interest, and provides information about the determinants of focality.

Our model of survey response builds on the general framework of Zaller and Feldman (1992). In this framework individuals do not always have a readily available answer to a survey question. Thus, they have to consult their memory or self-image to form an answer. When answering survey questions individuals draw several memories or opinions, sometimes conflicting, and aggregate them into one answer that they then provide. We refer to this drawing process as introspection. If, after this process of introspection, the individuals are too uncertain about the precision of their answer, they might prefer to reply with a focal answer to either indicate their unsureness or to avoid giving a (potentially wrong) answer. The costs of this introspection exercise may depend on characteristics of the individual such as education or conscientiousness, and of the situation, such as the difficulty of the question. Through their effect on introspection, these characteristics will

\footnotetext{
${ }^{2}$ Carroll et al. (1995) define differential measurement error as the error that occurs if $\bar{Y}$ is not conditionally independent of the other variables $X$, even after controlling for the true $Y^{*}$.

${ }^{3}$ Our behavioral response model is based on a distributional assumption about the latent error term that favors the use of interval regression methods. Under these parametric assumptions, the population parameters underlying our model are point identified under the same conditions as any other censoring models.
} 
influence the likelihood of giving a focal answer. In our model, we formalize the three processes of memory drawing, introspection, and focalization of answers.

We then develop an empirical framework that is consistent with this model. It jointly identifies characteristics leading to an increased probability to give focal answers, and then uses this knowledge to recover the underlying population parameters between dependent variables displaying focal answers and their regressors. We also discuss a variation of the model where we give up the ability to identify the drivers of focality in exchange for robustness regarding model misspecification. Both models can easily be implemented as a modified version of the heteroscedastic interval regression. ${ }^{4}$

Through various Monte Carlo simulations we show the usefulness and limits of our approach when compared to OLS methods that simply ignore focal points (naïve OLS). Our interval regression improves with an increase in either of the explained variance of the latent process (the underlying $R^{2}$ ), the heteroscedasticity captured by our model, the number of focal points or the share of variation captured by focal points. For most values of any of these parameters our method outperforms naïve OLS. Moreover, in all situations, the model can correctly identify the factors driving focal answers.

The paper is organized as follows. In Section 5.2 we present a model of response behavior. In Section 5.3 we introduce our econometric approach to account for focal responses in dependent variables and get estimates for the characteristics related to giving a focal response. In Section 5.4 we test our econometric approach and show the conditions and limitations for its usefulness using simulated data. Finally, in Section 5.5 we conclude.

\subsection{Model of survey response and introspection}

To properly understand our model, it is convenient to first discuss some important underlying assumptions. First, we assume that respondents want to give a correct (i.e., unbiased) answer. This assumption rules out situations in which individuals have incentives to misreport their answers, either strategically or due to factors such as social desirability. Second, we assume that the "introspection error" (i.e., the error of each introspective draw) is pure noise with constant variance and unrelated to previous draws or other factors. This implies that, given enough introspective draws, any individual would be able to answer the question with a precise and unbiased answer. ${ }^{5}$ With these assumptions in mind, our focal response model can most easily be explained if we divide it into three broad parts: How individuals form beliefs based on their process of introspection, the (costly) process of introspection itself, and the resulting answering behavior.

\footnotetext{
${ }^{4}$ Manski and Molinari (2010) also consider interval regressions to get better estimates on focal responses. However they calculate the propensity to answer with a focal response by a complex analysis of individual response behavior across several questions. While this is a very valuable approach, the merit of our suggested method is the simplicity of its application.

${ }^{5}$ This assumption rules out some interesting situations where the introspective sampling of answers is biased, a possibility recognized by axioms 2 and 3 of Zaller and Feldman (1992). In principle, these scenarios could also be accommodated by our model, but their analysis is left for future research.
} 


\subsubsection{How individuals form beliefs from introspection}

Every respondent $i$ of a survey is asked to report their true value of a variable, $Y_{i}^{*} \in \mathbb{R}$. However, the respondent will not have access to the true value $Y_{i}^{*}$ because she is not immediately aware of it or she does not remember it precisely. In order to provide an answer, the respondent tries to approximate $Y_{i}^{*}$ via an exercise of introspection. In this exercise she draws several estimations of $Y_{i}^{*}$ repeatedly from the her own memories or beliefs related to the concept in question. This stylization of the introspection process follows Zaller and Feldman (1992). Each estimate drawn, $Y_{i, k}$ is but a noisy signal of the true value, such that

$$
Y_{i, k}=Y_{i}^{*}+\varepsilon_{i, k},
$$

where the subscript $k$ refers to the $k^{t h}$ draw, and $k=1 \ldots K_{i} . K_{i}$ represents the total number of draws for the introspection exercise of respondent $i$. Consistent with our initial assumptions, the error $\varepsilon_{i, k}$ is i.i.d., and the respondent $i$ knows this.

To obtain the best estimate of the value $Y_{i}^{*}$ from the draws $Y_{i, k}, k=1 \ldots K_{i}$, the respondent aggregates all the draws by taking their mean. This estimator is

$$
\bar{Y}_{i, K_{i}}=\frac{1}{K_{i}} \sum_{k=1}^{K_{i}} Y_{i, k}=Y_{i}^{*}+\frac{1}{K_{i}} \sum_{k=1}^{K_{i}} \varepsilon_{i, k}
$$

At the end of this process, respondent $i$ will know the estimate $\bar{Y}_{i, K_{i}}$ and will also know that this is a noisy estimate of the true $Y_{i}^{*}$, with the noise being captured by $\sigma_{\bar{Y}_{i, K_{i}}}^{2}$, the variance of $\bar{Y}_{i, K_{i}}$.

\subsubsection{The process of introspection}

For respondent $i$, taking draws as part of her introspection process is costly in terms of time and effort. Hence she faces a trade-off between the precision of the response and the costs of introspection. Here is where the heterogeneity in characteristics of the respondents and the environment comes into play.

The intensity of introspection in this model is captured by the number of draws that each respondent makes. The general idea is that the more introspective draws a respondent makes, the more precise their estimate of $Y_{i}^{*}$ becomes. It is then natural to model the random number of draws as following a Poisson process, since each draw is an occurrence in what, for all intentional purposes, is a fixed period of time. To allow for respondents' heterogeneity in introspection we allow for individual-specific mean rates in the Poisson process that we model as a linear function of observable characteristics, such that

$$
K_{i} \sim \operatorname{Pois}\left(\phi^{\prime} z_{i}\right),
$$

where $z_{i}$ is a set of observable characteristics that are related to the introspection process. It should be immediately apparent that the variance of $\bar{Y}_{i, K_{i}}$ decreases in $\phi^{\prime} z_{i}$, which 
we formally show in Appendix 5.6. In Section 5.3 we show how we parameterize this heterogeneity in order to uncover the determinants of introspection.

\subsubsection{Reporting the answers}

Respondent $i$ now has an estimate $\bar{Y}_{i, K_{i}}$ of the value of $Y_{i}^{*}$, and she is aware of the inaccuracy of her estimate. This inaccuracy will affect the reported value $\hat{Y}_{i}$ in the presence of focal points in the following way. If there is a focal point "sufficiently close" to $\bar{Y}_{i, K_{i}}$, the respondent will report this more salient value rather than her original estimate. The reason for doing this is that rounding in this case is a way to convey local uncertainly; a way of saying "I believe the answer is more or less X". This intuition is a generalization of the 50-50 response reasoning behind Bruine de Bruin et al. (2000). ${ }^{6}$ Giving a focal answer allows respondents to avoid committing to a very specific number while still being able to give a close estimate within the range of values that they would consider as suitable answers.

The radius of the points that are sufficiently close depends on the level of uncertainty, i.e. on $\sigma_{\bar{Y}_{i, K_{i}}}^{2}$. We can represent the interval that the respondent $i$ deems likely to host the true value of $Y_{i}^{*}$ as an interval of all values that are close enough, $\left(\bar{Y}_{i, K_{i}}-\left(\frac{1}{\gamma}-\right.\right.$ 1) $\left.\sigma_{\bar{Y}_{i, K_{i}}}^{2}, \bar{Y}_{i, K_{i}}+\left(\frac{1}{\gamma}-1\right) \sigma_{\bar{Y}_{i, K_{i}}}^{2}\right)$ for an arbitrarily defined $\gamma \in(0,1]$ that models the general strength of focality. When $\gamma \rightarrow 0$ the interval becomes $(-\infty,+\infty)$ and for every respondent the interval will contain at least one focal point that is close enough. When $\gamma=1$ the interval for each individual collapses to the sole point $\bar{Y}_{i, K_{i}}$ which contains a focal point with probability zero, and thus no respondent reports a focal answer. For ease of notation we define a lower and an upper threshold value, $c_{i, K_{i}}^{l}=\bar{Y}_{i, K_{i}}-\left(\frac{1}{\gamma}-1\right) \sigma_{\bar{Y}_{i, K_{i}}}^{2}$ and $c_{i, K_{i}}^{h}=\bar{Y}_{i, K_{i}}+\left(\frac{1}{\gamma}-1\right) \sigma_{\bar{Y}_{i, K_{i}}}^{2}$, so that the interval of values close enough to $\bar{Y}_{i, K_{i}}$ is $\left(c_{i, K_{i}}^{l}, c_{i, K_{i}}^{h}\right)$.

The reporting behavior will now fall in one of three mutually exclusive scenarios. First, if there are no focal points close enough to the estimate, the respondent will simply report the estimate as calculated by her, that is $\bar{Y}_{i, K_{i}}$. Second, if one single focal point is close enough to the estimate, the respondent will report that focal point instead of her estimate. Third, if more than one focal point is close enough to the estimate, the respondent will report the focal point that is closest to the estimate. For defining the reporting behavior it is sufficient to define the next lowest and next highest focal points with respect to $\bar{Y}_{i, K_{i}}, f_{h-1}$ and $f_{h}$ respectively.

Respondent $i$ 's reported value of $Y_{i}^{*}$, captured in $\hat{Y}_{i}$, is therefore ${ }^{7}$

\footnotetext{
${ }^{6}$ Bruine de Bruin et al. (2000) suggest that the increased use of the answer "50\%" to probability questions can be explained by epistemic uncertainty. Individuals answer in the spirit of saying "fifty-fifty" and thereby avoid to report a precise number that might be not correct. Hill et al. (2004) follow up on that, explaining the phenomenon of answering with " $0 \%$ ", " $50 \%$ " or " $100 \%$ " with Knightian uncertainty. We extend this concept to answers which are not about probabilities and might have more than 3 focal points. The key point stays the same; answering with a salient number indicates higher uncertainty.

${ }^{7}$ This survey response censoring algorithm follows a similar form as the formation of interval data mechanism in Manski and Molinari (2010), with one key difference: our response algorithm does not rely on
} 


$$
\hat{Y}_{i}=\left\{\begin{array}{lll}
\bar{Y}_{i, K_{i}} & \text { if } f_{h-1} \notin\left(c_{i, K_{i}}^{l}, c_{i, K_{i}}^{h}\right) & \text { and } f_{h} \notin\left(c_{i, K_{i}}^{l}, c_{i, K_{i}}^{h}\right) \\
f_{h-1} & \text { if } f_{h-1} \in\left(c_{i, K_{i}}^{l}, c_{i, K_{i}}^{h}\right) \text { and } f_{h} \notin\left(c_{i, K_{i}}^{l}, c_{i, K_{i}}^{h}\right) \\
f_{h} & \text { if } f_{h-1} \notin\left(c_{i, K_{i}}^{l}, c_{i, K_{i}}^{h}\right) \text { and } f_{h} \in\left(c_{i, K_{i}}^{l}, c_{i, K_{i}}^{h}\right) \\
f_{h-1} H+f_{h}(1-H) & \text { if } f_{h-1} \in\left(c_{i, K_{i}}^{l}, c_{i, K_{i}}^{h}\right) \text { and } f_{h} \in\left(c_{i, K_{i}}, c_{i, K_{i}}^{h}\right)
\end{array}\right.
$$

where $H$ is an indicator function that takes the value of one if the lower focal point is closer to $\bar{Y}_{i, K_{i}}$ than the higher focal point, and is zero otherwise:

$$
H=1\left[\left|f_{h-1}-\bar{Y}_{i, K_{i}}\right|<\left|f_{h-1}-\bar{Y}_{i, K_{i}}\right|\right]
$$

This reporting behavior is illustrated in Figure 5.1.

\subsection{Econometric model}

Based on our model of costly introspection, we now describe its empirical counterpart. We show what kind of data is generated by such a behavior and how we can approach the problem of focal answers in a simple way in empirical analysis. Our empirical model incorporates the information given in variables with focal answers, estimates the factors that relate to a higher chance of giving a focal answer, and makes efficient use of this information.

We begin by noting that due to the behavior of respondents in our model, the measured variable $\hat{Y}_{i}$ can be a censored version of the respondent's best estimate (and the variable we would like to observe), $\bar{Y}_{i, K_{i}}$. When we observe $\hat{Y}_{i}$ taking the value of a focal point $\hat{Y}_{i}$ is likely to be censored. We can deduce two facts in this case: 1) the focal point reported is the nearest focal point to the best estimate $\bar{Y}_{i, K_{i}}$, and 2) the respondents' uncertainty about $\bar{Y}_{i, K_{i}}$ is large enough that she decided to report the focal point instead of the estimated $\bar{Y}_{i, K_{i}} .{ }^{8}$ The aim of our econometric model is to use the heterogeneity in introspection and its link to the variance of $\bar{Y}_{i, K_{i}}$ to make better inferences about the conditional expectation of the unobserved $\bar{Y}_{i, K_{i}}$.

Suppose that in the distribution of $\hat{Y}$ we can identify a set of $J$ focal points, $F=$ $\left\{f_{1}, \ldots, f_{J}\right\}$, ordered from small to large. Knowing these focal points and observing $\hat{Y}_{i}$, our inferences about $\bar{Y}_{i, K_{i}}$ will fall into two distinct categories, depending on whether a focal point was reported or not:

1. If $\hat{Y}_{i} \neq f_{j}$ for each $f_{j} \in F$, then $\bar{Y}_{i, K_{i}}=\hat{Y}_{i}$ and the uncertainty about $\bar{Y}_{i, K_{i}}$ is small enough (as defined above).

observing the response pattern in several questions. It can be applied to any one question that shows focal points or rounding. This results in our model being applicable to data in which only one survey response is analyzed as the dependent variable and the survey data does not provide further useful information about the rounding behavior of each respondent.

${ }^{8}$ This does however not yet inform us about the absolute size of the uncertainty, since the closer the estimated $\bar{Y}_{i, K_{i}}$ is to the focal point, the smaller the uncertainty needs to be. In the special case where $\bar{Y}_{i, K_{i}}=f_{h}$ we can not say anything about the uncertainty. 

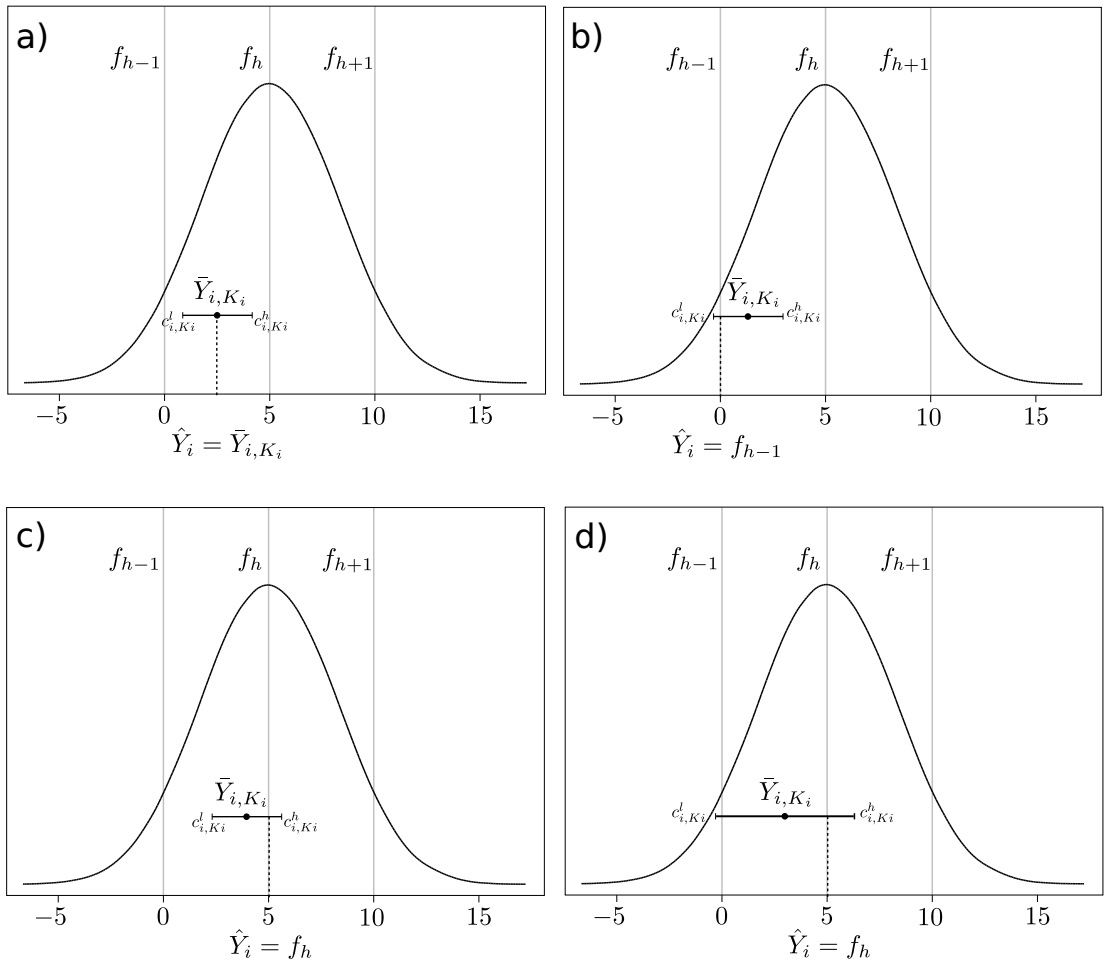

Figure 5.1: Response behavior

This figure illustrates the possible scenarios that individuals can face after drawing from memory. The first scenario, a), shows the situation when the confidence interval of the draws does not include any focal points. In this case the individual will report the estimated value. In situation b) and c) the interval of the draws includes just one focal point. The individual reports the focal point in these situations. Scenario d) illustrates what happens when the confidence interval is sufficiently large to include two or more focal points. The individual will in this case report the next closest focal point. 
2. If $\hat{Y}_{i}=f_{j}$ for any $f_{j} \in F$, then $\bar{Y}_{i, K_{i}} \in\left[\frac{f_{j-1}+f_{j}}{2}, \frac{f_{j}+f_{j+1}}{2}\right]$ and the uncertainty about $\bar{Y}_{i, K_{i}}$ is not small enough.

The interval $\left[\frac{f_{j-1}+f_{j}}{2}, \frac{f_{j}+f_{j+1}}{2}\right]$ corresponds to all the points for which $f_{j}$ is the closest focal point.

For simplicity, let us model the latent $\bar{Y}_{i, K_{i}}$ as a linear process with an additive error term, such that $\bar{Y}_{i, K_{i}}=\beta^{\prime} x_{i}+v_{i}$. Our main interest is in recovering the parameter estimates of $\beta$.

From our behavioral response model in Section 5.2 we know that $v_{i} \sim N\left(0, \sigma_{\bar{Y}_{i, K_{i}}}^{2}\right)$ and is independently distributed across $i$. Recall that $\sigma_{\bar{Y}_{i, K_{i}}}^{2}$ decreases in $K_{i}$, the number of introspective draws, and that those draws are Poisson distributed with mean $\phi^{\prime} z_{i}$, where $z_{i}$ is a set of observable characteristics that are related to the introspection process. We will model this heteroscedasticity as multiplicative, so that $\sigma_{\bar{Y}_{i, K_{i}}}^{2}\left(z_{i} ; \phi\right)=e^{\phi^{\prime} z_{i}}$. The parameter estimates of $\phi$ will inform us about which characteristics influence the introspection process. Under these assumptions, we can write the log-likelihood of our model as

$$
\begin{aligned}
\ln L=- & \frac{1}{2} \sum_{\hat{Y}_{i} \notin F} w_{i}\left\{\left(\frac{\hat{Y}_{i}-\beta^{\prime} x_{i}}{e^{\frac{\phi^{\prime} z_{i}}{2}}}\right)^{2}+\log 2 \pi e^{\phi^{\prime} z_{i}}\right\} \\
& +\sum_{\hat{Y}_{i} \in F} w_{i} \log \left\{\Phi\left(\frac{\frac{f_{j}+f_{j+1}}{2}-\beta^{\prime} x_{i}}{e^{\frac{\phi^{\prime} z_{i}}{2}}}\right)-\Phi\left(\frac{\frac{f_{j-1}+f_{j}}{2}-\beta^{\prime} x_{i}}{e^{\frac{\phi^{\prime} z_{i}}{2}}}\right)\right\},
\end{aligned}
$$

where $\Phi(\cdot)$ is the CDF of the Normal distribution. In this log-likelihood the characteristics $x_{i}$ and $z_{i}$, the reported $\hat{Y}_{i}$, and the focal points $f_{j}$ and $f_{j+1}$ are all observed, and the parameters $\beta$ and $\phi$ can be estimated via the usual maximization.

This log-likelihood maximization corresponds directly to estimating a heteroscedastic interval regression where the dependent variable is transformed to an interval with a lower bound $Y_{L}^{\text {int }}$ and an upper bound $Y_{U}^{\text {int }}$ as described below:

$$
\begin{gathered}
Y_{L}^{i n t}= \begin{cases}\hat{Y} & \text { for } \hat{Y} \notin F, \\
\frac{f_{j-1}+f_{j}}{2} & \text { for } \hat{Y} \in F,\end{cases} \\
Y_{U}^{i n t}= \begin{cases}\hat{Y} & \text { for } \hat{Y} \notin F, \\
\frac{f_{j}+f_{j+1}}{2} & \text { for } \hat{Y} \in F .\end{cases}
\end{gathered}
$$

Packages that estimate heteroscedastic interval regressions can be readily found in most statistical software.

\subsection{Simulations}

In this section we use Monte Carlo simulations to show the performance and limitations of our approach. We evaluate our methodology based on varying four different key aspects 
to our model: the variance of the outcome explained by the regressors (i.e., the fit of $\beta^{\prime} x_{i}$ on $\bar{Y}_{i}$ ), the variance of the heteroscedasticity explained by our observable characteristics (i.e., the fit of $\phi^{\prime} z_{i}$ on $\ln (\sigma)$ ), the proportion of responses that are focal, and the number of focal points in the distribution of the reported values $\hat{Y}_{i}$.

\subsubsection{The DGP and estimation strategy}

We simulate our data under the following Data Generating Process (DGP):

$$
\begin{aligned}
\bar{Y} & =\beta_{0}+\beta_{1} x+\varepsilon_{1} e^{\phi_{0}+\phi_{1} z+\varepsilon_{2}} \\
x & \sim N(0, p) \\
\varepsilon_{1} & \sim N(0,1-p) \\
z & \sim N(0, q) \\
\varepsilon_{2} & \sim N(0,1-q) \\
p, q & \in[0,1],
\end{aligned}
$$

where $\varepsilon_{1}$ is the heteroscedastic error term. We use $p$ and $q$ to link the proportion of the variance of $\bar{Y}$ and its heteroscedasticity explained by $x$ and $z$, respectively. In our simulations $x$ and $z$ are two uncorrelated single-variable vectors. ${ }^{9}$

The focal points in the distribution of $\bar{Y}$ are assumed to be evenly spread across its domain (the most prevalent case in survey data). The reported values, $\hat{Y}$, which display probability masses at the focal points are generated as

$$
\hat{Y}= \begin{cases}\bar{Y} & \text { if } f_{j} \notin\left[\bar{y}-\left(\left(\frac{1}{\gamma}-1\right) e^{\phi_{0}+\phi_{1} z+\varepsilon_{2}}\right), \bar{y}+\left(\left(\frac{1}{\gamma}-1\right) e^{\phi_{0}+\phi_{1} z+\varepsilon_{2}}\right)\right] \\ f_{j} & \text { if } f_{j} \in\left[\bar{y}-\left(\left(\frac{1}{\gamma}-1\right) e^{\phi_{0}+\phi_{1} z+\varepsilon_{2}}\right), \bar{y}+\left(\left(\frac{1}{\gamma}-1\right) e^{\phi_{0}+\phi_{1} z+\varepsilon_{2}}\right)\right],\end{cases}
$$

where $f_{j} \in F=f_{1}, \ldots, f_{J}$ is the focal point closest to $\bar{Y}$, and $\gamma \in(0,1]$ is as defined in Section 5.2.3 and captures the strength of focality. We are mainly interested in correctly estimating $\beta_{1}$ from the observed data on $\hat{Y}, x$, and $z$.

In our exercise we are interested in the performance of a heteroscedastic interval regression of $Y^{i n t}$ on $x$ where $z$ enters as a determinant of the heteroscedasticity. $Y^{\text {int }}$ is an interval; a modified version of the observed $\hat{Y}$ that includes a single point or a range of possible points, dependent on whether the answer is a focal point or not. This transformation is performed as described in Equations (5.7) and (5.8).

We maximize the likelihood function in Equation (5.6) using $Y^{\text {int }}$ as the dependent variable, $x$ as the linear regressor, and $z$ as an explanatory variable for the heteroscedasticity. The competing alternative we consider here is naïve OLS, which just ignores the focal point issue and regresses $\hat{Y}$ on $x$.

\footnotetext{
${ }^{9}$ We explore the impact of overlapping elements in $x$ and $z$ and further investigate the issue of model misspecification in Section 5.4.8.
} 
For this horse race we vary one by one the simulation parameters $p, q, \gamma$, and the number of focal points in $F$. Throughout we assume the error terms and regressors to be all independent of one another, set $\phi_{0}=\beta_{0}=0$ and $\phi_{1}=\beta_{1}=1$, and set the sample size to $N=5,000$ since at the moment we are not concerned with the small sample performance of our estimator. If not mentioned otherwise we take a distribution with 3 symmetric focal points.

\subsubsection{Strength of focality}

There is considerable heterogeneity in the level of focality among survey questions. Intuitively we expect that a larger share of focal answers poses a more severe problem to the naïve OLS. We thus start our simulation exercise by analyzing the performance of both competing estimators for different strengths of focality.

Figure 5.2 shows the performance of the estimators for different strengths of focality in the distribution of $\hat{Y}$, as captured by the parameter $\gamma$. Recall that $\gamma$ varies between zero (only focal answers reported) and one (no focal answers reported). This is arguably the most relevant parameter in our analyses since it informs us of the direct impact of the presence of focal points on the naïve OLS estimator, and how far can our interval regression method correct for it.

The figure shows a significant bias of the OLS estimator for almost all cases where focal points can be considered an issue. This is in striking contrast with the performance of the interval regression, which provides estimates very close to the true coefficients at all levels of introspection. Figure 5.2 provides a very clear depiction of the returns to using interval regression for analyzing data with prevalent focal points.

\subsubsection{Number of focal points}

Different types of questions allow for a varying amount of focal points. We now investigate how the number of focal points influences the efficiency of our estimator over the naïve OLS. Figure 5.3 shows the performance of the estimators for different numbers of focal points in the distribution. The result of increasing the number of focal points in a distribution bares resemblance to increasing the strength of focality (decreasing $\gamma$ ) in the sense that it increases the total share of answers that are focal. It differs in that these focal answers are now spread across the entire distribution and thus it could have different implications for the performance of the estimators. Nevertheless, the result is similar: the more focal points there are in the distribution of $\bar{Y}$, the worse the naïve OLS performs in comparison to the interval regression. The performance of the interval regression estimator is not really affected by the number of focal points it needs to accommodate; in fact, it even seems to improve as they increase. This result is likely also driven by the fact that more focal points mean more distortion in the variation used by naïve OLS while at the same time meaning more information that the interval regression conditional heteroscedasticity can use to correct the estimates. 




Figure 5.2: Relative performance of estimators for different strengths of focality 


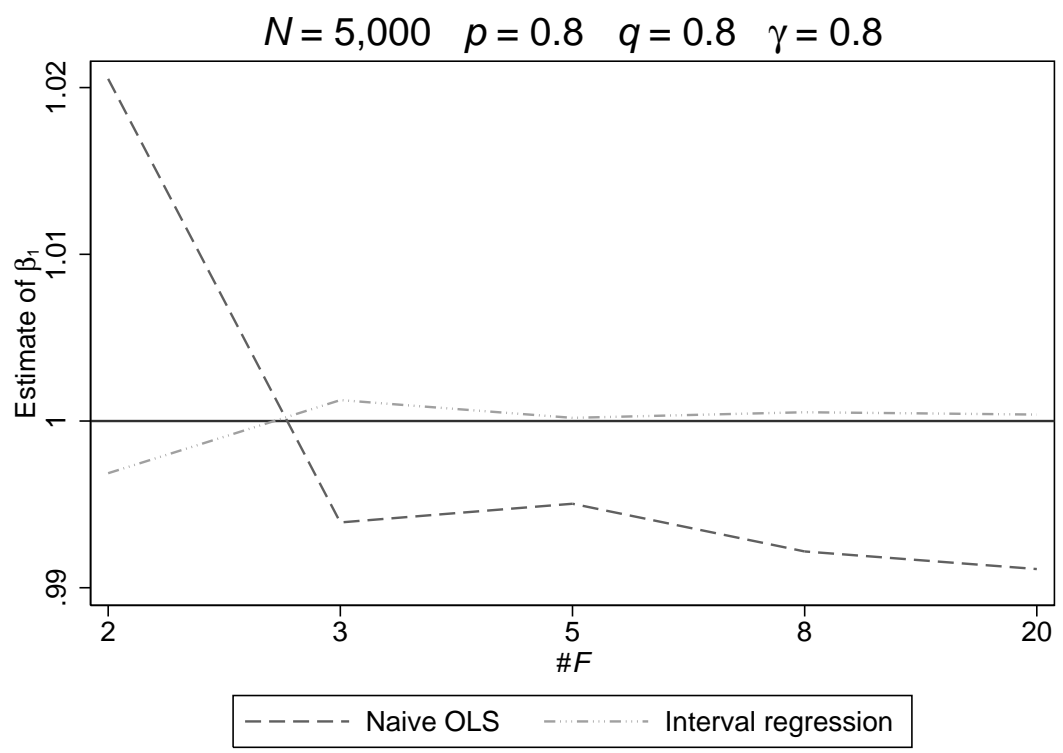

Figure 5.3: Relative performance of estimators for different number of focal points in the distribution 


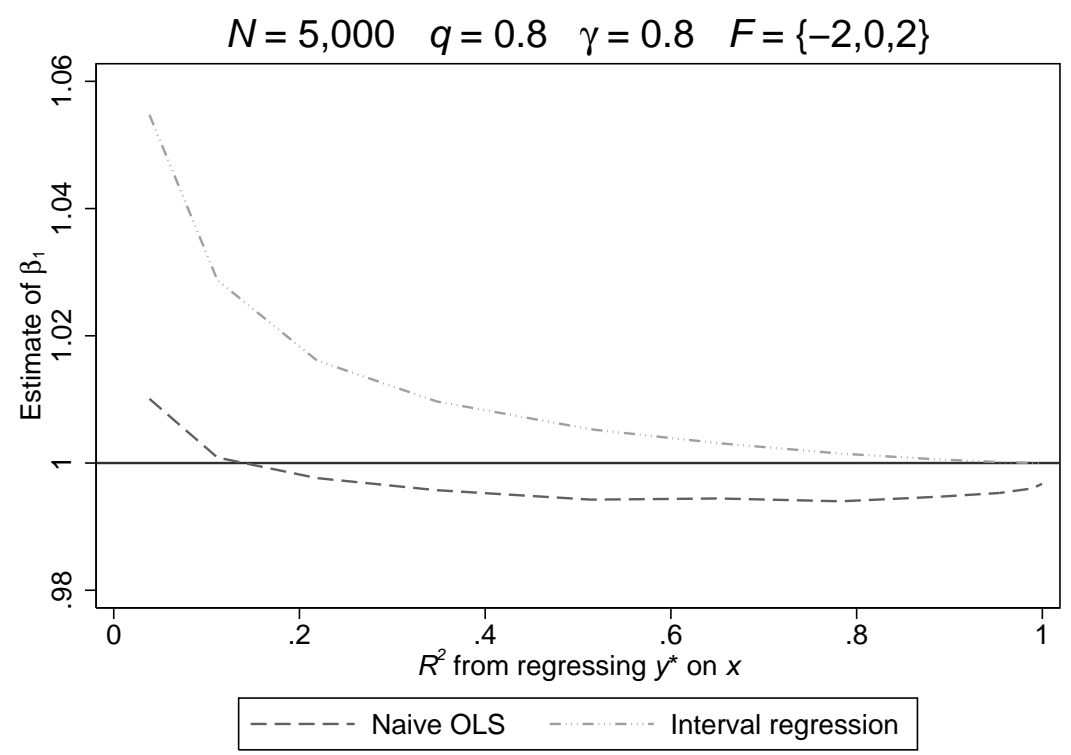

Figure 5.4: Relative performance of estimators for different $R^{2}$ of $\bar{Y}$ on $x$

\subsubsection{Explained Variance}

We now turn to analyzing the performance of both competing estimators for the whole range of explained variance of the underlying $\bar{Y}$ by the regressors. We modify this in our simulations by varying the parameter $p$, which links the variance of $x$ to the variance of the error term $\varepsilon_{1}$. This simulation will essentially inform us about the performance of our method in regressions with varying degrees of $R^{2} \mathrm{~s} .{ }^{10}$

Figure 5.4 shows the relative performance of both estimators and illustrates several important findings. First, the performance of both the naïve OLS and the interval regression improve as the latent $R^{2}$ increases, but the interval regression estimate strongly tends to the true $\beta_{1}$ whereas the naïve OLS remains biased. Second, the bias of both estimators can be substantial for very low values of the $R^{2}$. Third, it would seem that the OLS systematically undershoots the true coefficient whereas the interval regression overshoots it, thus tempting us to conclude that they provide bounds. However, this is misleading. This pattern in Figure 5.4 stems from the particular choice of parameters; in extensive unreported analyses we see that the true coefficient can also fall outside of these apparent bounds.

\footnotetext{
${ }^{10}$ While this measure is not directly observable, the $R^{2}$ of regressing $\hat{Y}$ on $x$ will be a good proxy for it in most cases. See Section 5.4.7 for further details on this.
} 


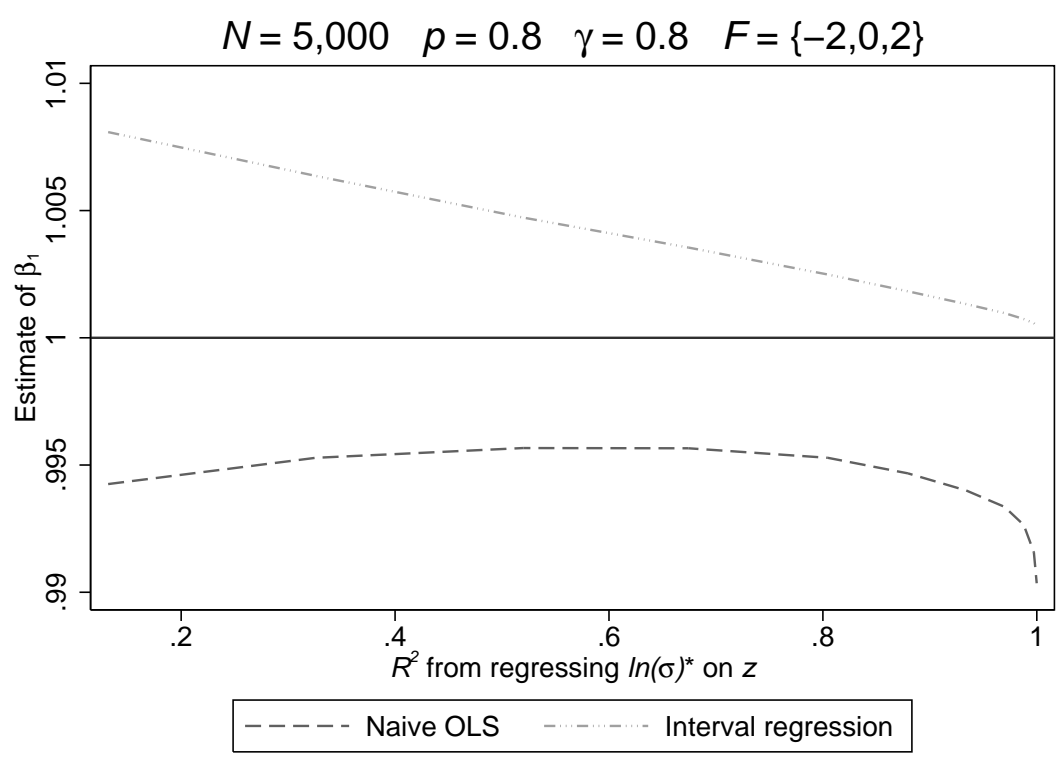

Figure 5.5: Relative performance of estimators for different $R^{2}$ of $\operatorname{Var}[\bar{Y}]$ on $z$

\subsubsection{Explained Heteroscedasticity}

We continue by showing the performance of both estimators for different values of the explained variation of $\bar{Y}$ - the explained heteroscedasticity. Figure 5.5 shows that, as expected, the interval regression gains precision when the heteroscedasticity is well explained by the observables in $z$. In these cases the heteroscedasticity parameters manage to accurately capture the conditional variance best, and therefore make the best use of the information in the focal observations. Also as expected, the bias of the naïve OLS estimator does not depend on the explained heteroscedasticity, except in the very extremes. Figure 5.6 illustrates the precision (as measured by the average standard error of the $\beta_{1}$ estimate) of the two estimators for $\beta_{1}$. The naïve OLS remains worse than the precision of the interval regression throughout, and the precision of the latter increases as more of the variance is explained by $z$, given the assumed values of the other parameters in this simulation.

\subsection{6 $\gamma$ and $p$ combinations}

So far we have shown simulation examples in which we let one of the parameters of the simulation vary while keeping the others constant. One could also question for which 


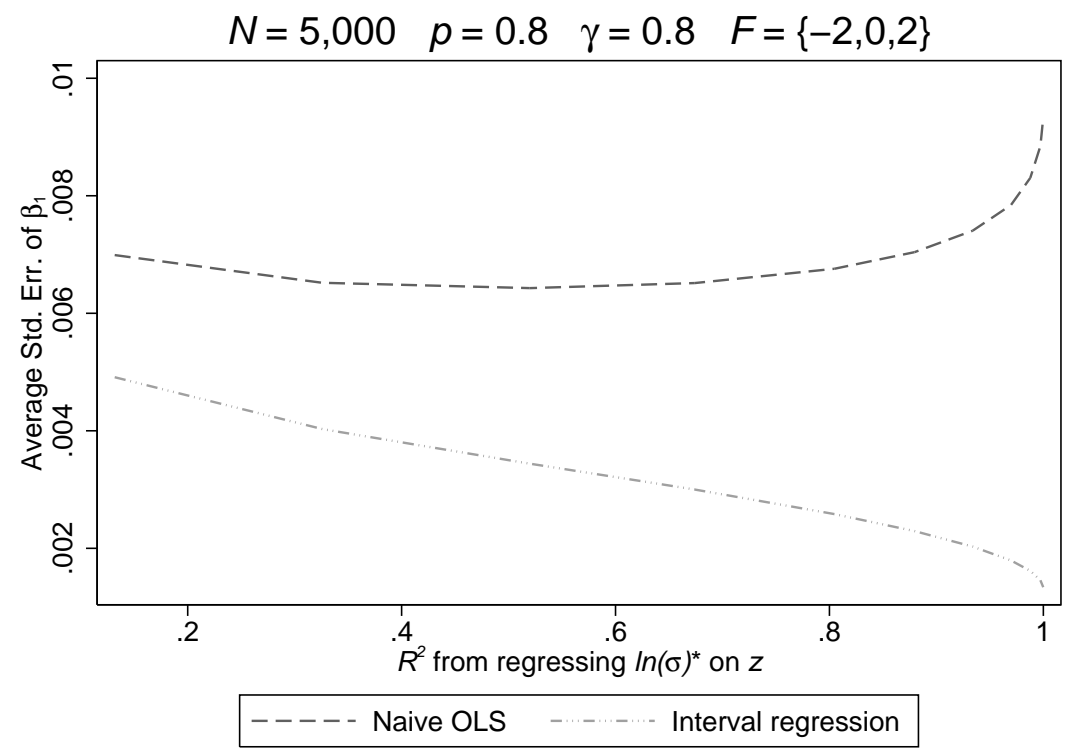

Figure 5.6: Relative precision of estimators for different $R^{2}$ of $\operatorname{Var}[\bar{Y}]$ on $z$ 


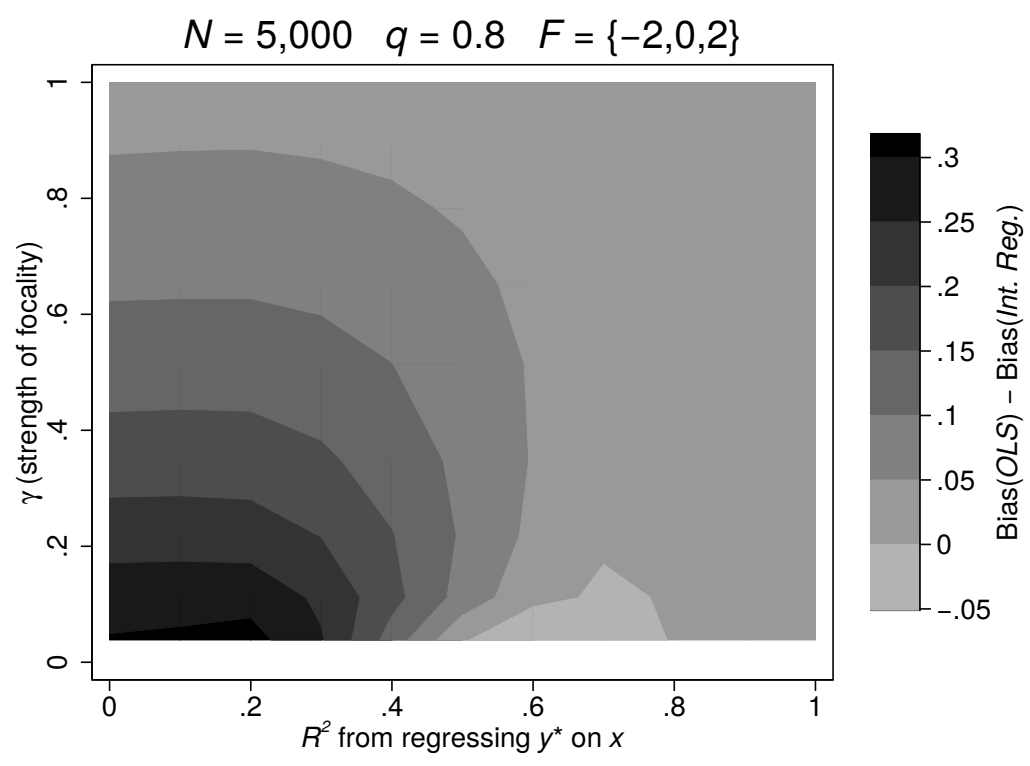

Figure 5.7: Relative performance of estimators for different strength of focality $(1-\gamma)$ and explained variance of $\bar{Y}$ by $x$

combination of parameter values the interval regression improves over the naïve OLS. Since we are mainly concerned in the variation of four parameters, a complete answer to this question would involve presenting our data in an intricate and likely unintelligible way. However, in Figure 5.7 we do show the relative performance of naïve OLS versus interval regression for the full range of strength of focality and explained variance of $\bar{Y}$.

Figure 5.7 shows the absolute bias in the naïve OLS estimator in excess of the absolute bias in the interval regression estimator $\left(\left|\beta_{1}^{O L S}-1\right|-\left|\beta_{1}^{I N T}-1\right|\right)$ as a function of the strength of focality $(1-\gamma)$, and the share of variance of $\bar{Y}$ explained by $x$ (governed by the parameter $p$ ). Darker areas in the contour plot represent value combinations for which naïve OLS performs worse than interval regression. Interval regression outperforms naïve OLS in all but the brightest gray area. This effectively means that it will be better to use the interval regression method for all but the most mild cases of focality in the data, as long as the explained variance of the dependent variable does not exceed 0.6-which is the most common case when using survey data. Moreover, since the true value of $\beta_{1}$ is one, the size of the difference can be interpreted as the percentage bias of naïve OLS over interval regression (i.e., an excess bias of 0.3 means that the naïve OLS bias is 30 percent larger than the interval regression bias). The figure shows that for a large array of levels of introspection and explained variance interval regression outperforms naïve OLS, and often by an important margin. 


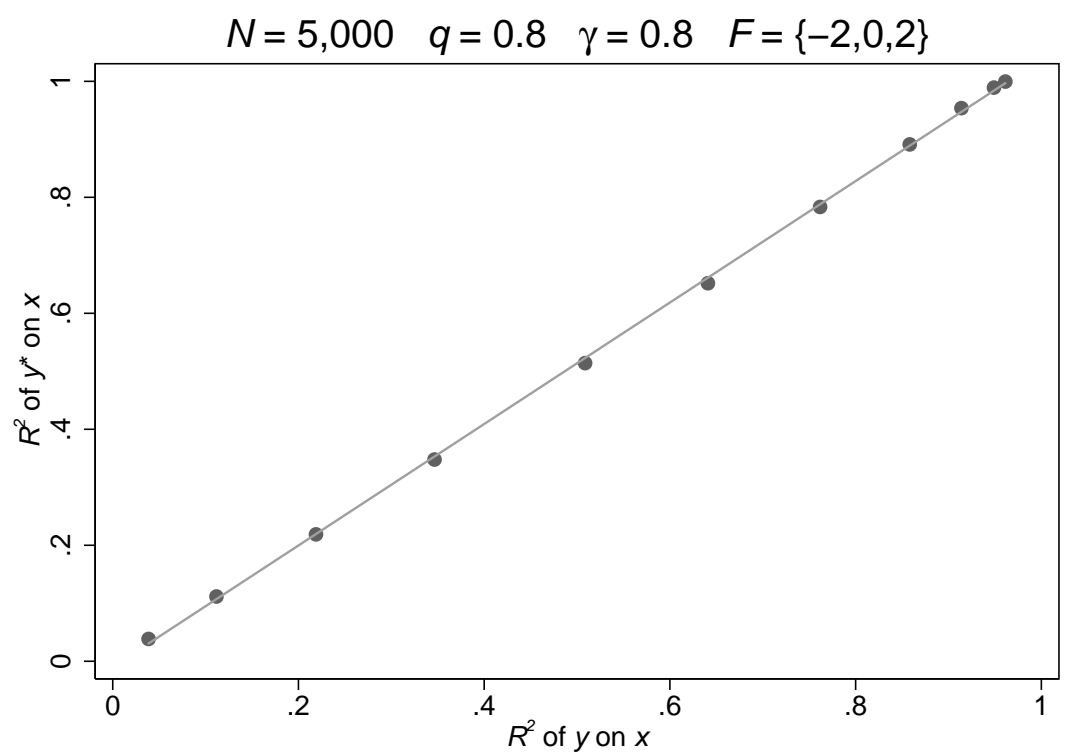

Figure 5.8: Correspondence between the unobserved $R^{2}$ of $\bar{Y}$ on $X_{i}$ and the observed $R^{2}$ of $\hat{Y}$ on $x$

\subsubsection{Extensions}

An important consideration is that, for pinpointing the relative accuracy of interval regression in an empirical setting, we require observable estimates of the parameters that we vary and analyze throughout this section. While all of these parameters are unobserved, we can construct proxy measures for them and calibrate these proxies via further simulations.

A natural proxy for the variation of the latent $\bar{Y}$ explained by $x$ is the $R^{2}$ of regressing the observed $\hat{Y}$ on $x$. In Figure 5.8 we show that the two values closely correspond to each other. A proxy for the variation of the latent $\operatorname{Var}[\bar{Y}]$ explained by $z$ is harder to construct, but a candidate is the $R^{2}$ of regressing $\ln \left(\hat{r}^{2}\right)$ on $z$, where $\hat{r}$ is the residual from the regression of the observed $\hat{Y}$ on $x$. This is in the spirit of the Breusch and Pagan (1979) test. This $R^{2}$ will inevitably fall short of the theoretically explained variance of $\operatorname{Var}[\bar{Y}]$ by $z$ because an important part of $\ln \left(\hat{r}^{2}\right)$ is also the unsystematic variation of the error term of $\hat{Y}$. Nevertheless, in Figure 5.9 we show that there is a non-linear correspondence between this proxy and the underlying $R^{2}$ that can be well approximated by a quadratic function. ${ }^{11}$

\footnotetext{
${ }^{11}$ The exact function that approximates the values in Figure 5.9 is $R_{\text {unobserved }}^{2}=-0.08+4.67 R_{\text {observed }}^{2}-$ $4.99\left(R_{\text {observed }}^{2}\right)^{2}$.
} 


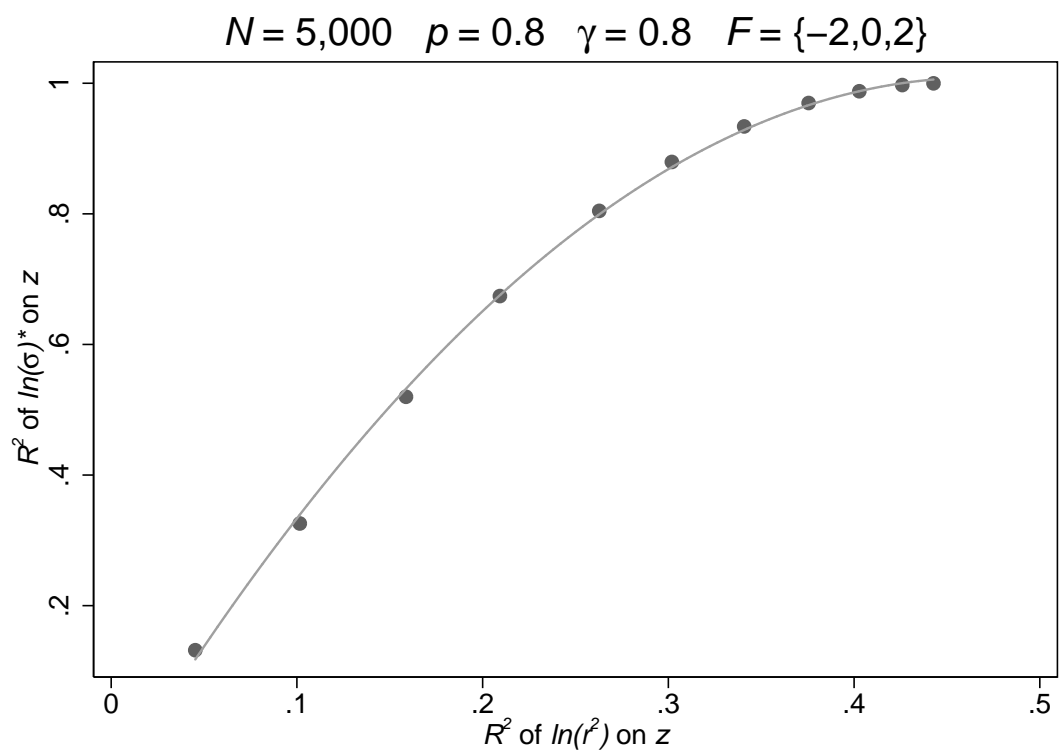

Figure 5.9: Correspondence between the unobserved $R^{2}$ of $\ln \sigma^{2}$ on $z$ and the observed $R^{2}$ of $\ln \left(\hat{r}^{2}\right)$ on $z$ 


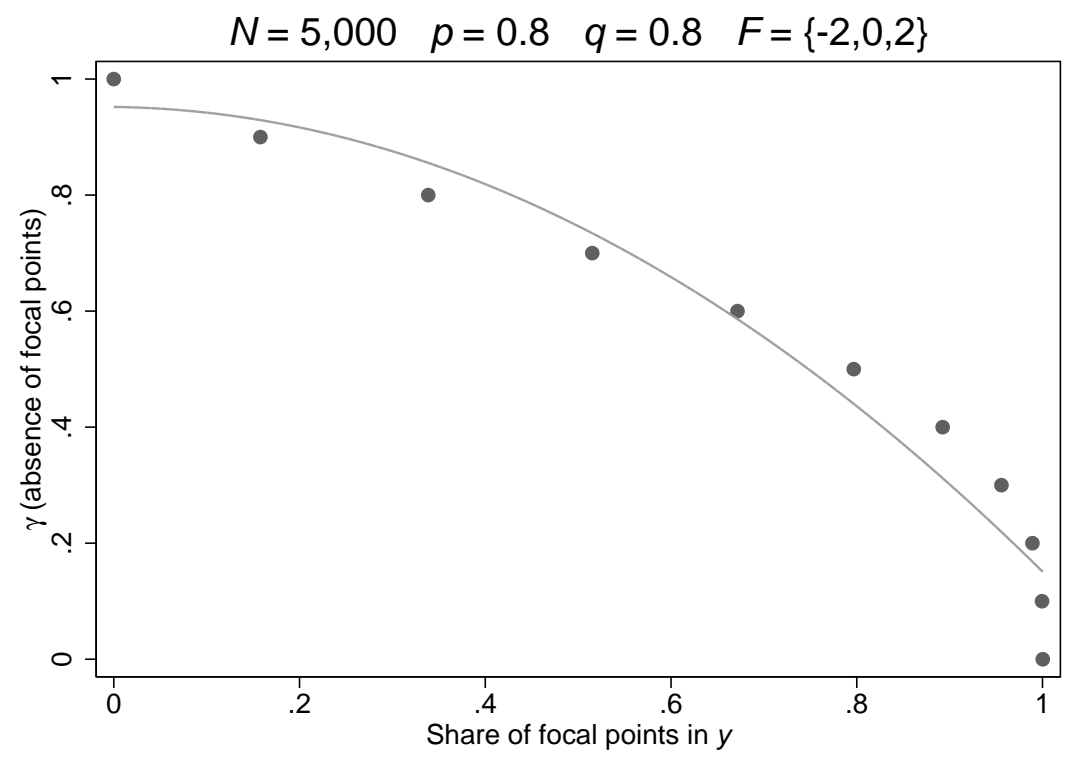

Figure 5.10: Correspondence between the unobserved $\gamma$ (absence of focal points) and the observed share of focal points in the distribution of $\hat{Y}$

A proxy for $\gamma$ can be constructed by observing the share of focal answers to the total answers. Figure 5.10 shows the correspondence between these two measures. Even though the proportion of focal points in the distribution is not directly measuring $\gamma$, it is informative of its level and we can use these results for mapping too. The mapping is highly non-linear, but it can be approximated using simple interpolation or fitting a fractional polynomial function.

Approximating the number of focal points in the distribution of $\hat{Y}$ is simpler, since it is readily observable from the survey data and, in most cases, it presents clearly. However, there will always be a degree of subjectivity in this process. Overall, we show that there are direct ways in which we can measure the parameters describing the severity of focal points in the distribution of a survey question, and that determine whether interval regression will improve over using naïve OLS methods.

\subsubsection{Robustness to model misspecification}

Our method, as described and evaluated above, assumes that we can correctly model the main equation. From this follows that the heteroscedasticity parameters can correctly identify the drivers of focality. However, in empirical estimations of heteroscedastic models when the main model is misspecified the heteroscedasticity can often no longer 
be modeled correctly. In our setting, this implies that we can only identify the drivers of focality if we correctly specify the main equation. What does that imply for the robustness of our model?

The first noteworthy remark on this issue is that even if the heteroscedasticity cannot be correctly modeled, the interval regression estimates of the main model parameters still outperform naïve OLS. We confirm this in additional simulations. This occurs because being agnostic about the nature of focal answers and allowing for heteroscedasticity to be related to whether a focal answer was provided or not (even if this heteroscedasticity is not correctly modeled) already does better in capturing the nature of focal response.

Based on this intuition we can construct a simpler interval regression model that acknowledges the limitations of properly modeling the heteroscedasticity with the information we usually have, while at the same time still outperforming naïve OLS. It further provides a formal test for the presence of introspection-based focal answering. This simplified model forgoes the ability to model the heteroscedasticity in the data but allows for two different variance parameters in the latent answers to be estimated: the variance of uncensored answers and the variance of focal (censored) answers: Thus, the model maximizes the following modified version of the likelihood function described in (5.6):

$$
\begin{aligned}
\ln L=- & \frac{1}{2} \sum_{\hat{Y}_{i} \notin F} w_{i}\left\{\left(\frac{\hat{Y}_{i}-\beta^{\prime} x_{i}}{\sigma_{\text {uncensored }}}\right)^{2}+\log 2 \pi \sigma_{\text {uncensored }}^{2}\right\} \\
& +\sum_{\hat{Y}_{i} \in F} w_{i} \log \left\{\Phi\left(\frac{\frac{f_{j-1}+f_{j}}{2}-\beta^{\prime} x_{i}}{\sigma_{\text {focal }}}\right)-\Phi\left(\frac{\frac{f_{j}+f_{j+1}}{2}-\beta^{\prime} x_{i}}{\sigma_{\text {focal }}}\right)\right\} .
\end{aligned}
$$

This model forgoes the ability to identify the drivers of focality based on the heteroscedasticity in favor of robustness and the ability to test whether there is evidence of our introspection-based focal answering. In the presence of introspection-based focal answering, the variance of the underlying latent variable for focal answers $\left(\sigma_{\text {focal }}^{2}\right)$ should exceed the variance of the underlying latent variable for the uncensored answers ( $\sigma_{\text {uncesnored }}^{2}$ ). Thus, the test would compare the null hypothesis of $H_{0}: \sigma_{\text {focal }}^{2}=\sigma_{\text {uncensored }}^{2}$ to the alternative hypothesis of $H_{1}: \sigma_{\text {focal }}^{2}>\sigma_{\text {uncensored }}^{2}$. This test can easily be constructed from the parameter estimates as a one-sided non-linear Wald test or a Likelihood Ratio test. Additional simulations confirm that 1) the estimates of this simplified model still outperform naïve OLS; 2) they do so even in the presence of a misspecified main equation; and 3) they are able to detect the presence of introspection-based focal answering. $^{12}$

\subsection{Discussion}

Starting from a behavioral model of survey response, we postulate a theory of how focal answers come about in survey data. We investigate how we can use the information in

\footnotetext{
${ }^{12}$ These results are available upon request.
} 
focal responses to obtain better population parameter estimates and to identify the drivers of these focal responses. The intuitions from our behavioral response model lead us to consider heteroscedasticity as a way to identify the factors driving focal answering. Econometrically, we show that estimating this heteroscedasticity and incorporating it into the main equation estimator improves the identification of our population parameters. This estimation method is not complex; as discussed in this paper it is nothing more than an heteroscedastic interval regression on an appropriately-adjusted dependent variable.

With extensive Monte Carlo simulations, we show that the heteroscedastic interval regression outperforms the naïve OLS (which ignores the problem of focal points altogether) in many cases. We point out the situations in which the interval regression is likely to provide better estimates, and suggest several indicators that can be estimated from typical survey data. Although our method still relies on making parametric assumptions about the latent variable (that is measured through survey questions) simulations show that our methodology often yields very useful estimates and an improvement over the naïve OLS. Due to its simplicity it could be more broadly applied than many existing alternatives to estimation with rounded data.

Our current results can be extended in various important ways. We have so far only analyzed the performance of single-regressor models in the simulations, with symmetric distributions of both the latent survey-measured variable and the focal points. In a number of empirical applications however, including wage regressions and self-reported measures of economic preferences, there are notable asymmetries. Further, in some cases not all the focal points have the same catchment area, but there is a hierarchical structure of more and less important focal points. Modeling and evaluating the performance of our heteroscedastic interval regression on these outcomes could have important implications for researchers using these survey data. Given the way our method responds to the strength of focality, we expect it to shine in these situations. The true value of our method is, however, in its simplicity. Focal responses and rounding haunt most micro-economists working with survey data. What we propose is a simple and intuitive way to not only correct for it but to learn from it too.

Finally, the most important addition to this project will be an empirical part, where we provide empirical examples of how the estimators can be improved and what we can learn about individuals by analyzing the type of their answer. We are currently working on an extension of the multivariate case with correlated regressors, which is a necessary basis for the empirical example. 


\subsection{Appendix}

\section{Variance of $\bar{Y}_{i, K_{i}}$}

We show that the variance of $\bar{Y}_{i, K_{i}}$ decreases in $\lambda_{i}$, the mean of the Poisson process driving $K_{i}$.

$$
\begin{aligned}
\operatorname{Var}\left[\bar{Y}_{i, K_{i}}\right] & =\operatorname{Var}\left[\frac{1}{K_{i}} \sum_{k=1}^{K_{i}} \varepsilon_{i, k}\right] \\
& =\mathrm{E}\left[\left(\sum_{k=1}^{K_{i}} \frac{\varepsilon_{i, k}}{K_{i}}\right)^{2}\right] \\
& =\sum_{d=1}^{\infty}\left(\frac{\lambda_{i}^{d-1}}{(d-1) !} e^{-\lambda_{i}} \mathrm{E}\left[\frac{\left(\sum_{k=1}^{d} \varepsilon_{i, k}\right)^{2}}{d^{2}}\right]\right)
\end{aligned}
$$

with $\frac{x^{d-1}}{(d-1) !} e^{-x}$ being the CMF of the Poisson process, and $d$ being the number of draws. Within the sum, $d$ is known and thus the only random variable is $\varepsilon_{i, k}$, which is iid by assumption. Expanding the sum of squares,

$$
\begin{aligned}
& =\sum_{d=1}^{\infty}\left(\frac{\lambda_{i}^{d-1}}{(d-1) !} e^{-\lambda_{i}} \frac{1}{d^{2}} \mathrm{E}\left[\sum_{k=1}^{d} \varepsilon_{i, k}^{2}+2 \sum_{\substack{k=1 \\
k<m}}^{d} \varepsilon_{i, k} \varepsilon_{i, m}\right]\right) \\
& =\sum_{d=1}^{\infty}\left(\frac{\lambda_{i}^{d-1}}{(d-1) ! d} e^{-\lambda_{i}} \operatorname{Var}\left[\varepsilon_{i, k}\right]\right) \\
& =\frac{\operatorname{Var}\left[\varepsilon_{i, k}\right]}{\lambda_{i}} e^{-\lambda_{i}} \sum_{d=1}^{\infty}\left(\frac{\lambda_{i}^{d}}{d !}\right) \\
& =\frac{\operatorname{Var}\left[\varepsilon_{i, k}\right]}{\lambda_{i}} e^{-\lambda_{i}}\left(e_{i}^{\lambda}-1\right) \\
& =\frac{\operatorname{Var}\left[\varepsilon_{i, k}\right]}{\lambda_{i}}\left(1-e^{-\lambda_{i}}\right)
\end{aligned}
$$

The first derivative of $\operatorname{Var}\left[\bar{Y}_{i, K_{i}}\right]$ with respect to $\lambda_{i}$ is

$$
\frac{\partial \operatorname{Var}\left[\bar{Y}_{i, K_{i}}\right]}{\partial \lambda_{i}}=\operatorname{Var}\left[\varepsilon_{i, k}\right] e^{-\lambda_{i}}\left(\frac{1}{\lambda_{i}}+\frac{1-e_{i}^{\lambda}}{\lambda_{i}^{2}}\right) .
$$

For $\lambda_{i}>0$ and bounded $\operatorname{Var}\left[\varepsilon_{i, k}\right]$ this derivative is always negative. 


\section{Chapter 6}

\section{Conclusion}

To understand heterogeneity in human behavior and decision making we have to know more about the underlying preferences. We have to know more about where preferences come from and how they are linked to behavior and decisions. This field is active and developing, and the papers in this thesis add to the growing picture.

I started with investigating the origins of preferences in Chapter 2. I found that parents who invest more in their children have children who are more similar to them with respect to risk and trust attitudes. This supports an important channel which is often assumed to be there, but hard to show in general (specific investments have been shown to have an impact). These findings are very interesting and important for a better understanding of social mobility. Policies that aim at facilitating social mobility have to take into account that not only external constraints, such as limited access to financial resources, but also preference based differences hinder social mobility, and by that perpetuate inequality. For example, acknowledging that there is transmission of preferences helps to understand why financial support for students from low socio-economic backgrounds does not completely solve the problem of intergenerational transmission of education. However, while the results of the study help understand the options and limits of certain policies, we have to be cautious applying the results for direct policy advise. We showed that there is a relation between investments and the transmission of attitudes, but with our data we can not make sure that this relation is causal. We cannot say that the parents we observe invest with the purpose of shaping their children nor can we clearly exclude that other factors are driving the relationship. But even if we could show causality, building a direct policy advise on this study would be difficult. It is not clear which preferences are good - or better - for the individual and society. Additionally, paternalism might not be desirable. The value of this study has thus to be seen in its contribution to the study of preferences, as a segment of a complex system, that helps us understanding human behavior and adjusting policies better.

For the findings of chapter 2 to be relevant to economists, preferences need to have an impact on how people structure their (economic) environment. While it is out of doubt that preferences do play an important role, the empirical evidence on how and which 
preferences influence different economic outcomes, such as labor market outcomes or educational choices, is still far from being complete. In chapter 3 I investigated a piece of the puzzle which is both, affected by preferences and in turn also relevant for the formation of preferences. I investigated how a particular preference, negative reciprocity, influences the formation and stability of a partnership. I found that like-minded individuals are more likely to form a relationship and to stay together. An important insight of the model, supported by the empirical evidence, is that not only individual preferences matter, but also the combination of preferences in a partnership is an important factor in the behavior of the group. This could have implications beyond the very specific setting of the model. It could for example explain firm culture, through selection but also exit decisions of not fitting employees. Further, the finding of positive assortative mating has an impact on the formation of preferences of the children of a couple. It makes the intergenerational transmission of preferences easier for each of the two parents, since they are reinforcing each other in the process. This in turn is important for the study of social mobility, as pointed out above.

At the core of many economic models and predictions there are assumptions about the preferences of individuals, frequently preferences are assumed to be stable. This assumption is often too strict, but to know what impact this discrepancy between the reality and the models has on the predictive power of the model, we need to understand to what extent economic preferences are stable. If they are malleable, it is important to know what the underlying factors are that make them change. Knowing which events in the lives of individuals or in their environment have an impact on their preferences helps to design better policies. It allows to predict confounding or augmenting effects in the reaction to policies that are due to a change in attitudes or preferences of the target group. Likewise it can help predict changes in behavior after external events, such as the financial crisis. On a different side the knowledge about the drivers of preference changes could also be used to time policies (e.g. offer insurance or pension saving plans to the parents of a new born child, using the increase in risk aversion that goes along with the birth of a child.) In chapter 4 I showed in a panel analysis that within individual changes in risk attitudes are related changes in economic news reports. The study captures that changes in the level of news over a longer period (one year) have stronger effects than over shorter periods. An important additional finding is that the strength of the relation (mainly for the longer period news measurements) differ by demographics and personality traits. The finding that events can have long lasting impacts on preferences, which was also shown in previous studies, e.g. helps understanding cohort differences in investment behavior. The study in this thesis strengthens previous findings that were cross-sectional by documenting the effects on within individual changes.

Finally, to empirically do research on or with preferences or attitudes, we need to be able to measure them. Given the complex nature of many research questions that involve preferences, and that often the explained variance of the respective models is very low and the effects of single preferences are small, it is crucial for the researcher to have a sufficiently large number of observations. This is most easily reached by using survey questions and simply asking individuals about their preferences. Among several potential sources of measurement errors, focal points are one. In chapter 5 I presented a model in 
which I show how uncertainty can lead individuals to resort to focal answers. Based on this model I suggested a simple empirical method that not only improves the estimator for the independent variables, but also allows to learn more about the individuals, based on their answering behavior. This method should allow applied economists to make more precise estimations in case of focal response, with very little extra requirements on their data. Additionally the insight from the model of survey response could help to design or embed particular survey questions in such a way that the amount of focal responses is minimized.

While the studies on the four topics chapters are on separate topics and based on different literature, they all have the same goal, providing evidence or tools to increase our knowledge of the drivers of human behavior. Preferences are an extremely complex and fragmented field to research. The effects that can be found in this field are small and explain little variance by themselves, since so much plays together. But we can build a more complete picture by creating pieces of the puzzle and one by one combining them. This thesis attempts just that: Constructing and providing evidence for a bigger picture. 



\section{Bibliography}

Alesina, A. and La Ferrara, E. (2002). Who trusts others? Journal of Public Economics, 85(2):207-234.

Almlund, M., Duckworth, A. L., Heckman, J., and Kautz, T. (2011). Personality psychology and economics. Handbook of the economics of education, 4(1):1-181.

Andersen, S., Harrison, G. W., Lau, M. I., and Rutström, E. (2008). Lost in state space: Are preferences stable? International Economic Review, 49(3):1091-1112.

Barsky, R. B., Juster, F. T., Kimball, M. S., and Shapiro, M. D. (1997). Preference parameters and behavioral heterogeneity: An experimental approach in the health and retirement study. The Quarterly Journal of Economics, 112(2):537-579.

Becker, A., Deckers, T., Dohmen, T., Falk, A., and Kosse, F. (2012). The relationship between economic preferences and psychological personality measures. Annual Review of Economics, 4(1):453-478.

Becker, G. (1974). A theory of marriage. In Economics of the family: Marriage, children, and human capital, pages 299-351. UMI.

Becker, G., Landes, E., and Michael, R. (1977). An economic analysis of marital instability. The Journal of Political Economy, 85:1141-1187.

Bisin, A. and Verdier, T. (2001). The economics of cultural transmission and the dynamics of preferences. Journal of Economic Theory, 97(2):298-319.

Björklund, A., Lindahl, L., and Lindquist, M. (2010). What more than parental income, education and occupation? An exploration of what Swedish siblings get from their parents. The BE Journal of Economic Analysis \& Policy, 10(1):102.

Björklund, A. and Salvanes, K. G. (2011). Education and family background: Mechanisms and policies. volume 3 of Handbook of the Economics of Education, chapter 3, pages 201-247. Elsevier.

Black, S. E. and Devereux, P. J. (2011). Recent developments in intergenerational mobility. Handbook of labor economics, 4:1487-1541. 
Borghans, L., Duckworth, A. L., Heckman, J. J., and Ter Weel, B. (2008). The economics and psychology of personality traits. Journal of Human Resources, 43(4):972-1059.

Bowles, S. and Gintis, H. (2002). The inheritance of inequality. The Journal of Economic Perspectives, 16(3):3-30.

Bowles, S. and Gintis, H. (2011). A cooperative species: Human reciprocity and its evolution. Princeton University Press.

Brachert, M. and Hyll, W. (2014). On the stability of perferences: Repercussions of entrepreneurship on risk attitudes. SOEPpapers 667-2014.

Breusch, T. S. and Pagan, A. R. (1979). A simple test for heteroscedasticity and random coefficient variation. Econometrica, 47(5):1287-1294.

Bruine de Bruin, W., Fischhoff, B., Millstein, S. G., and Halpern-Felsher, B. L. (2000). Verbal and Numerical Expressions of Probability: "It's a Fifty-Fifty Chance" . Organizational Behavior and Human Decision Processes, 81(1):115-131.

Bucciol, A. and Miniaci, R. (2013). Financial risk attitude, business cycles and perceived risk exposure. Netspar Discussion Paper 02/2013-050.

Butler, J., Giuliano, P., and Guiso, L. (2009). The right amount of trust. NBER Working Paper No. 15344.

Camerer, C. and Thaler, R. H. (1995). Anomalies: Ultimatums, dictators and manners. The Journal of Economic Perspectives, pages 209-219.

Carroll, R. J., Ruppert, D., and Stefanski, L. A. (1995). Measurement Error in Nonlinear Models, volume 105. CRC Press.

Cesarini, D., Dawes, C., Johannesson, M., Lichtenstein, P., and Wallace, B. (2009). Genetic variation in preferences for giving and risk taking. Quarterly Journal of Economics, 124(2):809-842.

Cho, I. S., Orazem, P. F., and Rosenblat, T. (2013). Are risk attitudes fixed factors or fleeting feelings? Iowa State University Working Paper, No. 13002.

Crocker, L. and Algina, J. (1986). Introduction to classical and modern test theory. Holt, Rinehart, and Winston.

Doepke, M. and Zilibotti, F. (2008). Occupational choice and the spirit of capitalism. The Quarterly Journal of Economics, 123(2):747-793.

Doepke, M. and Zilibotti, F. (2014). Parenting with style: Altruism and paternalism in intergenerational preference transmission. NBER Working Paper No. 20214.

Dohmen, T. (2014). Behavioral labor economics: Advances and future directions. Labour Economics, 30:71-85. 
Dohmen, T., Falk, A., Golsteyn, B. H., Huffman, D., and Sunde, U. (2014). Risk attitudes across the life course. Unpublished.

Dohmen, T., Falk, A., Huffman, D., and Sunde, U. (2006). Seemingly irrelevant events affect economic perceptions and expectations: The FIFA World Cup 2006 as a natural experiment. IZA Discussion Paper, No. 2275.

Dohmen, T., Falk, A., Huffman, D., and Sunde, U. (2009). Homo reciprocans: Survey evidence on behavioural outcomes*. The Economic Journal, 119(536):592-612.

Dohmen, T., Falk, A., Huffman, D., and Sunde, U. (2012). The intergenerational transmission of risk and trust attitudes. The Review of Economic Studies, 79(2):645677.

Dohmen, T., Falk, A., Huffman, D., Sunde, U., Schupp, J., and Wagner, G. G. (2011). Individual risk attitudes: Measurement, determinants, and behavioral consequences. Journal of the European Economic Association, 9(3):522-550.

Donkers, B., Melenberg, B., and Van Soest, A. (2001). Estimating risk attitudes using lotteries: A large sample approach. Journal of Risk and Uncertainty, 22(2):165-195.

Fehr, E., Fischbacher, U., and Gächter, S. (2002). Strong reciprocity, human cooperation, and the enforcement of social norms. Human nature, 13(1):1-25.

Fehr, E., Fischbacher, U., von Rosenbladt, B., Schupp, J., and Wagner, G. (2003). A nation-wide laboratory. Examining trust and trustworthiness by integrating behavioral experiments into representative survey. CESifo Working Paper Series.

Fehr, E. and Gächter, S. (2000). Cooperation and punishment in public goods experiments. American Economic Review, 90(4):980-994.

Fernandez, R. and Fogli, A. (2009). Culture: An empirical investigation of beliefs, work, and fertility. American Economic Journal: Macroeconomics, 1(1):146-177.

Gächter, S. and Herrmann, B. (2009). Reciprocity, culture and human cooperation: previous insights and a new cross-cultural experiment. Philosophical Transactions of the Royal Society B: Biological Sciences, 364(1518):791-806.

Garz, M. (2012). Job insecurity perceptions and media coverage of labor market policy. Journal of Labor Research, 33(4):528-544.

Gerlitz, J.-Y. and Schupp, J. (2005). Zur Erhebung der Big-Five-basierten Persoenlichkeitsmerkmale im SOEP. DIW Research Notes, No. 4.

Gintis, H. (2000). Strong reciprocity and human sociality. Journal of Theoretical Biology, 206(2):169-179.

Goldberg, L. R. (1993). The structure of phenotypic personality traits. American Psychologist, 48(1):26. 
Guiso, L., Sapienza, P., and Zingales, L. (2008). Alfred marshall lecture social capital as good culture. Journal of the European Economic Association, 6(2-3):295-320.

Guiso, L., Sapienza, P., and Zingales, L. (2013). Time varying risk aversion. NBER Working Paper, No. 19284.

Gürerk, Ö., Irlenbusch, B., and Rockenbach, B. (2006). The competitive advantage of sanctioning institutions. Science, 312(5770):108-111.

Hanaoka, C., Shigeoka, H., and Watanabe, Y. (2014). Do risk preferences change? Evidence from panel data before and after the great east Japan earthquake. SSRN Working Paper, id2543245.

Hartog, J., Ferrer-i Carbonell, A., and Jonker, N. (2002). Linking measured risk aversion to individual characteristics. Kyklos, 55(1):3-26.

Heckman, J. (2006). Skill formation and the economics of investing in disadvantaged children. Science, 312(5782):1900-1902.

Heckman, J. and Cunha, F. (2007). The technology of skill formation. American Economic Review, 97(2):31-47.

Heckman, J., Pinto, R., and Savelyev, P. (2013). Understanding the mechanisms through which an influential early childhood program boosted adult outcomes. American Economic Review, 103(6):2052-86.

Herrmann, B., Thöni, C., and Gächter, S. (2008). Antisocial punishment across societies. Science, 319(5868):1362-1367.

Hill, D., Perry, M., and Willis, R. J. (2004). Estimating knightian uncertainty from survival probability questions on the hrs. mimeo.

Hoderlein, S. and Winter, J. (2010). Structural measurement errors in nonseparable models. Journal of Econometrics, 157(2):432-440.

Holmlund, H., Lindahl, M., and Plug, E. (2011). The causal effect of parents' schooling on children's schooling: A comparison of estimation methods. Journal of Economic Literature, 49(3):615-651.

Hudomiet, P. and Willis, R. J. (2013). Estimating second order probability beliefs from subjective survival data. Decision Analysis, 10(2):152-170.

Jung, S. and Treibich, C. (2014). Is self-reporte risk aversion time variant? Thema Working Paper $n^{\circ}$ 2014-22 Université de Cergy Pontoise, France.

Kahneman, D., Ritov, I., and Schkade, D. (1999). Economic preferences or attitude expressions?: An analysis of dollar responses to public issues. Journal of Risk and Uncertainty, 19(13):220-242. 
Kleinjans, K. J. and Soest, A. V. (2014). Rounding, focal point answers and nonresponse to subjective probability questions. Journal of Applied Econometrics, 29(4):567-585.

Koch, A., Nafziger, J., and Nielsen, H. S. (2014). Behavioral economics of education. Journal of Economic Behavior \& Organization. forthcoming.

Lerner, J. S. and Keltner, D. (2000). Beyond valence: Toward a model of emotion-specific influences on judgement and choice. Cognition \& Emotion, 14(4):473-493.

Lerner, J. S. and Keltner, D. (2001). Fear, anger, and risk. Journal of personality and social psychology, 81(1):146.

Loehlin, J. C. (2008). Resemblance in personality and attitudes between parents and their children. In Bowles, S., Gintis, H., and Groves, M., editors, Unequal chances: Family background and economic success. Princeton University Press.

Lubotsky, D. and Wittenberg, M. (2006). Interpretation of regressions with multiple proxies. Review of Economics and Statistics, 88(3):549-562.

Lundberg, S. (2012). Personality and marital surplus. IZA Journal of Labor Economics, $1(1): 1-21$.

Malmendier, U. and Nagel, S. (2011). Depression babies: Do macroeconomic experiences affect risk taking? The Quarterly Journal of Economics, 126(1):373-416.

Manski, C. F. and Molinari, F. (2010). Rounding probabilistic expectations in surveys. Journal of Business \& Economic Statistics, 28(2):219-231.

Micevski, M. (2013). Reciprocity, matching, and wage competition. Technical report, Department of Economics, University of Konstanz.

Mischel, W. (2004). Toward an integrative science of the person. Annu. Rev. Psychol., 55:1-22.

Page, T., Putterman, L., and Unel, B. (2005). Voluntary association in public goods experiments: Reciprocity, mimicry and efficiency. The Economic Journal, 115(506):10321053.

Patacchini, E. and Zenou, Y. (2011). Social networks and parental behavior in the intergenerational transmission of religion. CEPR Discussion Paper No. DP8443.

Perugini, M., Gallucci, M., Presaghi, F., and Ercolani, A. P. (2003). The personal norm of reciprocity. European Journal of Personality, 17(4):251-283.

Rabin, M. (1993). Incorporating fairness into game theory and economics. American Economic Review, 83:1281-1302.

Raghunathan, R. and Pham, M. T. (1999). All negative moods are not equal: Motivational influences of anxiety and sadness on decision making. Organizational Behavior and Human Decision Processes, 79(1):56-77. 
Ruud, P. A., Schunk, D., and Winter, J. K. (2013). Uncertainty causes rounding: an experimental study. Experimental Economics, pages 1-23.

Sahm, C. R. (2012). How much does risk tolerance change? The Quarterly Journal of Finance, 2(04).

Schupp, J. and Wagner, G. G. (2002). Maintenance of and innovation in long-term panel studies: The case of the german socio-economic panel (GSOEP). Allgemeines Statistisches Archiv / Journal of the German Statistical Society, 86(2):163-175.

Smith, A. (1761). The Theory of Moral Sentiments. A. Millar, second edition.

Sobel, J. (2005). Interdependent preferences and reciprocity. Journal of Economic Literature, 43(2):pp.392-436.

Wagner, G., Burkhauser, R., and Behringer, F. (1993). The English language public use file of the German Socio-Economic Panel. Journal of Human Resources, 28(2):429433.

Wagner, G. G., Frick, J. R., and Schupp, J. (2007). The German Socio-Economic Panel study (SOEP)-scope, evolution and enhancements. Schmollers Jahrbuch, 127(1):139169.

Wagner, G. G., Göbel, J., Krause, P., Pischner, R., and Sieber, I. (2008). Das Soziooekonomische Panel (SOEP): Multidisziplinäres Haushaltspanel und Kohortenstudie für Deutschland-Eine Einführung (für neue Datennutzer) mit einem Ausblick (für erfahrene Anwender). AStA Wirtschafts-und Sozialstatistisches Archiv, 2(4):301-328.

Wahlberg, A. A. and Sjoberg, L. (2000). Risk perception and the media. Journal of Risk Research, 3(1):31-50.

Weinhardt, M. and Schupp, J. (2011). Multi-Itemskalen im SOEP Jugendfragebogen. Technical report, DIW Berlin, German Institute for Economic Research.

Weiss, Y. and Willis, R. (1997). Match quality, new information, and marital dissolution. Journal of Labor Economics, 15:293-329.

Zaller, J. and Feldman, S. (1992). A simple theory of the survey response: Answering questions versus revealing preferences. American Journal of Political Science, 36(3):579-616. 


\section{Valorization}

Research on economic preferences strives to provide a better understanding of the very basis of how economic decisions are made. The insights gained by this research field are very valuable to study decision making, i.e. a myriad of topics in economics. However, research on preferences is very complex and the field is fragmented. Currently much of the economic research on this topic is mainly of a fundamental scientific nature and insights should be applied in very cautious ways if it comes to policy advice, despite the fact that the findings are of great interest to policy makers so that one is tempted to draw immediate conclusions for policy. A premature application of findings is however not advisable. I discuss this important point in more detail at the end of this valorization addendum, after an overview of the findings of my thesis.

\section{This thesis}

The value of the insights gained in this thesis is mainly of academic nature. While the papers in this thesis and many other recent studies on economic preferences, attitudes and personality traits study and partially explain human motivation and human behavior, much of the variance in behavior remains unexplained. Accordingly, the main goal of this thesis is to provide insights that are useful to the field of study and that will help understand behavior in a broader context, rather than provide ready-made answers to current policy questions. In the long run however, the knowledge that is accumulated in this field will be very valuable for policy design and predictions of economic outcomes. In the following I repeat briefly the main points of each chapter for the valorization. A more detailed discussion of the mentioned points is found in the conclusions of the respective chapter and in the conclusion of the thesis in chapter 6.

Chapter 2 shows that parents who invest more in their children have children who are more similar to them with respect to risk and trust attitudes. This finding points to a potential mechanism of the intergenerational transmission of preferences in which parents could purposefully invest in their children to shape their children's preferences according to their own. This in turn adds to the understanding of social (im)mobility and inequality. Further it provides empirical evidence in support of assumptions on which theoretical models of intergenerational transmission of culture and preferences are based. 
In Chapter 3 I show theoretically and empirically that the match in preferences is important for the stability of a partnership. I show that it is useful not only to look at levels when investigating preferences, but also at the interaction of preferences of different individuals. With respect to the empirical application, the findings of this chapter provide evidence that there is positive assortative mating in terms of negative reciprocal inclinations. Positive assortative mating has been shown to strengthen the intergenerational transmission of the respective characteristic or preference. If the respective characteristics or preferences are linked to outcomes, e.g. as risk or time preferences are linked to educational outcomes, positive assortative mating will reinforce the intergenerational transmission of outcomes. The results therefore also contribute to the understanding of the mechanisms that lead to social immobility.

Chapter 4 deals with the question of stability of preferences. Many theoretical and empirical findings on preferences are based on the assumption of stability of preferences. Empirical studies have however shown that there is sizable within-individual variation in measured preferences. The analysis in this chapter investigates the within-individual variation and shows that there is a long-lasting effect of economic environment on selfstated risk attitudes. This means that the variation in risk attitudes over time is partially predictable and if everybody experienced a similar change in the economic environment, the rank-order stability of preferences might not be affected. Further the results point out the heterogeneity in malleability of preferences. This means that policies that affect the risk environment of individuals could result in very heterogeneous responses across different population groups. This is important for the external validity of policy evaluation on policies that target specific groups, i.e. the responses from one group cannot easily be extrapolated to the population as a whole.

In Chapter 5 I discuss the problem of focal answers, a data related problem that is incommoding the measurement of preferences in survey data. A small theoretical model offers an explanation of focal answer behavior which helps understand what focal answers mean and how they can be interpreted. The chapter then suggests a simple econometric tool to improve on estimators and discover the correlates of individual's uncertainty in case of measurement error due to focal responses.

\section{General remarks on policy advice concerning preferences and attitudes}

There are three main challenges that have to be considered before one attempts to draw conclusions and shape policies on the basis of research on preferences. Firstly we should pause to consider whether it is at all advisable and ethical to try to change people's preferences, i.e. the very core of their individuality; or whether this paternalistic approach is inadequate. But even if we deem it ethically unproblematic to change preferences, it is important to acknowledge that it is not clear what optimal preferences (individually and socially) are. The optimum is unlikely to be a corner solution. Trust, for example, is an important trait in a society which relies on interpersonal transactions, but too much trust 
can be harmful to the individual, depending on the environment in which the individual interacts. Additionally, there might be individual heterogeneity in the optimal preference level. The social optimum in risk aversion for example might depend on the level of other individual abilities, for example it could be beneficial for less able individuals to be more risk averse, while more able individuals would profit from a higher willingness to take risks.

The second major challenge is causality. It is very difficult to establish causality in research on preferences since it is hard to find exogenous variation in preferences, and it is likely to be unethical, if not impossible to induce such a variation. Preferences are innate characteristics of individuals, that are correlated with other preferences, with personality and sometimes also external factors as the socioeconomic background. There are some programs, for example the Perry preschool program, that have been conducted and that arguably led to exogenous variation in preferences. These quasi experiments however also do not allow to causally link specific preferences to outcomes. Experiments in the lab provide insights into the heterogeneity in preferences, but they are not well suited to study the causal impact of preferences on choices, since we are mostly interested in innate, stable individual preferences, that cannot be easily changed (at the very least not in a sufficiently short time horizon). The ethical concern about tempering with individuals' preferences is particularly grave if we don't have compelling evidence that certain preferences are indeed welfare enhancing. Hence, much of the current research on economic preferences is correlational, suggesting possible effects.

Finally, the third challenge is that the effects of a single preference on an outcome or behavior typically explain only a small fraction of the total heterogeneity in outcomes, as many - potentially interdependent - factors are simultaneously at play. We can build a more complete picture by creating pieces of the puzzle and one by one combining them. This however also means that it is very hard to use insights from the studies in this field directly for policy recommendations. While a particular policy might be in line with a particular finding, it is difficult to design the policy to only influence a particular preference and keep everything else unchanged. Unanticipated correlated side effects of the policy might render the intervention useless or even do the opposite of what was intended. On the other side of the same coin insights on how economic preferences are related to outcomes can help understanding what went wrong, when policies do not have the expected effects. Examples for such are unintended selection effects (e.g. payment schemes in the banking system not only increase the effort of employees, but are also attracting more risk loving employees), or motivational crowding out (e.g. being paid for blood donations might demotivate certain individuals who then stop donating).

Altogether research on economic preferences and attitudes is a promising venue for understanding policy and eventually also basing policies on. Given the current constraints much research is still needed in this field, which has seen much interest recently and developed quickly over the past decade. 



\section{Curriculum Vitae}

Maria studied at the University of Bern, where she obtained her bachelors degree in Economics and Political Science in 2008 and her masters degree in Economics in 2010, summa cum laude. She joined the Research Centre for Education and the Labour Market at Maastricht University in March 2010 to start her PhD project on economic preferences. In 2013 she visited Princeton University for a four month research stay. From March 2014 to February 2015 Maria worked at the Institute for Applied Micro Economics at the University of Bonn as a research associate. Since March 2015 Maria works at the Institute for Economics of Education at the University of Bern.

Maria's research focuses on economic preferences, behavioral economics, economics of education, intergenerational mobility, inequality and applied micro-econometrics. 



\section{ROA Dissertation Series}

1. Lex Borghans (1993), Educational Choice and Labour Market Information, Maastricht, Research Centre for Education and the Labour Market.

2. Frank Cörvers (1999), The Impact of Human Capital on International Competitiveness and Trade Performance of Manufacturing Sectors, Maastricht, Research Centre for Education and the Labour Market.

3. Ben Kriechel (2003), Heterogeneity Among Displaced Workers, Maastricht, Research Centre for Education and the Labour Market.

4. Arnaud Dupuy (2004), Assignment and Substitution in the Labour Market, Maastricht, Research Centre for Education and the Labour Market.

5. Wendy Smits (2005), The Quality of Apprenticeship Training, Conflicting Interests of Firms and Apprentices, Maastricht, Research Centre for Education and the Labour Market.

6. Judith Semeijn (2005), Academic Competences and Labour Market Entry: Studies Among Dutch Graduates, Maastricht, Research Centre for Education and the Labour Market.

7. Jasper van Loo (2005), Training, Labor Market Outcomes and Self-Management, Maastricht, Research Centre for Education and the Labour Market.

8. Christoph Meng (2005), Discipline-Specific or Academic? Acquisition, Role and Value of Higher Education Competencies, Maastricht, Research Centre for Education and the Labour Market.

9. Andreas Ammermüller (2007), Institutional Effects in the Production of Education: Evidence from European Schooling Systems, Maastricht, Research Centre for Education and the Labour Market.

10. Bart Golsteyn (2007), The Ability to Invest in Human Capital, Maastricht, Research Centre for Education and the Labour Market.

11. Raymond Montizaan (2010), Pension Rights, human capital development and well-being, Maastricht, Research Centre for Education and the Labour Market. 
12. Annemarie Nelen (2012), Part-Time Employment and Human Capital Development, Maastricht, Research Centre for Education and the Labour Market.

13. Jan Sauermann (2013), Human Capital, Incentives, and Performance Out- comes, Maastricht, Research Centre for Education and the Labour Market

14. Harald Ulrich Pfeifer (2013), Empirical Investigations of Costs and Benefits of Vocational Education and Training, Maastricht, Research Centre for Education and the Labour Market.

15. Charlotte Büchner (2013), Social Background, Educational Attainment and Labor Market Integration: An Exploration of Underlying Processes and Dynamics, Maastricht, Research Centre for Education and the Labour Market.

16. Martin Humburg (2014), Skills and the Employability of University Graduates, Maastricht, Research Centre for Education and the Labour Market.

17. Jan Feld (2014), Making the Invisible Visible, Essays on Overconfidence, Discrimination and Peer Effects, Maastricht, Research Centre for Education and the Labour Market.

18. Olga Skriabikova (2014), Preferences, Institutions, and Economic Outcomes: an Empirical Investigation, Research Centre for Education and the Labour Market.

19. Gabriele Marconi (2015), Higher Education in the National and Global Economy, Research Centre for Education and the Labour Market.

20. Nicolas Salamanca Acosta (2015), Economic Preferences and Financial RiskTaking, Research Centre for Education and the Labour Market.

21. Ahmed Elsayed Mohamed (2015), Essays on Working Hours, Maastricht, Research Centre for Education and the Labour Market.

22. Roxanne Amanda Korthals (2015), Tracking Students in Secondary Education, Consequences for Student Performance and Inequality, Maastricht, Research Centre for Education and the Labour Market.

23. Maria Zumbuehl (2015), Economic Preferences and Attitudes: Origins, Behavioral Impact, Stability and Measurement, Maastricht, Research Centre for Education and the Labour Market. 